\title{
Polarity sensitive bioorthogonally applicable far-red emitting labels for postsynthetic nucleic acid labeling by copper-catalyzed and copper-free cycloaddition
}

\author{
Ádám Eördögh, ${ }^{\S, \mathrm{a}}$ Jeannine Steinmeyer, ${ }^{\S, \mathrm{b}}$ Krisana Peewasan, ${ }^{\mathrm{b}}$ Ute Schepers, ${ }^{\mathrm{c}}$ Hans-Achim \\ Wagenknecht*,b and Péter Kele*,a
}

\begin{abstract}
a Chemical Biology Research Group, Institute of Organic Chemistry, Research Centre for Natural Sciences, Hungarian Academy of Sciences. Magyar tudósok krt. 2, H-1117, Budapest, Hungary. E-mail: kele.peter@ttk.mta.hu

b Institute of Organic Chemistry, Karlsruhe Institute of Technology (KIT), Fritz-Haber-Weg 6, 76131 Karlsruhe, Germany. E-mail: Wagenknecht@kit.edu

${ }^{\mathrm{c}}$ Institute of Toxicology and Genetics, Karlsruhe Institute of Technology (KIT), H.-v.-Helmholtz-Platz 1, 76344 Eggenstein-Leopoldshafen, Germany.

$\S$ These authors contributed equally to the work
\end{abstract}

Electronic supporting information

\section{Contents:}

General Information for Dye Synthesis ................................................................................. 2

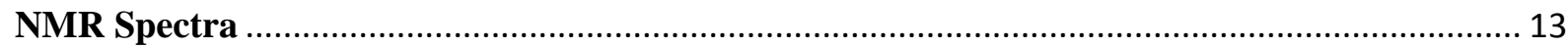

Materials and Methods for DNA Synthesis and Characterization: ........................................... 37

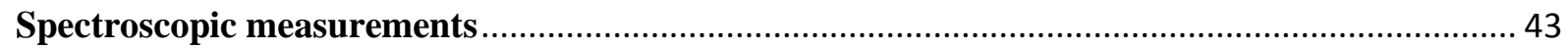

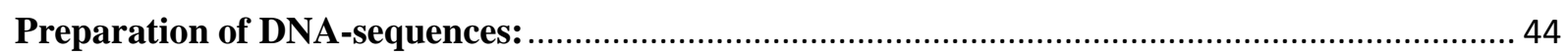

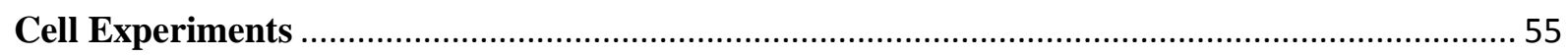

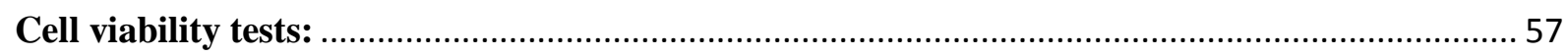




\section{General Information for Dye Synthesis}

Unless otherwise indicated, all starting materials were obtained from commercial suppliers (Sigma-Aldrich, Fluka, Merck, Alfa Aesar, Reanal, Molar Chemicals) and used without further purification. Dichloromethane stabilized with ethanol was used, unless otherwise mentioned. SCO was purchased from Sichem (Bremen, Germany). Analytical thin-layer chromatography (TLC) was performed on silica gel 60 F254 precoated aluminum TLC plates from Merck. Column chromatography was carried out with flash silica gel $(0.040-0.063 \mathrm{~mm})$ from Molar Chemicals. Preparative HPLC was carried out using Phenomenex d=25mm C18 column, with the gradient elution mixed from the following solutions: $\mathrm{A}: \mathrm{H}_{2} \mathrm{O}, 0.1 \% \mathrm{TFA}$; $\mathrm{B} 80 \% \mathrm{MeCN}$, $20 \% \mathrm{H}_{2} \mathrm{O}, 0.4 \%$ TFA.Visualization of TLC samples was performed with a 254/365 nm UV. NMR spectra were recorded on a NMR spectra were acquired on Varian Innova 600, 500, 400 and Bruker Avance $250 \mathrm{MHz}$ spectrometer. Chemical shifts $(\delta)$ are given in parts per million (ppm) using solvent signals as the reference. Coupling constants $(J)$ are reported in Hertz $(\mathrm{Hz})$. Splitting patterns are designated as s (singlet), d (doublet), t (triplet), qr (quadruplet), qv (quintuplet), m (multiplet), dd (doublet of a doublet), td (triplet doublet), dt (doublet triplet), br s (broad singlet). The exact masses were determined with an Agilent 6230 time-of-flight mass spectrometer. Samples were introduced by the Agilent 1260 Infinity LC system and the mass spectrometer was operated in conjunction with a JetStream source in positive/negative ion mode. All melting points were measured on a Bibby Scientific SMP10 Melting Point Apparatus and are uncorrected. IR spectra were obtained on a Bruker Alpha-P spectrometer on a singlereflection diamond ATR unit. Fluorescence spectra acquisitions were performed on Jasco FP8300 fluorimeter, and absorbance measurements were done using uvcam500 spectrophotometer. For HRMS Waters Q-TOF Premier mass spectrometer was used. For routine LCMS analysis Shimadzu 2020 system was used.AntonPaar monowave 400 microwave reactor used, heating program was set to heat ASAP in all cases. For HRMS a Waters Q-TOF Premier mass spectrometer was used. For routine LCMS analysis Shimadzu 2020 system was used.

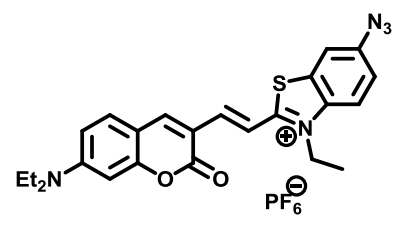

(E)-6-azido-2-(2-(7-(diethylamino)-2-oxo-2H-chromen-3-yl)vinyl)-3-ethylbenzo[d]thiazol-3ium hexafluorophospate (2a)

$80 \mathrm{mg}(0.141 \mathrm{mmol})$ amino derivative $(\mathbf{6 a})$ was dissolved in $15 \mathrm{ml} 6 \mathrm{M} \mathrm{HCl}$ and cooled to $0{ }^{\circ} \mathrm{C}$. A solution of $17 \mathrm{mg}(0.220 \mathrm{mmol}) \mathrm{NaNO}_{2}$ in $1 \mathrm{ml} \mathrm{H} \mathrm{H}_{2} \mathrm{O}$ was added dropwise. After 5 minutes, 
a solution of $42 \mathrm{mg}(0.646 \mathrm{mmol}) \mathrm{NaN}_{3}$ in $1 \mathrm{~mL} \mathrm{H}_{2} \mathrm{O}$ was added. The reaction was stirred for $1.5 \mathrm{~h}$ meanwhile it was allowed to warm up to r.t. The reaction mixture was neutralized with $\mathrm{NaOH}$ to reach neutral $\mathrm{pH}$, which was buffered with $10 \mathrm{ml}$ of ${ }_{\mathrm{cc}} \mathrm{NaHCO}_{3}$. After extraction with $3 \times 25 \mathrm{ml}$ DCM the combined organic phases were washed with $2 \times 25 \mathrm{ml}$ water and $25 \mathrm{ml}$ brine and dried with $\mathrm{MgSO}_{4}$. The solution was filtered then concentrated in vacuo. Product was purified on silica gel using DCM:MeOH 20:1 - 9:1 v/v gradient eluent. Following purification the product was dissolved in $\mathrm{MeCN}$ and $\mathrm{NH}_{4} \mathrm{PF}_{6}$ was added in excess then the solvent was removed in vacuo. Removal of excess $\mathrm{NH}_{4} \mathrm{PF}_{6}$ was carried out, by extraction in water-DCM. The organic phase was dried using $\mathrm{MgSO}_{4}$, filtered and concentrated to furnish $64 \mathrm{mg}(68 \%)$ green crystalline product.

m.p.: 192-195 ${ }^{\circ} \mathrm{C}$ (decomp); ${ }^{1} \mathrm{H}$ NMR $(600 \mathrm{MHz}, \mathrm{DMSO}) \delta 8.59$ (s, 1H), 8.25 (d, $J=9.1 \mathrm{~Hz}$, $1 \mathrm{H}), 8.21(\mathrm{~d}, J=2.1 \mathrm{~Hz}, 1 \mathrm{H}), 8.01(\mathrm{~s}, 2 \mathrm{H}), 7.58(\mathrm{~d}, J=9.1 \mathrm{~Hz}, 1 \mathrm{H}), 7.54\left(\mathrm{dd}, J_{1}=9.0 \mathrm{~Hz}, J_{2}=\right.$ $2.1 \mathrm{~Hz}, 1 \mathrm{H}), 6.88\left(\mathrm{dd}, J_{1}=9.1 \mathrm{~Hz}, J_{2}=2.1 \mathrm{~Hz}, \mathrm{~Hz}, 1 \mathrm{H}\right), 6.68(\mathrm{~d}, J=1.8 \mathrm{~Hz}, 1 \mathrm{H}), 4.76(\mathrm{q}, J=$ $7.3 \mathrm{~Hz}, 2 \mathrm{H}), 3.54(\mathrm{q}, J=7.0 \mathrm{~Hz}, 4 \mathrm{H}), 1.47(\mathrm{t}, J=7.3 \mathrm{~Hz}, 3 \mathrm{H}), 1.17(\mathrm{t}, J=7.3 \mathrm{~Hz}, 6 \mathrm{H}) ;{ }^{13} \mathrm{C}$ NMR (151 MHz, DMSO) $\delta 170.4,159.5,157.2,153.4,148.3,144.7,140.0,138.2,131.8,129.6$, 121.3, 117.5, 114.0, 111.9, 110.9, 110.5, 108.9, 96.5, 44.7, 44.4, 13.7, 12.4; HRMS (ESI) $[M]^{+}$: $\left[\mathrm{C}_{24} \mathrm{H}_{24} \mathrm{~N}_{5} \mathrm{O}_{2} \mathrm{~S}\right]^{+}$calculated: 446.1645 , measured: 446.1658 .

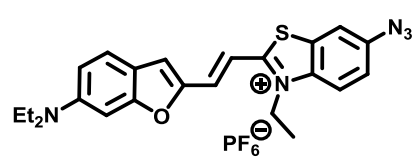

(E)-6-azido-2-(2-(6-(diethylamino)benzofuran-2-yl)vinyl)-3-ethylbenzo[d]thiazol-3-ium hexafluorophospate (2b)

$110 \mathrm{mg}(0.204 \mathrm{mmol})$ amine derivative $(\mathbf{9 b})$ was dissolved in $15 \mathrm{ml} 6 \mathrm{M} \mathrm{HCl}$ and cooled to 0 ${ }^{\circ} \mathrm{C}$, A solution of $17 \mathrm{mg}(0.245 \mathrm{mmol}) \mathrm{NaNO}_{2}$ in $1 \mathrm{ml} \mathrm{H}_{2} \mathrm{O}$ was added dropwise. After 5 minutes, a solution of $43 \mathrm{mg}(0.661 \mathrm{mmol}) \mathrm{NaN}_{3}$ in $1 \mathrm{ml} \mathrm{H}_{2} \mathrm{O}$ was added. The reaction was stirred for $4,5 \mathrm{~h}$ while it was allowed to warm to r.t. The reaction mixture was neutralized with $\mathrm{NaOH}$. After extraction with $3 \times 25 \mathrm{ml}$ DCM the combined organic phases were washed with $2 \times 25 \mathrm{ml}$ water and $25 \mathrm{ml}$ brine and dried with $\mathrm{MgSO}_{4}$. The solution was filtered then concentrated in vacuo. Product was purified on silica gel using DCM:MeOH 20:1 - 9:1 gradient eluent. Following purification the product was dissolved in $\mathrm{MeCN}$ and $\mathrm{NH}_{4} \mathrm{PF}_{6}$ was added in excess then the solvent was removed in vacuo. Removal of excess $\mathrm{NH}_{4} \mathrm{PF}_{6}$ was carried out, by extraction in water-DCM. Solvent was removed in vacuo to provide $79 \mathrm{mg}(69 \%)$ green crystalline product.

m.p.: $233-235{ }^{\circ} \mathrm{C}$ (decomp.); ${ }^{1} \mathrm{H}$ NMR (600 MHz, DMSO) $\delta 8.19$ (d, $\left.J=1.6 \mathrm{~Hz}, 1 \mathrm{H}\right), 8.18$ (s, $1 \mathrm{H}), 8.09(\mathrm{~d}, J=14.9 \mathrm{~Hz}, 1 \mathrm{H}), 7.62(\mathrm{~s}, 1 \mathrm{H}), 7.59(\mathrm{~d}, J=8.9 \mathrm{~Hz}, 1 \mathrm{H}), 7.52\left(\mathrm{dd}, J_{1}=9.0, J_{2}=2.2\right.$ $\mathrm{Hz}, 1 \mathrm{H}), 7.35(\mathrm{~d}, J=15.0 \mathrm{~Hz}, 1 \mathrm{H}), 6.86\left(\mathrm{dd}, J_{1}=9.0, J_{2}=2.0 \mathrm{~Hz}, 1 \mathrm{H}\right), 6.78(\mathrm{~s}, 1 \mathrm{H}), 4.80(\mathrm{q}, J$ $=7.20 \mathrm{~Hz}, 2 \mathrm{H}), 3.49(\mathrm{q}, J=7.0 \mathrm{~Hz}, 4 \mathrm{H}), 1.44(\mathrm{t}, J=7.20 \mathrm{~Hz}, 3 \mathrm{H}), 1.17(\mathrm{t}, J=7.206 \mathrm{H}) ;{ }^{13} \mathrm{C}$ NMR (151 MHz, DMSO) $\delta$ 168.7, 160.0, 149.9, 149.7, 139.8, 138.3, 133.7, 129.4, 124.2, 121.2, 120.5, 117.8, 117.3, 114.0, 111.6, 106.6, 91.5, 44.6, 44.0, 13.9, 12.5; HRMS (ESI) $[M]^{+}$: $\left[\mathrm{C}_{23} \mathrm{H}_{24} \mathrm{~N}_{5} \mathrm{OS}\right]^{+}$calculated: 418.1696, measured: 418.1707 . 


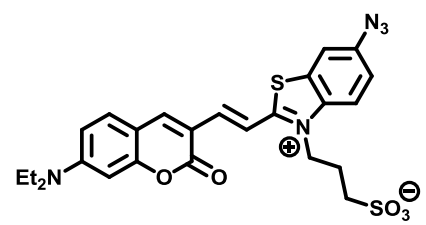

(E)-3-(6-azido-2-(2-(7-(diethylamino)-2-oxo-2H-chromen-3-yl)vinyl)benzo[d]thiazol-3-ium3-yl)propane-1-sulfonate (3a)

$120 \mathrm{mg}(0.234 \mathrm{mmol})$ of amine-derivative $(\mathbf{1 0 a})$ was dissolved in $6 \mathrm{M} \mathrm{HCl}$ and cooled to $0^{\circ} \mathrm{C}$ $18 \mathrm{mg}(0.260)$ of $\mathrm{NaNO}_{2}$ was dissolved in $1 \mathrm{ml} \mathrm{H} \mathrm{H}_{2} \mathrm{O}$ and added to the reaction dropwise. After 5 minutes $45 \mathrm{mg}(0.692 \mathrm{mmol}) \mathrm{NaN}_{3}$ in $1 \mathrm{~mL} \mathrm{H} \mathrm{H}_{2} \mathrm{O}$ was added. The reaction was stirred overnight and then it was concentrated in vacuo onto silica gel. Product was then transferred to a silica column and it was purified could be isolated using DCM-MeOH gradient elution. Optimal product elution occurs at 15:1 v/v. The pure fractions were combined and solvent was removed in vacuo to give $45 \mathrm{mg}$ (36\%) purple solid. During the procedure direct contact with natural light was avoided by using aluminum foil as a shield.

m.p.: $197-199{ }^{\circ} \mathrm{C}$ (decomp.); ${ }^{1} \mathrm{H}$ NMR (400 MHz, DMSO) $\delta 8.80$ (s, $\left.1 \mathrm{H}\right), 8.32$ (d, $J=9.1 \mathrm{~Hz}$, $1 \mathrm{H}), 8.16(\mathrm{~d}, J=1.8 \mathrm{~Hz}, 1 \mathrm{H}), 8.06(\mathrm{~d}, J=15.6 \mathrm{~Hz}, 1 \mathrm{H}), 7.97(\mathrm{~d}, J=15.5 \mathrm{~Hz}, 1 \mathrm{H}), 7.58-7.50$ $(\mathrm{m}$, containing $\mathrm{d}$ and $\mathrm{dd}, 2 \mathrm{H}), 6.88(\mathrm{~d} J=9.1 \mathrm{~Hz}, 1 \mathrm{H}), 6.66(\mathrm{~s}, 1 \mathrm{H}), 4.92(\mathrm{t}, J=7.3 \mathrm{~Hz}, 2 \mathrm{H})$, $3.57(\mathrm{~d}, J=5.6 \mathrm{~Hz}, 4 \mathrm{H}$, distorted by water signal), $2.68-2.62(\mathrm{~m}, 2 \mathrm{H}), 2.25-2.14(\mathrm{~m}, 2 \mathrm{H})$, $1.17(\mathrm{t}, J=7.0 \mathrm{~Hz}, 6 \mathrm{H}) ;{ }^{1} \mathrm{H}$ NMR $(500 \mathrm{MHz}, \mathrm{TFA}) \delta 8.74(\mathrm{~s}, 1 \mathrm{H}), 8.60(\mathrm{~d}, J=15.9 \mathrm{~Hz}, 1 \mathrm{H})$, $8.29(\mathrm{~d}, J=9.2 \mathrm{~Hz}, 1 \mathrm{H}), 8.19(\mathrm{~d}, J=8.4 \mathrm{~Hz}, 1 \mathrm{H}), 8.06(\mathrm{~d}, J=15.8 \mathrm{~Hz}, 1 \mathrm{H}), 7.81(\mathrm{~s}, 2 \mathrm{H}), 7.71$ $(\mathrm{d}, J=8.5 \mathrm{~Hz}, 1 \mathrm{H}), 7.63(\mathrm{~d}, J=9.1 \mathrm{~Hz}, 1 \mathrm{H}), 5.28(\mathrm{t}, J=8.1 \mathrm{~Hz}, 2 \mathrm{H}), 3.94(\mathrm{q}, J=7.3 \mathrm{~Hz}, 4 \mathrm{H})$, $3.61(\mathrm{t}, J=6.4 \mathrm{~Hz}, 2 \mathrm{H}), 2.78(\mathrm{q}, J=8.0,7.3 \mathrm{~Hz}, 2 \mathrm{H}), 1.37(\mathrm{t}, J=7.1 \mathrm{~Hz}, 6 \mathrm{H}),{ }^{13} \mathrm{C}$ NMR $(151$ MHz, TFA, based on HSQC,HMBC) $\delta 169.60,160.95,154.19,145.39,144.38,140.56,140.17$, 138.12, 132.68, 130.49, 123.23, 122.83, 121.24, 119.35, 118.11 112.18, 111.01, 55.38, 48.11, 47.78, 23.70, 8.90; HRMS (ESI) $[M+N a]^{+}:\left[\mathrm{C}_{25} \mathrm{H}_{25} \mathrm{~N}_{5} \mathrm{O}_{5} \mathrm{~S}_{2}+\mathrm{Na}\right]^{+}$calculated: 562.1195 measured: 562.1198 .<smiles></smiles>

(E)-3-(6-azido-2-(2-(6-(diethylamino)benzofuran-2-yl)vinyl)benzo[d]thiazol-3-ium-3yl)propane-1-sulfonate (3b)

$160 \mathrm{mg}(0.330 \mathrm{mmol})$ amine derivative $(\mathbf{1 0 b})$ was dissolved in $10 \mathrm{ml} 6 \mathrm{M} \mathrm{HCl}$ and cooled to 0 ${ }^{\circ} \mathrm{C}$. A solution of $25 \mathrm{mg}(0.360 \mathrm{mmol})$ of $\mathrm{NaNO}_{2}$ in $1 \mathrm{ml} \mathrm{H}_{2} \mathrm{O}$ was added dropwise. After 5 minutes, an aqueous solution of $65 \mathrm{mg}(0.100 \mathrm{mmol}) \mathrm{NaN}_{3}$ in $1 \mathrm{~mL} \mathrm{H}_{2} \mathrm{O}$ was added. The reaction was stirred overnight, letting it to warm up to $22^{\circ} \mathrm{C}$. While cooled with ice, $\mathrm{NaOH}$ solution was added to the reaction mixture to reach neutral $\mathrm{pH}$ range. After the reaction was concentrated under vacuum, the crushed salty mixture was placed on a short silica column and the product was purified using DCM-MeOH gradient elution. After the evaporation of the solvent, $140 \mathrm{mg}$ (83\%) green crystalline product could be isolated. During the procedure direct contact with natural light was avoided by using aluminum foil as a shield.

m.p.: $194-196{ }^{\circ} \mathrm{C}$ (decomp.); ${ }^{1} \mathrm{H}$ NMR $(500 \mathrm{MHz}, \mathrm{TFA}) \delta 8.33$ (d, $\left.J=5.9 \mathrm{~Hz}, 1 \mathrm{H}\right), 8.30(\mathrm{~s}, 1 \mathrm{H})$, $8.10(\mathrm{~d}, J=8.5 \mathrm{~Hz}, 1 \mathrm{H}), 8.07(\mathrm{~s}, 1 \mathrm{H}), 7.98(\mathrm{~d}, J=15.3 \mathrm{~Hz}, 1 \mathrm{H}), 7.86(\mathrm{~s}, 1 \mathrm{H}), 7.68(\mathrm{~d}, J=9.0$ 
$\mathrm{Hz}, 1 \mathrm{H}), 7.59-7.51(\mathrm{~m}, 2 \mathrm{H}), 5.39(\mathrm{t}, J=8.3 \mathrm{~Hz}, 2 \mathrm{H}), 3.99(\mathrm{ddq}, J=20.1,13.6,7.2 \mathrm{~Hz}, 4 \mathrm{H})$, $3.75(\mathrm{t}, J=6.0 \mathrm{~Hz}, 2 \mathrm{H}), 2.87(\mathrm{~s}, 2 \mathrm{H}), 1.44$ (t, $J=7.4 \mathrm{~Hz}, 6 \mathrm{H}) ;{ }^{13} \mathrm{C}$ NMR $(151 \mathrm{MHz}$, TFA, based on HSQC,HMBC) $\delta 169.0,156.0,154.2,144.1,137.9,135.4,133.1,130.8,130.2$, 125.1, 122.4, 117.2, 117.0, 115.1, 114.1, 112. 2, 112.2, 106.4, 55. 7, 47.9, 47.8, 23.6, 9.0; HRMS (ESI) $[M+H]+:$ [C24H25N5O4S2+H]+ calculated: 512.1426, measured: 512.1428.

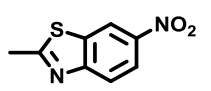

2-methyl-6-nitrobenzothiazole (4)

$1.2 \mathrm{ml}(9.41 \mathrm{mmol}) 2$-methylbenzothiazole and $6 \mathrm{ml}$ of ${ }_{\mathrm{cc}} \mathrm{H}_{2} \mathrm{SO}_{4}$, was cooled to $0{ }^{\circ} \mathrm{C}$. A mixture of $2 \mathrm{ml} \mathrm{95 \%} \mathrm{HNO}_{3}$ and $1.5 \mathrm{ml}_{\mathrm{cc}} \mathrm{H}_{2} \mathrm{SO}_{4}$ was added dropwise. The reaction mixture was stirred overnight while it was allowed to warm to r.t. After that the reaction mixture was poured onto ice and the precipitate was filtered and washed with water and dried under vacuum. Product was recrystallized from $250 \mathrm{ml} \mathrm{EtOH}$ to provide 4 as a white solid $1.19 \mathrm{~g}(65 \%)$.

$R_{\mathrm{f}}=0.27(\mathrm{Hex}$, EtOAc $3: 1)$; MP: $170-172^{\circ} \mathrm{C} ; \mathrm{IR}: v_{\max / \mathrm{cm}^{-1}} 1505$ and $1331\left(\mathrm{NO}_{2}\right) ;{ }^{1} \mathrm{HNMR}(250$ $\left.\mathrm{MHz}, \mathrm{CDCl}_{3}\right): \delta 8.78(\mathrm{~d}, J=2.4 \mathrm{~Hz}, 1 \mathrm{H}), 8.30\left(\mathrm{dd}, J_{l}=8.9 \mathrm{~Hz}, J_{2}=2.3 \mathrm{~Hz}, 1 \mathrm{H}\right), 8.00(\mathrm{~d}, J=$ $9.0 \mathrm{~Hz}, 1 \mathrm{H}), 2.90$ (s, 3H); ${ }^{13} \mathrm{C}-\mathrm{NMR}\left(62.5 \mathrm{MHz}, \mathrm{CDCl}_{3}\right): \delta 173.2,157.1,144.7,136.0,122.6$, 121.5, 117.9, 20.6; HRMS (ESI) $[M+H]^{+}:\left[\mathrm{C}_{8} \mathrm{H}_{6} \mathrm{~N}_{2} \mathrm{O}_{2} \mathrm{~S}+\mathrm{H}\right]^{+}:$195.0223, measured: 195.0231 .

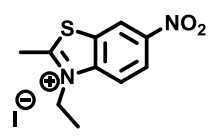

3-ethyl-2-methyl-6-nitrobenzothiazol-3-ium iodide (5)

$1.2 \mathrm{~g}(6.18 \mathrm{mmol})$ 2-methyl-6-nitrobenzothiazole (4) and $2.50 \mathrm{ml}$ (31.2 mmol) ethyl iodide was added in a $10 \mathrm{ml}$ Microwave vial. After homogenizing the suspension, the reaction mixture was heated to $190{ }^{\circ} \mathrm{C}$ for 20 minutes using microwave reactor, ensuring high speed stirring for the whole time. The resulting brown slurry was washed using vacuum filtration, with $4 \times 10 \mathrm{ml}$ EtOAc and $3 \times 5 \mathrm{ml}$ hexane solvents. The remaining green powder was than fuiltered using vacuum filtration and dried in vacuo to yield $630 \mathrm{mg}(29 \%)$ pure product.

m.p.: 214-216 ${ }^{\circ} \mathrm{C}$ (decomp.); IR: $v_{\max / \mathrm{cm}^{-1}} 1505$ and $1340\left(\mathrm{NO}_{2}\right) ;{ }^{1} \mathrm{H}$ NMR (600 MHz, DMSO) $\delta 9.45(\mathrm{~s}, 1 \mathrm{H}), 8.66(\mathrm{~d}, J=8.9 \mathrm{~Hz}, 1 \mathrm{H}), 8.57(\mathrm{~d}, J=9.2 \mathrm{~Hz}, 1 \mathrm{H}), 4.82(\mathrm{q}, J=6.9 \mathrm{~Hz}, 2 \mathrm{H}), 3.29$ $(\mathrm{s}, 3 \mathrm{H}), 1.47(\mathrm{t}, J=7.1 \mathrm{~Hz}, 3 \mathrm{H}) ;{ }^{13} \mathrm{C} \mathrm{NMR}(151 \mathrm{MHz}, \mathrm{DMSO}) \delta 182.72,146.12,143.98,130.21$, 124.28, 121.34, 117.87, 45.43, 17.44, 13.09; HRMS (ESI) $[M]^{+}:\left[\mathrm{C}_{10} \mathrm{H}_{11} \mathrm{~N}_{2} \mathrm{O}_{2} \mathrm{~S}\right]^{+}$: calculated: 223.0536, measured: 223.0549 . 


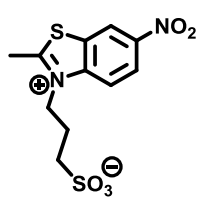

3-(2-methyl-6-nitrobenzo[d]thiazol-3-ium-3-yl)propane-1-sulfonate (6)

$765 \mathrm{mg}$ (3.94 mmol) 2-methyl-6-nitrobenzothiazole (4) and $2.0 \mathrm{ml}$ (22.8 mmol) of 1,3-propane sultone was homogenized in a $10 \mathrm{ml}$ Microwave at $\sim 80{ }^{\circ} \mathrm{C}$. The clear viscous solution was placed in a microwave reactor for $30 \mathrm{~min}$ at $100{ }^{\circ} \mathrm{C}$. The resulting suspension was filtered in vacuum, and the remaining light blue solid was washed with $50 \mathrm{ml}$ of EtOAc, and 2x10 ml of hexane and dried in vacuo to furnish $875 \mathrm{mg}$ (70\%) light blue product which could be used without further purification in the proceeding steps.

m.p.: $235-238{ }^{\circ} \mathrm{C}$ (decomp.); IR: $v_{\max / \mathrm{cm}^{-1}} 1032\left(\mathrm{SO}_{3}{ }^{-}\right), 1541$ and $1345\left(\mathrm{NO}_{2}\right) ;{ }^{1} \mathrm{H}$ NMR (500 $\left.\mathrm{MHz}, \mathrm{D}_{2} \mathrm{O}\right) \delta 9.16(\mathrm{~d}, J=2.0 \mathrm{~Hz}, 1 \mathrm{H}), 8.72(\mathrm{dd}, J=9.3,2.1 \mathrm{~Hz}, 1 \mathrm{H}), 8.44(\mathrm{~d}, J=9.3 \mathrm{~Hz}, 1 \mathrm{H})$, $5.05-4.95(\mathrm{~m}, 2 \mathrm{H}), 3.34$ ( - distorted, $3 \mathrm{H}), 3.16(\mathrm{t}, J=6.9 \mathrm{~Hz}, 2 \mathrm{H}), 2.48-2.39(\mathrm{~m}, 2 \mathrm{H}) ;{ }^{13} \mathrm{C}$ NMR (151 MHz, DMSO) $\delta$ 182.72, 146.12, 143.98, 130.21, 124.28, 121.34, 117.87, 45.43, 17.44, 13.09; HRMS (ESI) $[M+H]^{+}:\left[\mathrm{C}_{11} \mathrm{H}_{12} \mathrm{~N}_{2} \mathrm{O}_{5} \mathrm{~S}_{2}+\mathrm{H}\right]^{+}$calculated: 317.0266, measured: 317.0271 .<smiles></smiles>

(E)-2-(2-(7-(diethylamino)-2-oxo-2H-chromen-3-yl)vinyl)-3-ethyl-6-nitrobenzo[d]thiazol-3ium hexafluorophosphate (7a)

$350 \mathrm{mg}$ (0.857 mmol) 3-ethyl-2-methyl-6-nitrobenzothiazol-3-ium iodide (5) and $284 \mathrm{mg}$ (0.906 mmol) 6-(diethylamino)coumarin-3-carbaldehyde ${ }^{1}$ and 3-4 drops of catalytic amount of piperidine were dissolved in $20 \mathrm{ml}$ of $\mathrm{EtOH}$, and stirred for 3 hours at reflux temperature. Further $20 \mathrm{ml}$ of $\mathrm{EtOH}$ was added to the blue reaction mixture and it was heated to boiling temperature, and $900 \mathrm{mg}$ of $\mathrm{NH}_{4} \mathrm{PF}_{6}$ was added to the solution. Upon cooling to r.t. green crystals precipitated. The crystalline material was filtered, and washed with $5 \mathrm{ml}$ of ice-cold $\mathrm{EtOH}$, then dried under vacuum to obtain $550 \mathrm{mg}(92 \%)$ greenish-gold crystalline product.

m.p.: decomposes above $218-220{ }^{\circ} \mathrm{C} ;{ }^{1} \mathrm{H}$ NMR (600 MHz, DMSO) $\delta 9.30(\mathrm{~d}, J=1.9 \mathrm{~Hz}, 1 \mathrm{H})$, $8.64(\mathrm{~s}, 1 \mathrm{H}), 8.53\left(\mathrm{dd}, J_{1}=9.2, J_{2}=1.9 \mathrm{~Hz} 1 \mathrm{H}\right), 8.38(\mathrm{~d}, J=9.2 \mathrm{~Hz}, 1 \mathrm{H}), 8.13(\mathrm{~d}, J=15.1 \mathrm{~Hz}$, $1 \mathrm{H}), 7.97(\mathrm{~d}, J=15.2 \mathrm{~Hz}, 1 \mathrm{H}), 7.55(\mathrm{~d}, J=9.1 \mathrm{~Hz}, 1 \mathrm{H}), 6.86(\mathrm{~d}, J=7.5 \mathrm{~Hz}, 1 \mathrm{H}), 6.63(\mathrm{~s}, 1 \mathrm{H})$, $4.76(\mathrm{q}, J=7.0 \mathrm{~Hz}, 2 \mathrm{H}), 3.52(\mathrm{q}, J=6.9 \mathrm{~Hz}, 4 \mathrm{H}), 1.46(\mathrm{t}, J=7.2 \mathrm{~Hz}, 3 \mathrm{H}), 1.14(\mathrm{t}, J=7.0 \mathrm{~Hz}$, $6 \mathrm{H}) ;{ }^{13} \mathrm{C}$ NMR $(151 \mathrm{MHz}, \mathrm{DMSO}) \delta 175.11,159.49,157.57,153.95,149.32,147.52,145.72$, 144.86, 132.37, 128.79, 124.41, 120.73, 116.89, 111.82, 111.36, 110.00, 109.38, 96.61, 44.91, 44.75, 13.56, 12.51; HRMS (ESI) $[M]^{+}:\left[\mathrm{C}_{24} \mathrm{H}_{24} \mathrm{~N}_{3} \mathrm{O}_{4} \mathrm{~S}\right]^{+}$calculated: 450.1482 , measured: 450.1460 .

\footnotetext{
1 Synthesis based on: Wu, J. S., Liu, W. M., Zhuang, X. Q. et al. (2007) Org. Lett. 9, 33.
} 


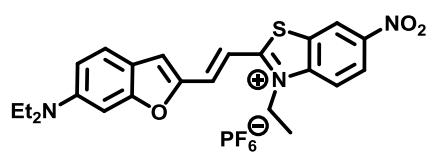

(E)-2-(2-(6-(diethylamino)benzofuran-2-yl)vinyl)-3-ethyl-6-nitrobenzo[d]thiazol-3-ium hexafluorophospate $(\mathbf{7 b})$

$300 \mathrm{mg}$ (0.857 mmol) 3-ethyl-2-methyl-6-nitrobenzothiazol-3-ium iodide (5) and $230 \mathrm{mg}$ (0.906 mmol) 6-(diethylamino)benzofuran-2-carbaldehyde-hydrochloride ${ }^{2}$ and $93 \mu \mathrm{l}$ $(0.942 \mathrm{mmol})$ of piperidine were dissolved in $20 \mathrm{ml}$ of EtOH, and stirred for 5 hours at EtOH reflux temperature. The deep-blue reaction mixture was concentrated under vacuum, purified on silica gel using DCM-MeOH gradient eluent and $\mathrm{MeCN} \mathrm{NH}_{4} \mathrm{PF}_{6}$ solution at the end of separation. Dissolving the substance in $\mathrm{MeCN}$ solution with excess of $\mathrm{NH}_{4} \mathrm{PF}_{6}$ it was concentrated again in vacuum. Removal of excess $\mathrm{NH}_{4} \mathrm{PF}_{6}$ was carried out, by extraction in water-DCM system. After concentrating and drying the organic phase under vacuum, $430 \mathrm{mg}$ $(88 \%)$ green crystalline product was obtained.

m.p.: 223-225 ${ }^{\circ} \mathrm{C}$ (decomp.); ${ }^{1} \mathrm{H}$ NMR $(600 \mathrm{MHz}, \mathrm{DMSO}) \delta 9.31(\mathrm{~s}, 1 \mathrm{H}), 8.55$ (d, $J=8.2 \mathrm{~Hz}$, $1 \mathrm{H}), 8.32(\mathrm{~d}, J=8.7 \mathrm{~Hz}, 1 \mathrm{H}), 8.23(\mathrm{~d}, J=14.6 \mathrm{~Hz}, 1 \mathrm{H}), 7.77(\mathrm{~s}, 1 \mathrm{H}), 7.63(\mathrm{~d}, J=8.4 \mathrm{~Hz}, 1 \mathrm{H})$, $7.34(\mathrm{~d}, J=14.5 \mathrm{~Hz}, 1 \mathrm{H}), 6.91(\mathrm{~d}, J=8.0 \mathrm{~Hz}, 1 \mathrm{H}), 6.78(\mathrm{~s}, 1 \mathrm{H}), 4.83(\mathrm{q}, J=5.9 \mathrm{~Hz}, 2 \mathrm{H}), 3.52$ $(\mathrm{q}, J=5.7 \mathrm{~Hz}, 4 \mathrm{H}), 1.45(\mathrm{t}, J=6.0 \mathrm{~Hz}, 3 \mathrm{H}), 1.18(\mathrm{t}, J=5.6 \mathrm{~Hz}, 6 \mathrm{H}) ;{ }^{13} \mathrm{C} \mathrm{NMR}(151 \mathrm{MHz}$, DMSO) $\delta 172.48,160.78,150.72,150.03,145.41,144.98,135.23,128.44,124.80,124.30$, 123.25, 120.52, 118.38, 116.24, 112.29, 105.61, 91.29, 44.72, 44.04, 13.55, 12.45; HRMS (ESI) $[M]^{+}:\left[\mathrm{C}_{23} \mathrm{H}_{24} \mathrm{~N}_{3} \mathrm{O}_{3} \mathrm{~S}\right]^{+}$calculated: 422.1533 , measured: 422.1547.

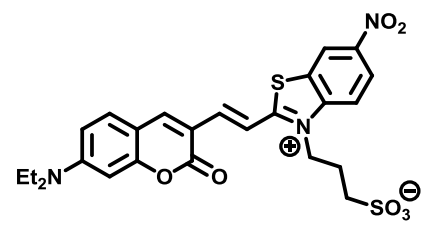

(E)-3-(2-(2-(7-(diethylamino)-2-oxo-2H-chromen-3-yl)vinyl)-6-nitrobenzo[d]thiazol-3-ium3-yl)propane-1-sulfonate (8a)

$410 \mathrm{mg}(1.61 \mathrm{mmol})$ diethylamino-formyl-coumarine and $510 \mathrm{mg}(1.61 \mathrm{mmol})$ of benzothiazolium (6) derivate were dissolved in $40 \mathrm{ml}$ DMF. After $5 \mu \mathrm{l}$ of piperidine was added to the solution, and the reaction was kept at $70{ }^{\circ} \mathrm{C}$ for 24 hours. The purple reaction mixture was than concentrated under vacuum. The solid material was purified by placing the solid on a very short silica column, and the organic components were eluted using DCM-MeOH gradient elution. The solvent was evaporated from the right fractions in vacuum, and $505 \mathrm{mg}(58 \%)$ green crystalline product was obtained.

m.p.: 207-209 ${ }^{\circ} \mathrm{C}$ (decomp.); ${ }^{1} \mathrm{H}$ NMR $(500 \mathrm{MHz}$, TFA) $\delta 9.20$ (s, 1H), $8.83(\mathrm{~d}, J=8.8 \mathrm{~Hz}$, $1 \mathrm{H}), 8.80(\mathrm{~s}, 1 \mathrm{H}), 8.72(\mathrm{~d}, J=15.6 \mathrm{~Hz}, 1 \mathrm{H}), 8.56(\mathrm{~d}, J=9.1 \mathrm{~Hz}, 1 \mathrm{H}), 8.25(\mathrm{~s}, 1 \mathrm{H}), 8.21(\mathrm{~d}, J=$ $8.0 \mathrm{~Hz}, 1 \mathrm{H}), 7.82(\mathrm{~s}, 1 \mathrm{H}), 7.73(\mathrm{~d}, J=8.0 \mathrm{~Hz}, 1 \mathrm{H}), 5.38(\mathrm{~s}, 2 \mathrm{H}), 3.94(\mathrm{~d}, J=5.7 \mathrm{~Hz}, 4 \mathrm{H}), 3.64$ (s, 2H), $2.81(\mathrm{~s}, 2 \mathrm{H}), 1.38(\mathrm{~s}, 7 \mathrm{H}) ;{ }^{13} \mathrm{C}$ NMR (151 MHz, TFA, based on HSQC,HMBC) $\delta$ $176.21,160.37,154.22,147.51,147.05,144.64,143.40,140.93,133.02,125.87,122.86$,

\footnotetext{
2 Synthesis based on: Klymchenko, S., Pivovarenki, V. G., Ozturk, T., Demchenko, A. P. (2003) New J. Chem. 27, 1336.
} 
120.04, 119.39, 117.90, 117.64, 111.19, 55.42, 48.79, 47.68, 23.55, 8.89; HRMS (ESI) $[M+H]^{+}:\left[\mathrm{C}_{25} \mathrm{H}_{25} \mathrm{~N}_{3} \mathrm{O}_{7} \mathrm{~S}_{2}+\mathrm{H}\right]^{+}$calculated: 544.1212, measured: 544.1219.<smiles>Cc1ccc2oc(/C=C/c3sc4cc([N+](=O)[O-])ccc4[n+]3CCCO)cc2c1</smiles>

(E)-3-(2-(2-(6-(diethylamino)benzofuran-2-yl)vinyl)-6-nitrobenzo[d]thiazol-3-ium-3yl)propane-1-sulfonate $(\mathbf{8 b})$

$291 \mathrm{mg}$ (1.147 mmol) 6-(diethylamino)benzofuran-2-carbaldehyde-hydrochloride was neutralized from its acidic form by dissolving the substance in $30 \mathrm{ml}$ of DCM, which was extracted with $\mathrm{NaHCO}_{3}$. The DCM was evaporated and the remaining compound was dissolved in $40 \mathrm{ml}$ of DMF. $364 \mathrm{mg}(1.15 \mathrm{mmol})$ thiazolium compound (6) and $5 \mu \mathrm{l}$ of piperidine were added to the solution. The reaction was kept at $70{ }^{\circ} \mathrm{C}$ for 24 hours. The deep-blue reaction mixture was concentrated under vacuum, purified with silica gel flash chromatography using DCM-MeOH gradient eluent. After the evaporation of the eluent in vacuum, $378 \mathrm{mg}(64 \%)$ green crystalline product was obtained.

m.p.: 202-204 ${ }^{\circ} \mathrm{C}$ (decomp.); ${ }^{1} \mathrm{H}$ NMR (500 MHz, DMSO) $\delta 9.27$ (s, 1H), 8.52 (d, $J=8.6 \mathrm{~Hz}$, $1 \mathrm{H}), 8.42(\mathrm{~d}, J=9.1 \mathrm{~Hz}, 1 \mathrm{H}), 8.18(\mathrm{~d}, J=14.6 \mathrm{~Hz}, 1 \mathrm{H}), 7.79(\mathrm{~s}, 1 \mathrm{H}), 7.60(\mathrm{~d}, J=8.8 \mathrm{~Hz}, 1 \mathrm{H})$, $7.46(\mathrm{~d}, J=14.6 \mathrm{~Hz}, 1 \mathrm{H}), 6.88(\mathrm{~d}, J=6.2 \mathrm{~Hz}, 1 \mathrm{H}), 6.78(\mathrm{~s}, 1 \mathrm{H}), 5.73(\mathrm{~s}, 1 \mathrm{H}), 4.92(\mathrm{~s}, 2 \mathrm{H})$, $3.50(\mathrm{q}, J=6.7 \mathrm{~Hz}, 4 \mathrm{H}), 2.66(\mathrm{t}, J=6.5 \mathrm{~Hz}, 2 \mathrm{H}), 2.15(\mathrm{t}, J=7.8 \mathrm{~Hz}, 2 \mathrm{H}), 1.16$ (t, $J=6.7 \mathrm{~Hz}$, $6 \mathrm{H}) ;{ }^{1} \mathrm{H}$ NMR $(500 \mathrm{MHz}, \mathrm{TFA}) \delta 9.55(\mathrm{~d}, J=2.3 \mathrm{~Hz}, 1 \mathrm{H}), 9.21$ (dd, $\left.J=9.4,2.2 \mathrm{~Hz}, 1 \mathrm{H}\right)$, $8.89(\mathrm{~d}, J=9.4 \mathrm{~Hz}, 1 \mathrm{H}), 8.71(\mathrm{~d}, J=15.3 \mathrm{~Hz}, 1 \mathrm{H}), 8.50(\mathrm{~d}, J=15.2 \mathrm{~Hz}, 1 \mathrm{H}), 8.46(\mathrm{~d}, J=8.5$ $\mathrm{Hz}, 1 \mathrm{H}), 8.40(\mathrm{~s}, 1 \mathrm{H}), 7.99(\mathrm{~s}, 1 \mathrm{H}), 7.91(\mathrm{dd}, J=8.6,2.2 \mathrm{~Hz}, 1 \mathrm{H}), 5.81(\mathrm{t}, J=8.4 \mathrm{~Hz}, 2 \mathrm{H})$, $4.39-4.25(\mathrm{~m}, 4 \mathrm{H}), 4.09(\mathrm{t}, J=5.9 \mathrm{~Hz}, 2 \mathrm{H}), 3.22(\mathrm{~s}, 2 \mathrm{H}), 1.75(\mathrm{t}, J=7.3 \mathrm{~Hz}, 6 \mathrm{H}) ;{ }^{13} \mathrm{C} \mathrm{NMR}$ (151 MHz, TFA, based on HSQC,HMBC) $\delta 175.43,156.60,154.16,147.65,144.88,136.24$, 130.98, 129.26, 125.99, 125.92, 120.24, 117.64, 117.90, 117.45, 117.30, 114.14, 106.75, 55.90, 48.89, 47.86, 23.40, 9.20; HRMS (ESI) $[M+H]^{+}:\left[\mathrm{C}_{24} \mathrm{H}_{25} \mathrm{~N}_{3} \mathrm{O}_{6} \mathrm{~S}_{2}+\mathrm{H}\right]^{+}$calculated: 516.1263, measured: 516.1263.

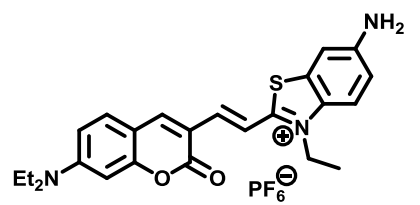

(E)-6-amino-2-(2-(7-(diethylamino)-2-oxo-2H-chromen-3-yl)vinyl)-3-ethylbenzo[d]thiazol-3ium hexafluorophosphate (9a)

$470 \mathrm{mg}(2.08 \mathrm{mmol})$ of $\mathrm{SnCl}_{2} \cdot 2 \mathrm{H}_{2} \mathrm{O}$ was suspended in $12 \mathrm{ml} \mathrm{cc} H C l$ than $330 \mathrm{mg}(0.555 \mathrm{mmol})$ of nitro compound (7a) was added. The reaction was stirred for $5 \mathrm{~h}$ at r.t. then it was poured onto ice, and $\mathrm{NaOH}$ was added until neutral $\mathrm{pH}$ was reached. The purple reaction mixture was extracted with $3 \times 100 \mathrm{ml}$ DCM. The combined organic phases were washed with $2 \times 50 \mathrm{ml} \mathrm{H}_{2} \mathrm{O}$, and $50 \mathrm{ml}$ brine, and then dried on $\mathrm{MgSO}_{4}$. After the reaction was concentrated under vacuum, product was purified with silica gel chromatography using DCM-MeOH gradient eluent and $\mathrm{MeCN} \mathrm{NH}_{4} \mathrm{PF}_{6}$ solution at the end of separation. The substance was dissolved in $\mathrm{MeCN}$ solution containing excess of $\mathrm{NH}_{4} \mathrm{PF}_{6}$ then it was concentrated in vacuum. Removal of excess $\mathrm{NH}_{4} \mathrm{PF}_{6}$ was carried out, by extraction in water-DCM system. After concentrating and drying the organic phase under vacuum, $160 \mathrm{mg}(51 \%)$ green crystalline product was obtained. 
m.p.: 203-205 ${ }^{\circ} \mathrm{C}$ (decomp.); ${ }^{1} \mathrm{H}$ NMR (600 MHz, DMSO) $\delta 8.57$ (s, $\left.1 \mathrm{H}\right), 7.95$ (d, $J=15.5 \mathrm{~Hz}$, $1 \mathrm{H}), 7.89(\mathrm{~d}, J=9.1 \mathrm{~Hz}, 1 \mathrm{H}), 7.74(\mathrm{~d}, J=15.4 \mathrm{~Hz}, 1 \mathrm{H}), 7.54(\mathrm{~d}, J=9.0 \mathrm{~Hz}, 1 \mathrm{H}), 7.27(\mathrm{~d}, J=$ $1.4 \mathrm{~Hz}, 1 \mathrm{H}), 7.03(\mathrm{~d}, J=9.0 \mathrm{~Hz}, 1 \mathrm{H}), 6.84\left(\mathrm{dd}, J_{1}=9.0, J_{2}=1.4 \mathrm{~Hz}, 1 \mathrm{H}\right), 6.63(\mathrm{~s}, 1 \mathrm{H}), 4.67(\mathrm{q}$, $2 \mathrm{H}), 3.51(\mathrm{q}, J=6.8 \mathrm{~Hz}, 4 \mathrm{H}), 1.44(\mathrm{t}, J=7.2 \mathrm{~Hz}, 3 \mathrm{H}), 1.16(\mathrm{t}, J=7.0 \mathrm{~Hz}, 6 \mathrm{H})($ amine $\mathrm{H}$ signal not visible); ${ }^{13} \mathrm{C}$ NMR (151 MHz, DMSO) $\delta 163.58,159.74,156.82,152.75,149.98,146.62$, $140.79,131.49,131.35,130.32$, 117.11, 117.02, 112.42, 111.41, 110.60, 108.70, 104.55, 96.41, 44.56, 44.01, 14.03, 12.43; HRMS (ESI) $[M]^{+}:\left[\mathrm{C}_{24} \mathrm{H}_{26} \mathrm{~N}_{3} \mathrm{O}_{2} \mathrm{~S}\right]^{+}$calculated: 420.1740, measured: 420.7151.

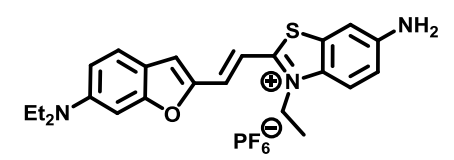

(E)-6-amino-2-(2-(6-(diethylamino)benzofuran-2-yl)vinyl)-3-ethylbenzo[d]thiazol-3-ium hexafluorophospate (9b)

$440 \mathrm{mg}(1.95 \mathrm{mmol})$ of $\mathrm{SnCl}_{2} \cdot 2 \mathrm{H}_{2} \mathrm{O}$ was suspended in $14 \mathrm{ml} \mathrm{cc} H C l$ than $180 \mathrm{mg}$ of nitro derivative (7b) was added. After the reaction was stirred for $5 \mathrm{~h}$ at $22^{\circ} \mathrm{C}$ it was poured onto ice, and $\mathrm{NaOH}$ was added until neutral $\mathrm{pH}$ was reached. Reaction mixture was extracted by $3 \times 75$ $\mathrm{ml}$ DCM. The organic phase was washed with $2 \times 20 \mathrm{ml} \mathrm{H}_{2} \mathrm{O}$, and $10 \mathrm{ml}$ brine. After the reaction was concentrated under vacuum, purified with silica gel chromatography using DCM-MeOH gradient eluent and $\mathrm{MeCN} \mathrm{NH}_{4} \mathrm{PF}_{6}$ solution at the end of separation. The substance was dissolved in $\mathrm{MeCN}$ solution containing excess of $\mathrm{NH}_{4} \mathrm{PF}_{6}$ then it was concentrated in vacuum. Removal of excess $\mathrm{NH}_{4} \mathrm{PF}_{6}$ was carried out, by extraction in water-DCM system. After concentrating and drying the organic phase under vacuum, $120 \mathrm{mg}(70 \%)$ green crystalline product was obtained.

m.p.: $217-220{ }^{\circ} \mathrm{C}$ (decomp.); ${ }^{1} \mathrm{H}$ NMR (600 MHz, DMSO) $\delta 7.87(\mathrm{~d}, J=9.1 \mathrm{~Hz}, 1 \mathrm{H}), 7.82(\mathrm{~d}$, $J=15.1 \mathrm{~Hz}, 1 \mathrm{H}), 7.54(\mathrm{~d}, J=8.8 \mathrm{~Hz}, 1 \mathrm{H}), 7.47(\mathrm{~s}, 1 \mathrm{H}), 7.33(\mathrm{~d}, J=15.1 \mathrm{~Hz}, 1 \mathrm{H}), 7.25(\mathrm{~d}, J=$ $1.3 \mathrm{~Hz}, 1 \mathrm{H}), 7.01(\mathrm{~d}, J=9.0 \mathrm{~Hz}, 1 \mathrm{H}), 6.82(\mathrm{~d}, J=8.6 \mathrm{~Hz}, 1 \mathrm{H}), 6.78(\mathrm{~s}, 1 \mathrm{H}), 6.15$ (broad, $2 \mathrm{H})$, $4.72(\mathrm{q}, J=7.0 \mathrm{~Hz}, 2 \mathrm{H}), 3.47(\mathrm{q}, J=7.0 \mathrm{~Hz}, 4 \mathrm{H}), 1.43(\mathrm{t}, J=7.1 \mathrm{~Hz}, 3 \mathrm{H}), 1.15(\mathrm{t}, J=7.0 \mathrm{~Hz}$, $6 \mathrm{H}) ;{ }^{13} \mathrm{C}$ NMR (151 MHz, DMSO) $\delta 162.43,159.21,149.84,149.72,131.53,130.90,130.15$, 123.55, 117.62, 117.45, 116.98, 116.87, 114.38, 111.00, 107.70, 104.61, 91.80, 44.51, 43.68, 14.12, 12.40; HRMS (ESI) $[M]^{+}:\left[\mathrm{C}_{23} \mathrm{H}_{26} \mathrm{~N}_{3} \mathrm{OS}\right]^{+}$calculated: 392.1791 , measured: 392.1801.

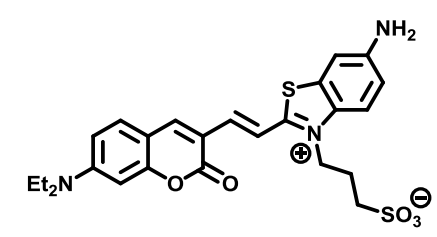

(E)-3-(6-amino-2-(2-(7-(diethylamino)-2-oxo-2H-chromen-3-yl)vinyl)benzo[d]thiazol-3-ium3-yl)propane-1-sulfonate (10a)

$760 \mathrm{mg}$ (3.80 mmol) of anhydrous $\mathrm{SnCl}_{2}$ and $360 \mathrm{mg}(0.662 \mathrm{mmol})$ of nitro derivative were suspended in $150 \mathrm{ml}$ of EtOH assisted with ultrasonic bath. The reaction mixture was kept at reflux temperature overnight. The solvent was evaporated, and the remaining material was placed on a short column of basic alumina. The product was eluted using DCM-MeOH gradient elution, product only elutes at 9:1 v/v. The right fractions were collected and the solvent was removed in vacuum. Product was obtained as a dark solid $(230 \mathrm{mg}, 68 \%)$ which was used without further purification. Analytical sample was prepared with preparative HPLC. 
m.p.: 207-209 ${ }^{\circ} \mathrm{C}$ (decomp.); ${ }^{1} \mathrm{H}$ NMR $(500 \mathrm{MHz}$, DMSO) $\delta 8.80(\mathrm{~s}, 1 \mathrm{H}), 8.51(\mathrm{~s}, 1 \mathrm{H}), 8.08(\mathrm{~d}$, $J=15.7 \mathrm{~Hz}, 1 \mathrm{H}), 8.03(\mathrm{~d}, J=9.1 \mathrm{~Hz}, 1 \mathrm{H}), 7.77(\mathrm{~d}, J=15.6 \mathrm{~Hz}, 1 \mathrm{H}), 7.56(\mathrm{~d}, J=9.1 \mathrm{~Hz}, 1 \mathrm{H})$, $7.06(\mathrm{dd}, J=9.1,2.0 \mathrm{~Hz}, 1 \mathrm{H}), 6.90(\mathrm{dd}, J=9.0,2.1 \mathrm{~Hz}, 1 \mathrm{H}), 6.69(\mathrm{~s}, 1 \mathrm{H}), 6.22(\mathrm{~s}, 1 \mathrm{H}), 4.90(\mathrm{t}$, $J=7.3 \mathrm{~Hz}, 2 \mathrm{H}), 3.56(\mathrm{dd}, J=12.9,6.1 \mathrm{~Hz}, 4 \mathrm{H}), 2.65(\mathrm{t}, J=6.5 \mathrm{~Hz}, 2 \mathrm{H}), 2.26-2.16(\mathrm{~m}, 2 \mathrm{H})$, $1.21(\mathrm{t}, J=6.9 \mathrm{~Hz}, 6 \mathrm{H}) ;{ }^{1} \mathrm{H}$ NMR $(500 \mathrm{MHz},) \delta 8.96-8.84(\mathrm{~m}, 2 \mathrm{H}), 8.79-8.68(\mathrm{~m}, 2 \mathrm{H}), 8.39$ $-8.27(\mathrm{~m}, 3 \mathrm{H}), 7.98(\mathrm{~s}, 1 \mathrm{H}), 7.87(\mathrm{~d}, J=8.7 \mathrm{~Hz}, 1 \mathrm{H}), 5.49(\mathrm{~d}, J=8.6 \mathrm{~Hz}, 2 \mathrm{H}), 4.24(\mathrm{~s}, 1 \mathrm{H})$, $4.08(\mathrm{~d}, J=9.1 \mathrm{~Hz}, 4 \mathrm{H}), 3.78(\mathrm{t}, J=6.5 \mathrm{~Hz}, 2 \mathrm{H}), 2.92(\mathrm{~s}, 2 \mathrm{H}), 1.51(\mathrm{t}, J=6.5 \mathrm{~Hz}, 6 \mathrm{H}),{ }^{13} \mathrm{C} \mathrm{NMR}$ (151 MHz, TFA, based on HSQC,HMBC) $\delta 174.54,160.68,154.24,147.31,143.01,142.26$, 141.03, 133.04, 130.14, 126.15, 122.90, 121.20, 119.92, 119.30, 118.55, 118.06, 111.41, 55.67, 48.61, 47.90, 29.35, 23.57, 9.05; HRMS (ESI) $[M+H]^{+}:\left[\mathrm{C}_{25} \mathrm{H}_{27} \mathrm{~N}_{3} \mathrm{O}_{5} \mathrm{~S}_{2}+\mathrm{H}\right]^{+}$calculated: 514.147, measured: 514.1473.

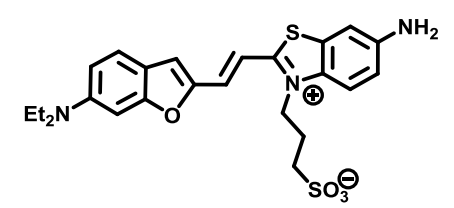

(E)-3-(6-amino-2-(2-(6-(diethylamino)benzofuran-2-yl)vinyl)benzo[d]thiazol-3-ium-3yl)propane-1-sulfonate (10b)

$500 \mathrm{mg}(2.22 \mathrm{mmol})$ of $\mathrm{SnCl}_{2} \cdot 2 \mathrm{H}_{2} \mathrm{O}$ was dissolved in $14 \mathrm{ml} \mathrm{cc} H C l .290 \mathrm{mg}$ of nitro-derivative $(\mathbf{8 b})$ was added to the solution. After the reaction was stirred overnight at $22{ }^{\circ} \mathrm{C}$ it was poured onto ice, and $\mathrm{NaOH}$ was added until neutral $\mathrm{pH}$ was reached. The water was evaporated in vacuum and the salty mixture was purified by placing the crushed solid on a short silica column, and the product was eluted with DCM-MeOH gradient eluent. The product elution is expected at 9:1 v/v. After concentrating and drying the pure fractions under vacuum, $300 \mathrm{mg}(81 \%)$ green crystalline product was obtained.

m.p.: 200-203 ${ }^{\circ} \mathrm{C}$ (decomp.); ${ }^{1} \mathrm{H}$ NMR (400 MHz, DMSO) $\delta 7.95(\mathrm{~d}, J=9.2 \mathrm{~Hz}, 1 \mathrm{H}), 7.79$ (d, $J=15.1 \mathrm{~Hz}, 1 \mathrm{H}), 7.52(\mathrm{~d}, J=8.8 \mathrm{~Hz}, 1 \mathrm{H}), 7.48(\mathrm{~s}, 1 \mathrm{H}), 7.41(\mathrm{~d}, J=15.2 \mathrm{~Hz}, 1 \mathrm{H}), 7.22(\mathrm{~d}, J=$ $2.2 \mathrm{~Hz}, 1 \mathrm{H}), 7.00(\mathrm{dd}, J=9.1,2.2 \mathrm{~Hz}, 1 \mathrm{H}), 6.83-6.74(\mathrm{~m}, 2 \mathrm{H}), 6.16(\mathrm{~s}, 2 \mathrm{H}), 4.87-4.75(\mathrm{~m}$, $2 \mathrm{H}), 3.43(\mathrm{~d}, J=6.7 \mathrm{~Hz}, 4 \mathrm{H}), 2.63(\mathrm{t}, J=7.0 \mathrm{~Hz}, 2 \mathrm{H}), 2.17-2.07(\mathrm{~m}, 2 \mathrm{H}), 1.14(\mathrm{t}, J=7.0$ $\mathrm{Hz}, 6 \mathrm{H}) ;{ }^{13} \mathrm{C}$ NMR $(101 \mathrm{MHz}$, DMSO) $\delta 162.95,159.38,149.90,149.84,149.13,132.10$, 131.04, 130.09, 123.59, 117.60, 117.21, 117.04, 111.04, 108.02, 104.53, 91.89, 47.66, 44.55, 25.34, 12.55, 8.73; HRMS (ESI) $[M+H]^{+}:\left[\mathrm{C}_{24} \mathrm{H}_{27} \mathrm{~N}_{3} \mathrm{O}_{4} \mathrm{~S}_{2}+\mathrm{H}\right]^{+}$calculated: 486.1521, measured: 486.1516 .

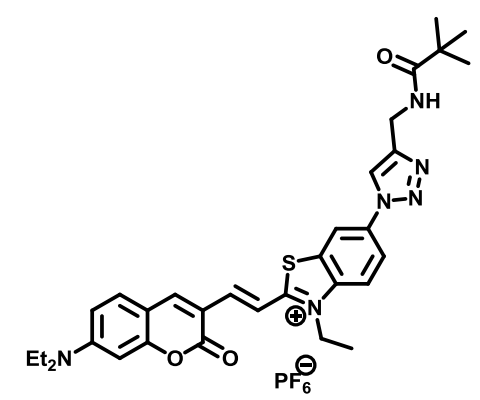

(E)-2-(2-(7-(diethylamino)-2-oxo-2H-chromen-3-yl)vinyl)-3-ethyl-6-(4-(pivalamidomethyl)1H-1,2,3-triazol-1-yl)benzo[d]thiazol-3-ium hexafluorophospate (11a) 
$8 \mathrm{mg}(0.0135 \mathrm{mmol})$ azide product $(\mathbf{2 a})$ and $5 \mathrm{mg}(0.0575 \mathrm{mmol})$ propargyl-pivalamide were dissolved in $8 \mathrm{ml}$ of DCM. After adding $3 \mu \mathrm{TEA}$ and catalytic $\mathrm{Cu}\left(\mathrm{PPh}_{3}\right)_{2} \mathrm{NO}_{3}$ the reaction was stirred overnight. The reaction mixture was concentrated under vacuum, and the product was purified with silica gel chromatography using DCM:MeOH 20:1-9:1 gradient eluent. Excess amount of $\mathrm{NH}_{4} \mathrm{PF}_{6}$ was added to the right fractions at the end of separation, and it was concentrated again in vacuum. Removal of excess $\mathrm{NH}_{4} \mathrm{PF}_{6}$ was carried out by extraction in water-DCM system. After concentrating and drying the organic phase under vacuum, $5 \mathrm{mg}$ $(51 \%)$ dark crystalline product was obtained.

m.p.: 206-209 ${ }^{\circ} \mathrm{C}$ (decomp.); ${ }^{1} \mathrm{H}$ NMR $(500 \mathrm{MHz}$, d-TFA) $\delta 9.37$ (s, 1H), 9.14 (s, 1H), 8.91 $(\mathrm{d}, J=15.7 \mathrm{~Hz}, 1 \mathrm{H}), 8.84(\mathrm{~s}, 1 \mathrm{H}), 8.72(\mathrm{~d}, J=9.5 \mathrm{~Hz}, 1 \mathrm{H}), 8.62(\mathrm{~d}, J=9.2 \mathrm{~Hz}, 1 \mathrm{H}), 8.38-$ $8.29(\mathrm{~m}, 2 \mathrm{H}), 8.00(\mathrm{~s}, 1 \mathrm{H}), 7.90(\mathrm{~d}, J=8.7 \mathrm{~Hz}, 1 \mathrm{H}), 5.24(\mathrm{~d}, J=7.7 \mathrm{~Hz}, 2 \mathrm{H}), 5.09(\mathrm{~s}, 2 \mathrm{H})$, $4.25(\mathrm{~s}, 1 \mathrm{H}), 4.09$ (q, $J=7.4 \mathrm{~Hz}, 4 \mathrm{H}), 1.99(\mathrm{t}, J=7.4 \mathrm{~Hz}, 3 \mathrm{H}), 1.54$ (t, $J=7.5 \mathrm{~Hz} 6 \mathrm{H}), 1.50$ (s, $9 \mathrm{H}){ }^{13} \mathrm{C}$ NMR (151 MHz, TFA, based on HSQC,HMBC) $\delta 185.94,174.83,160.49,154.21$, 149.21, 144.01, 142.94, 141.87, 141.35, 135.22, 132.93, 130.60, 127.12, 122.54, 121.06, 119.52, 118.35, 117.99, 117.91, 111.42, 55.57, 46.48, 39.15, 32.68, 25.47, 12.46, 9.17; HRMS (ESI) $[M]^{+}:\left[\mathrm{C}_{32} \mathrm{H}_{37} \mathrm{~N}_{6} \mathrm{O}_{3} \mathrm{~S}\right]^{+}$calculated: 585.2642, measured: 585.2654.

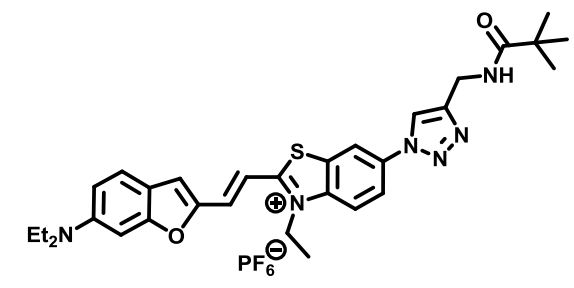

(E)-2-(2-(6-(diethylamino)benzofuran-2-yl)vinyl)-3-ethyl-6-(4-(pivalamidomethyl)-1H-1,2,3triazol-1-yl)benzo[d]thiazol-3-ium hexafluorophospate (11b)

$25 \mathrm{mg}(0.0443 \mathrm{mmol})$ azide-derivative $(\mathbf{2 b}), 25 \mathrm{mg}(0.179 \mathrm{mmol})$ propargyl-pivalamide were dissolved in $8 \mathrm{ml}$ of DCM. After adding $3 \mu \mathrm{l}$ TEA and catalytic $\mathrm{Cu}\left(\mathrm{PPh}_{3}\right)_{2} \mathrm{NO}_{3}$ the reaction was stirred overnight. The reaction was concentrated under vacuum, and product was purified with silica gel chromatography using $\mathrm{DCM}-\mathrm{MeOH}$ gradient eluent and $\mathrm{MeCN}-\mathrm{NH}_{4} \mathrm{PF}_{6}$ solution at the end of separation. Dissolving the substance in $\mathrm{MeCN}$ solution with excess amount of $\mathrm{NH}_{4} \mathrm{PF}_{6}$ it was concentrated again in vacuum. Removal of excess $\mathrm{NH}_{4} \mathrm{PF}_{6}$ was carried out, by extraction in water-DCM system. After concentrating and drying the organic phase under vacuum, $23 \mathrm{mg}$ (74\%) dark crystalline product was obtained.

m.p.: 208-210 ${ }^{\circ} \mathrm{C}$ (decomp.); ${ }^{1} \mathrm{H}$ NMR $(500 \mathrm{MHz}$, TFA) $\delta 9.27$ (s, 1H), 9.02 (s, 1H), 8.63 (d, $J$ $=8.7 \mathrm{~Hz}, 1 \mathrm{H}), 8.51(\mathrm{~d}, J=8.7 \mathrm{~Hz}, 1 \mathrm{H}), 8.25(\mathrm{~d}, J=15.3 \mathrm{~Hz}, 1 \mathrm{H}), 8.17(\mathrm{~d}, J=8.5 \mathrm{~Hz}, 1 \mathrm{H}), 8.03$ $(\mathrm{m}, 2 \mathrm{H}), 7.71(\mathrm{~s}, 1 \mathrm{H}), 7.61(\mathrm{~d}, J=8.5 \mathrm{~Hz}, 1 \mathrm{H}), 5.17(\mathrm{q}, J=7.1 \mathrm{~Hz}, 2 \mathrm{H}), 5.02(\mathrm{~s}, 2 \mathrm{H}), 4.05(\mathrm{dt}$, $J=13.3,7.3 \mathrm{~Hz}, 2 \mathrm{H}), 3.92(\mathrm{dt}, J=13.2,6.9 \mathrm{~Hz}, 2 \mathrm{H}), 1.92(\mathrm{t}, J=7.2 \mathrm{~Hz}, 3 \mathrm{H}), 1.44(\mathrm{~m}, 15 \mathrm{H})$; (151 MHz, TFA, based on HSQC,HMBC); $\delta 187.65,173.68,160.37,156.33,153.78,142.79$, 136.06, 135.94, 135.04, 130.41, 125.73, 123.73, 118.12, 117. 70, 117.25, 116.74, 112.44, 106.92, 55.62, 46.26, 34.76, 32.40, 25.39, 12.53, 9.02; HRMS (ESI) $[M]^{+}:\left[\mathrm{C}_{31} \mathrm{H}_{37} \mathrm{~N}_{6} \mathrm{O}_{2} \mathrm{~S}\right]^{+}$ calculated: 557.2693, measured: 557.2693. 


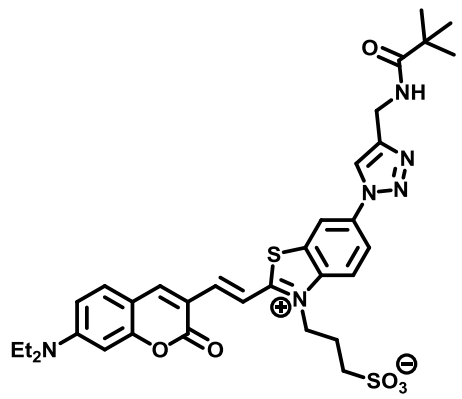

(E)-3-(2-(2-(7-(diethylamino)-2-oxo-2H-chromen-3-yl)vinyl)-6-(4-(pivalamidomethyl)-1H1,2,3-triazol-1-yl)benzo[d]thiazol-3-ium-3-yl)propane-1-sulfonate (12a)

$12 \mathrm{mg}(0.0222 \mathrm{mmol})$ azide-derivative $(\mathbf{2 b}), 12 \mathrm{mg}(0.0862 \mathrm{mmol})$ propargyl-pivalamide were dissolved in $7 \mathrm{ml}$ of DCM. $2 \mu \mathrm{l}$ of TEA and catalytic amounts $\mathrm{Cu}\left(\mathrm{PPh}_{3}\right)_{2} \mathrm{NO}_{3}$ was placed in the reaction mixture, which was stirred overnight at $22{ }^{\circ} \mathrm{C}$. The product was isolated by placing the reaction mixture on a very short silica column, and the product could be separated from other organic components using DCM-MeOH gradient elution. The product elutes at DCM-MeOH 9:1 v/v. After drying the organic phase under vacuum, $16 \mathrm{mg}(74 \%)$ dark crystalline product was obtained.

m.p.: 201-203 ${ }^{\circ} \mathrm{C}$ (decomp.); ${ }^{1} \mathrm{H}$ NMR $(500 \mathrm{MHz}$, dmso) $\delta 8.96$ (s, 1H), 8.87 (s, 1H), 8.64 (s, $1 \mathrm{H}), 8.53(\mathrm{~d}, J=9.4 \mathrm{~Hz}, 1 \mathrm{H}), 8.34(\mathrm{~s}, 1 \mathrm{H}), 8.10(\mathrm{~d}, J=3.8 \mathrm{~Hz}, 1 \mathrm{H}), 8.02(\mathrm{~d}, J=11.2 \mathrm{~Hz}, 1 \mathrm{H})$, $7.59(\mathrm{~s}, 1 \mathrm{H}), 6.88(\mathrm{~d}, J=7.1 \mathrm{~Hz}, 1 \mathrm{H}), 6.66(\mathrm{~s}, 1 \mathrm{H}), 5.03-4.96(\mathrm{~m}, 2 \mathrm{H}), 4.40(\mathrm{~d}, J 5.3 \mathrm{~Hz}, 2 \mathrm{H})$, $3.51-3.47(\mathrm{~m}, 4 \mathrm{H}$ distorted q), $2.65(\mathrm{~d}, J=6.7 \mathrm{~Hz}, 2 \mathrm{H}), 2.20-2,14(\mathrm{~m}, 2 \mathrm{H}), 1.16(\mathrm{t}, J=5,1$ $\mathrm{Hz}, 6 \mathrm{H}), 1.12(\mathrm{~s}, 9 \mathrm{H})$. HRMS (ESI) $[M+H]^{+}:\left[\mathrm{C}_{33} \mathrm{H}_{38} \mathrm{~N}_{6} \mathrm{O}_{6} \mathrm{~S}_{2}+\mathrm{H}\right]^{+}$calculated: 701.2192, measured: 701.2208 .

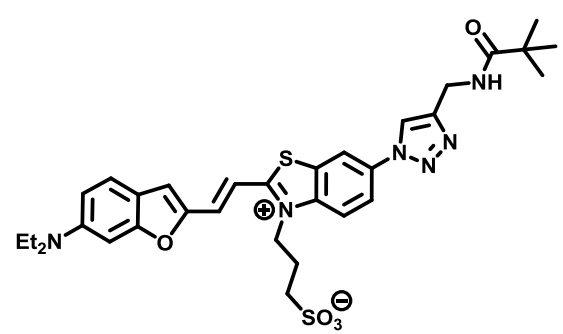

(E)-3-(2-(2-(6-(diethylamino)benzofuran-2-yl)vinyl)-6-(4-(pivalamidomethyl)-1H-1,2,3triazol-1-yl)benzo[d]thiazol-3-ium-3-yl)propane-1-sulfonate (12b)

$22 \mathrm{mg}(0.043 \mathrm{mmol})$ azide-derivative $(\mathbf{2 b}), 19 \mathrm{mg}(0.136 \mathrm{mmol})$ propargyl-pivalamide were dissolved in $10 \mathrm{ml}$ of DCM. $3 \mathrm{ul}$ of TEA and catalytic amounts $\mathrm{Cu}\left(\mathrm{PPh}_{3}\right)_{2} \mathrm{NO}_{3}$ was placed in the reaction mixture, which was stirred overnight at $22{ }^{\circ} \mathrm{C}$. The product was isolated by placing the reaction mixture on a very short silica column, and $\mathrm{DCM}-\mathrm{MeOH}$ gradient elution was used for purification. The organic solvent was removed under vacuum, $16 \mathrm{mg}(74 \%)$ dark crystalline product was obtained.

m.p.: $197-199{ }^{\circ} \mathrm{C}$ (decomp.) ${ }^{1} \mathrm{H}$ NMR $(500 \mathrm{MHz},) \delta 9.29$ (s, 1H), 9.05 (s, 1H), 8.74 (d, $J=8.8$ $\mathrm{Hz}, 1 \mathrm{H}), 8.64(\mathrm{~d}, J=8.4 \mathrm{~Hz}, 1 \mathrm{H}), 8.46(\mathrm{~d}, J=15.3 \mathrm{~Hz}, 1 \mathrm{H}), 8.27-8.11(\mathrm{~m}, 3 \mathrm{H}), 7.71(\mathrm{~s}, 1 \mathrm{H})$, $7.64(\mathrm{~d}, J=8.5 \mathrm{~Hz}, 1 \mathrm{H}), 5.55(\mathrm{~d}, J=9.3 \mathrm{~Hz}, 2 \mathrm{H}), 5.07(\mathrm{~s}, 2 \mathrm{H}), 4.15-3.98(\mathrm{~m}, 4 \mathrm{H}), 3.82(\mathrm{~d}, J$ $=12.8 \mathrm{~Hz}, 2 \mathrm{H}), 2.97(\mathrm{~s}, 2 \mathrm{H}), 1.57-1.37(\mathrm{~m}, 15 \mathrm{H})$; (151 MHz, TFA, based on HSQC, CH carbons only); $\delta 135.65,125.45,123.64,120.79,118.32,117.15,16.94,113.93,106.82,55.84$, 48.23, 47.42, 25.66, 23.44, 9.10; HRMS (ESI) $[M+H]^{+}:\left[\mathrm{C}_{32} \mathrm{H}_{38} \mathrm{~N}_{6} \mathrm{O}_{5} \mathrm{~S}_{2}+\mathrm{H}\right]^{+}$calculated: 651.2423, measured: 651.2426. 


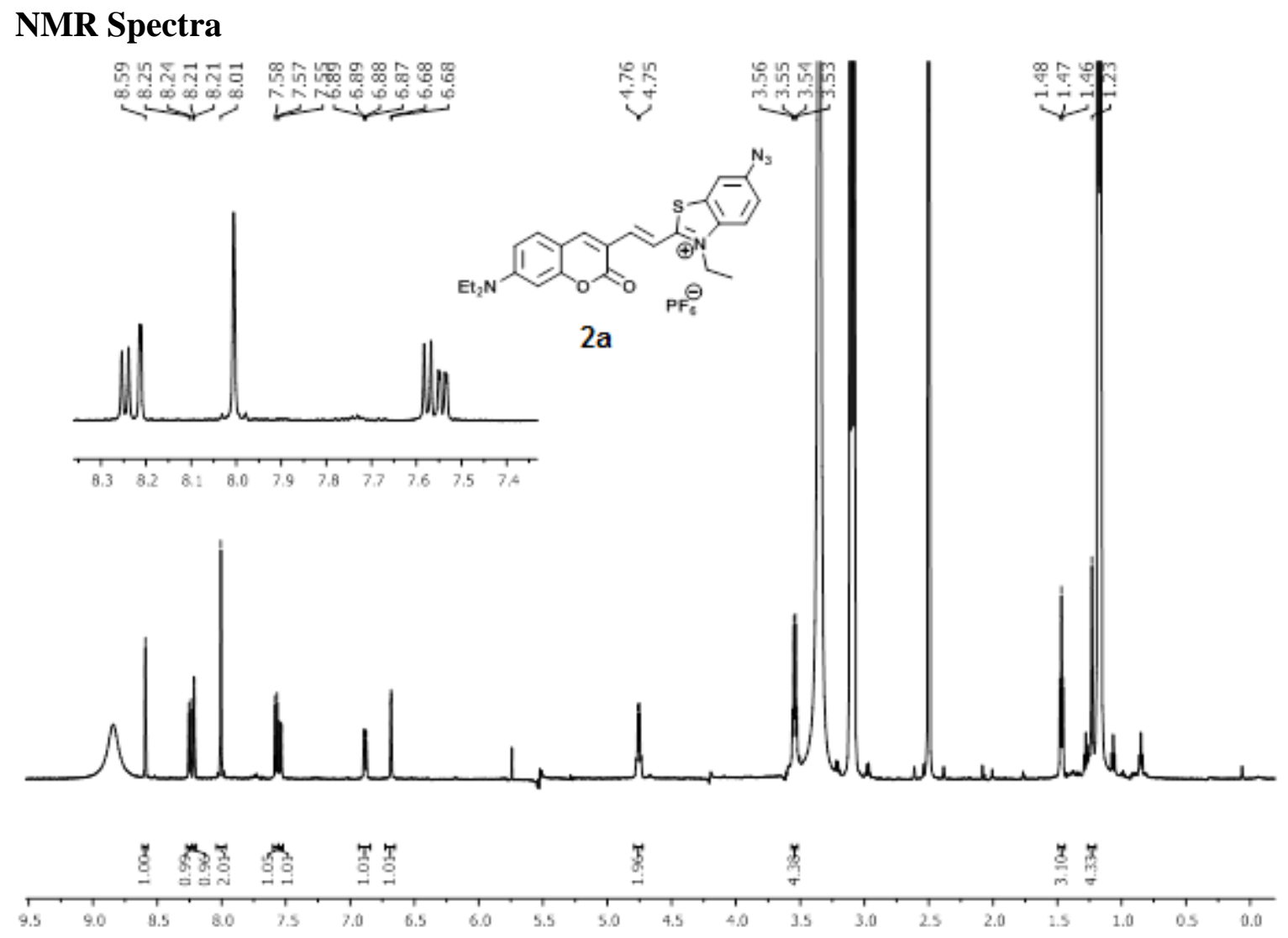

蛋

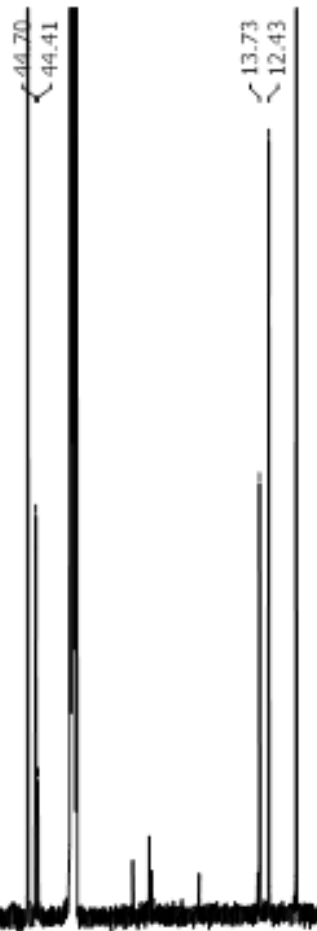




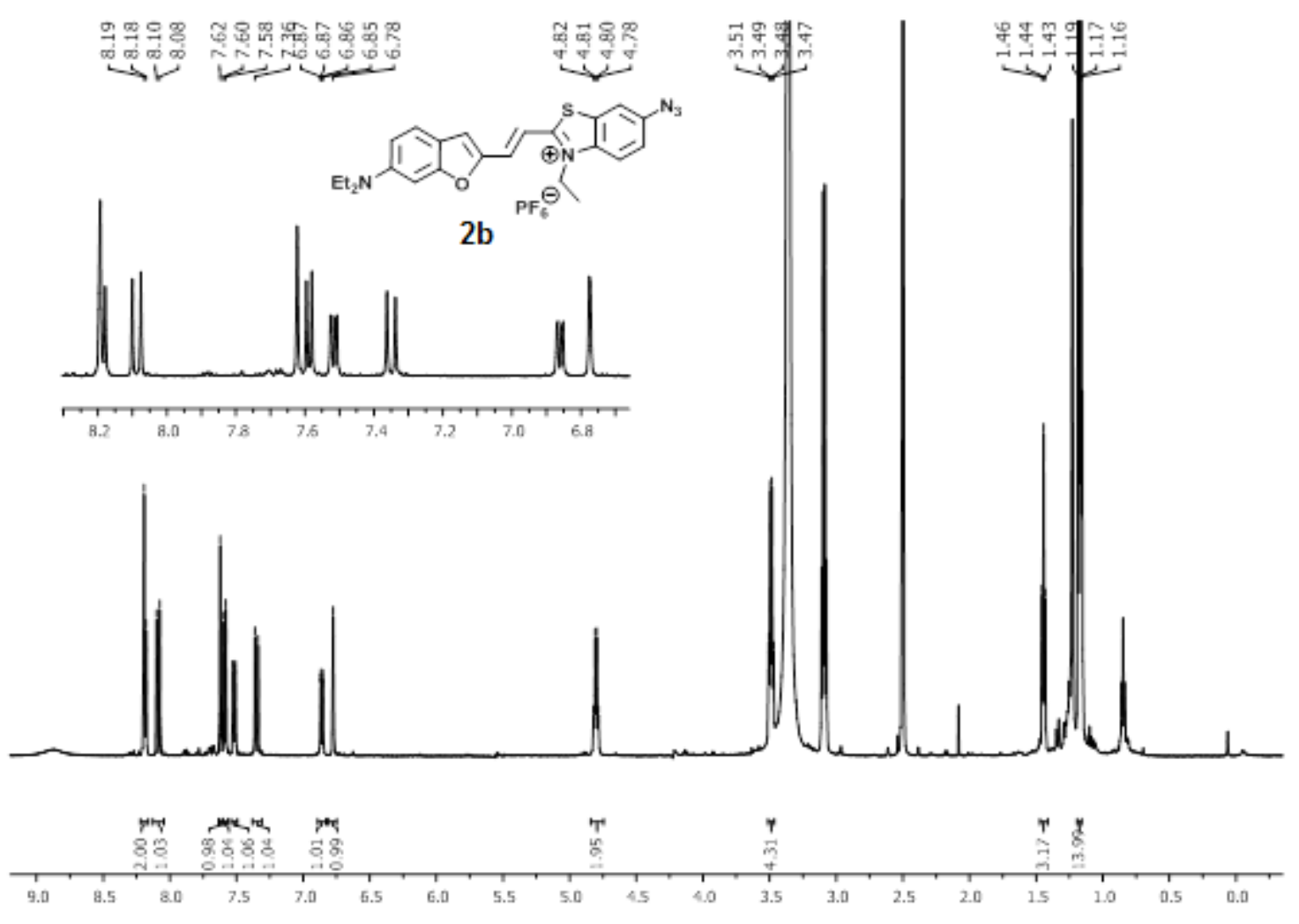

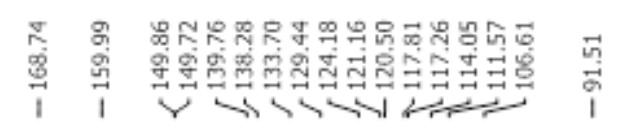

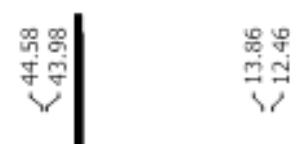

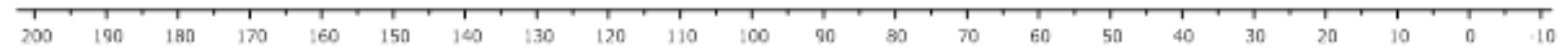




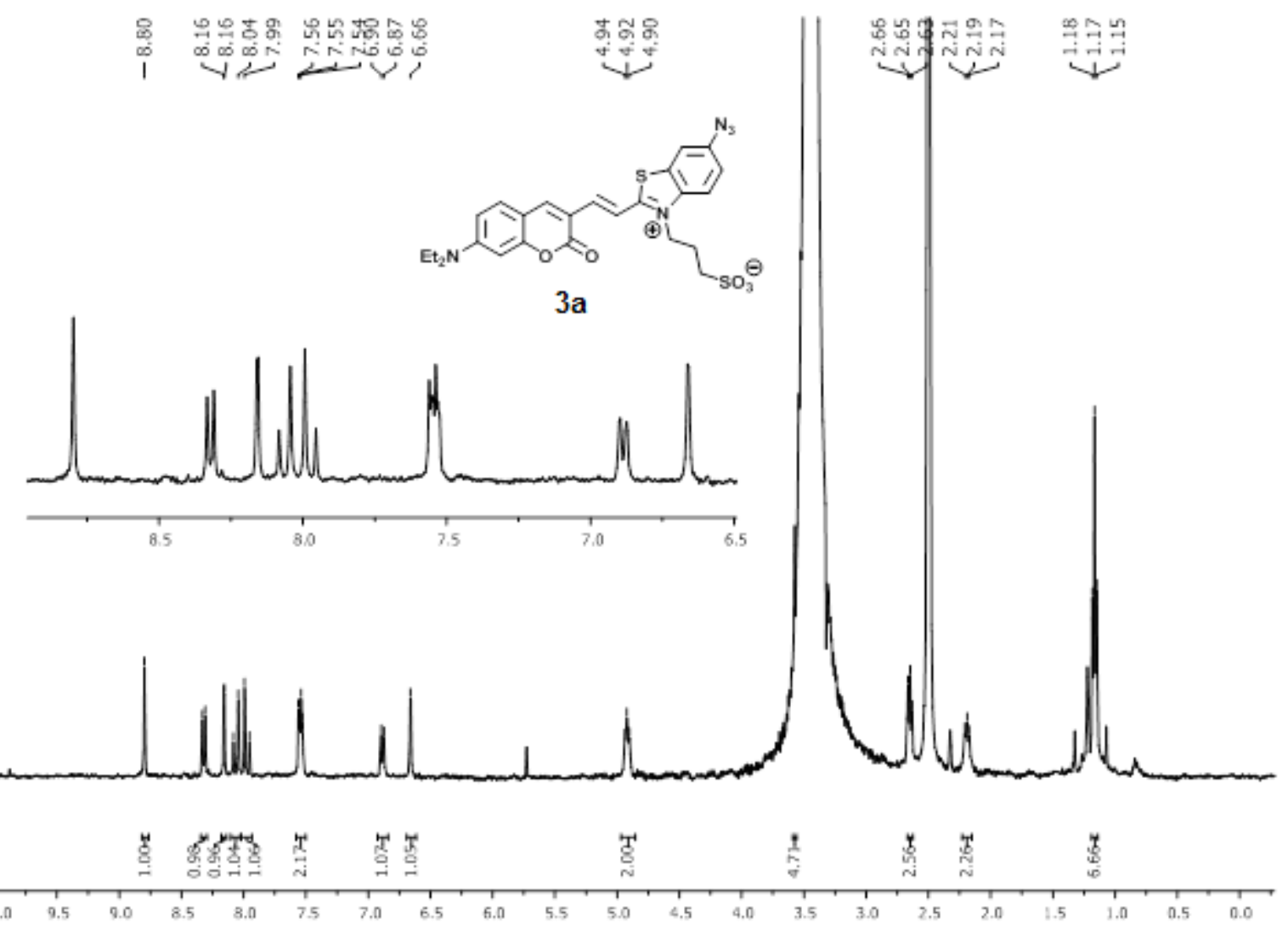

${ }^{1} \mathrm{H}$ (TFA)

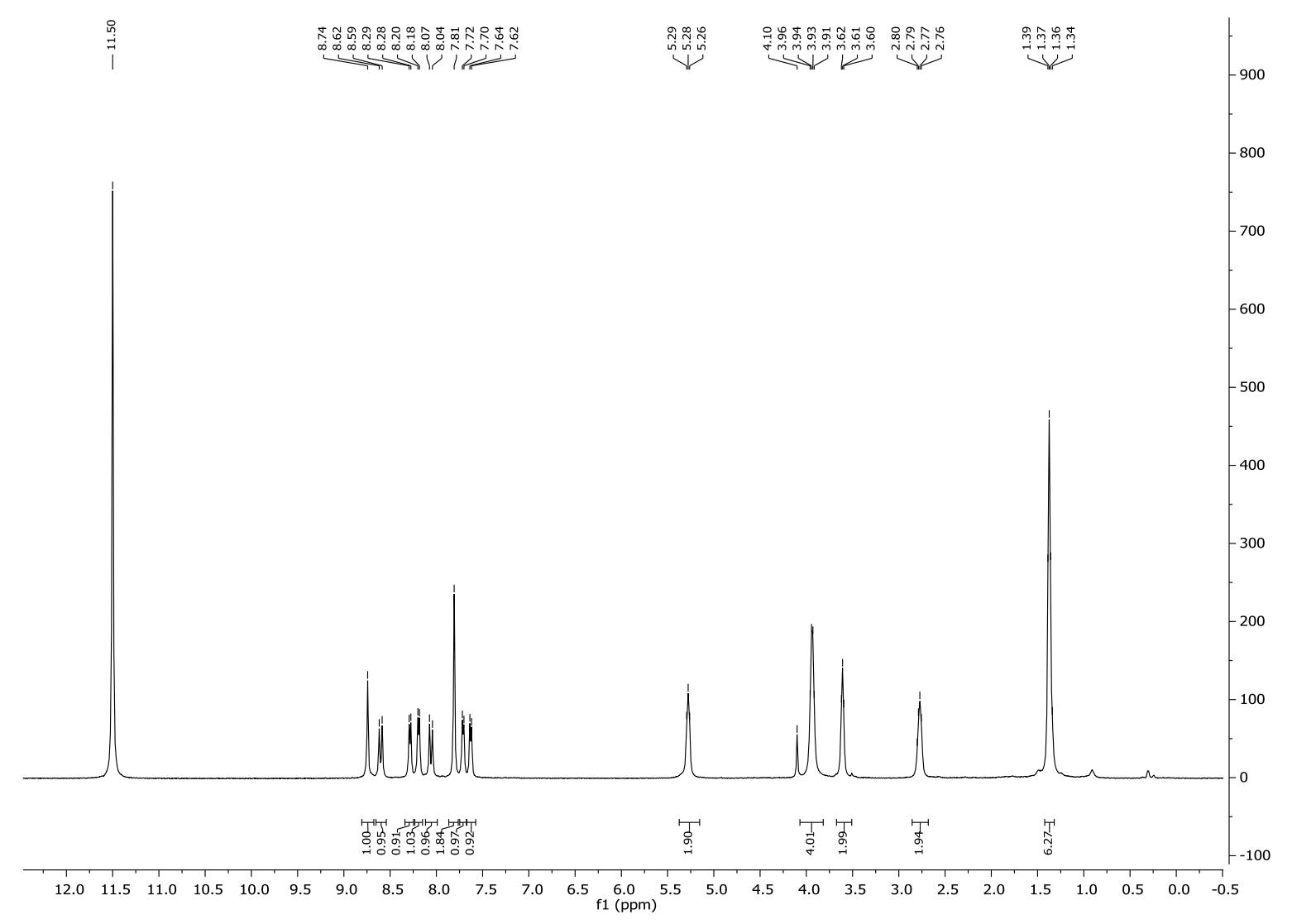




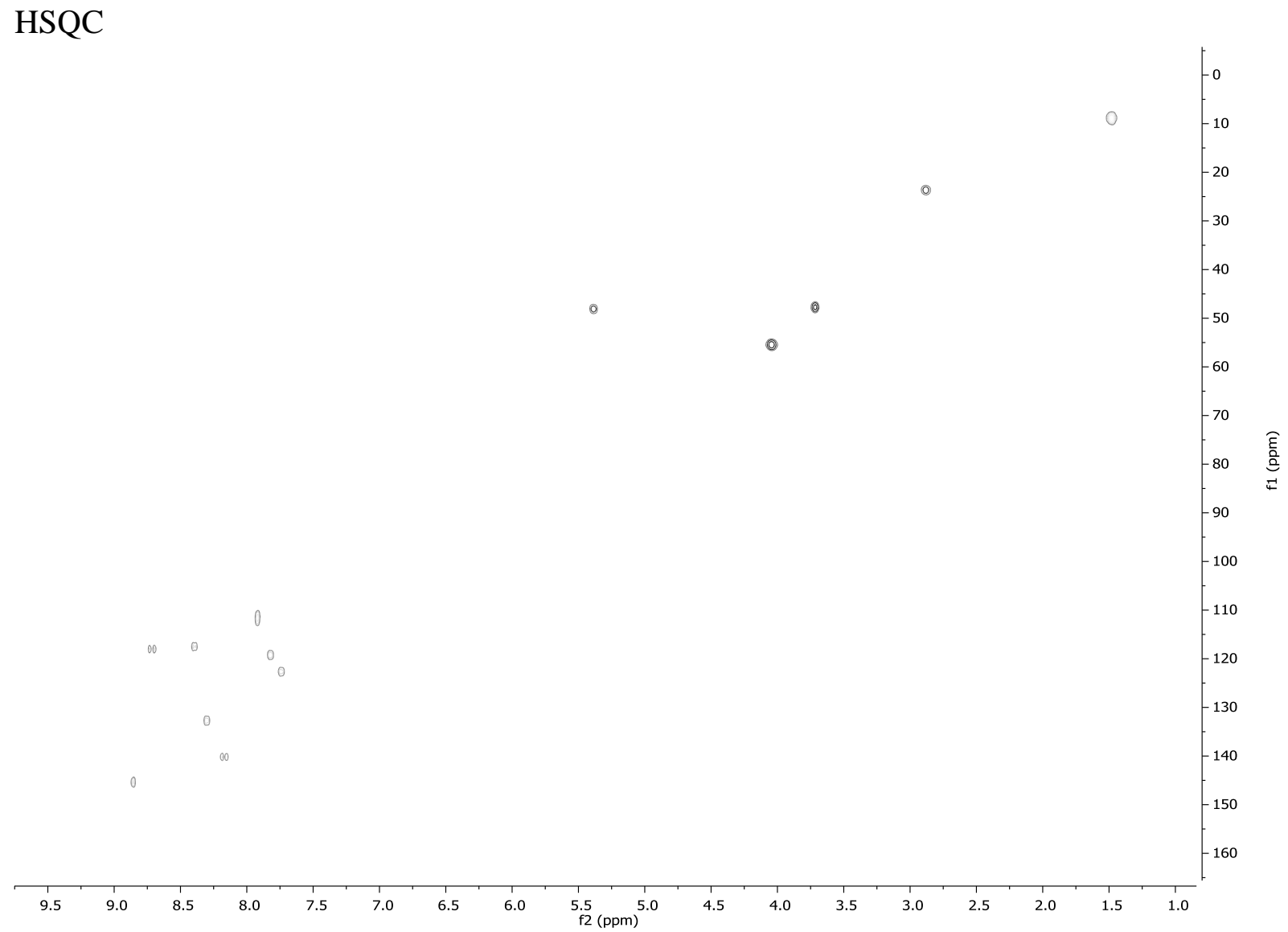

HMBC

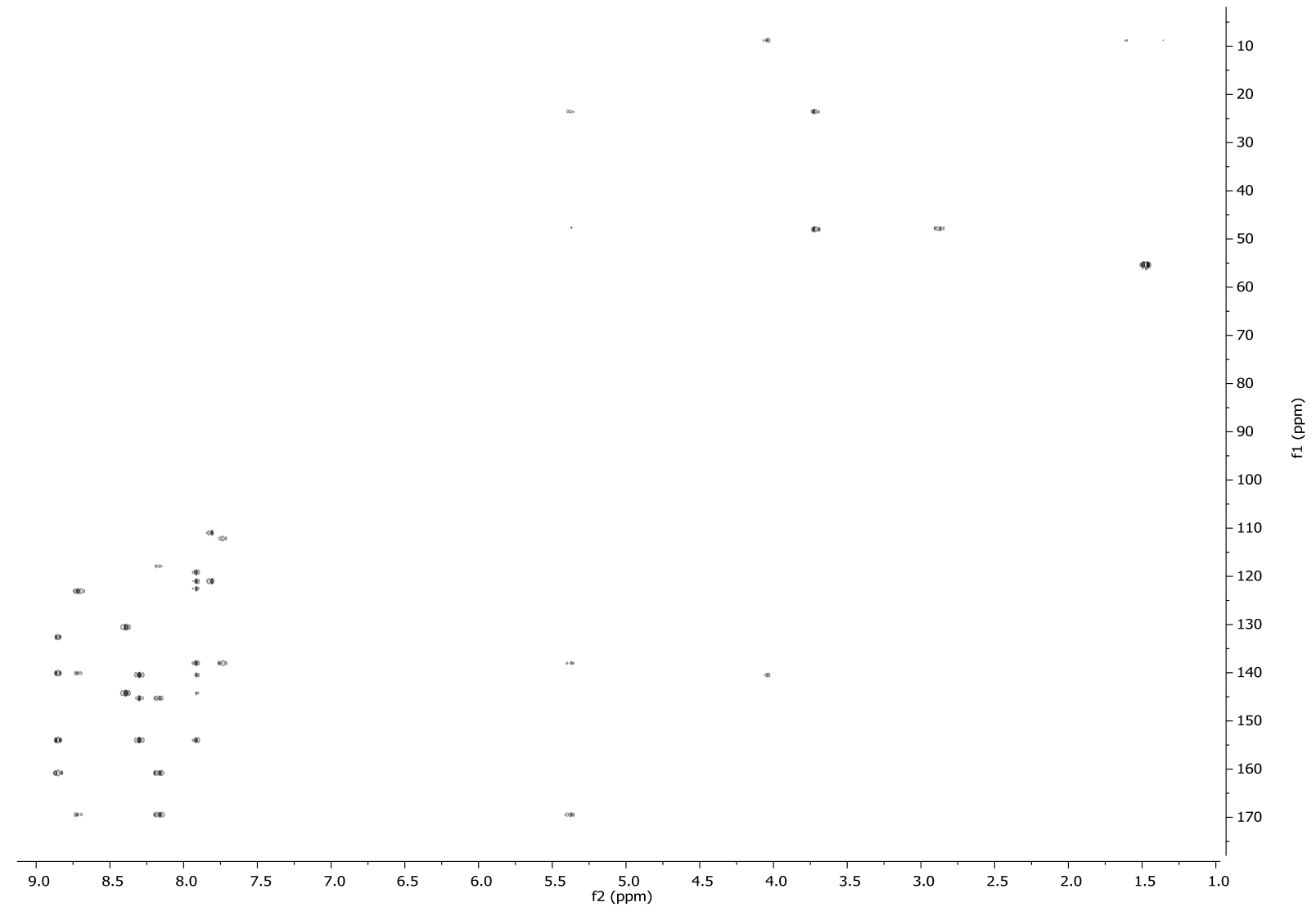




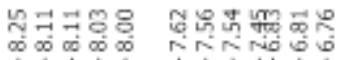

我舟

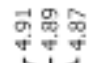

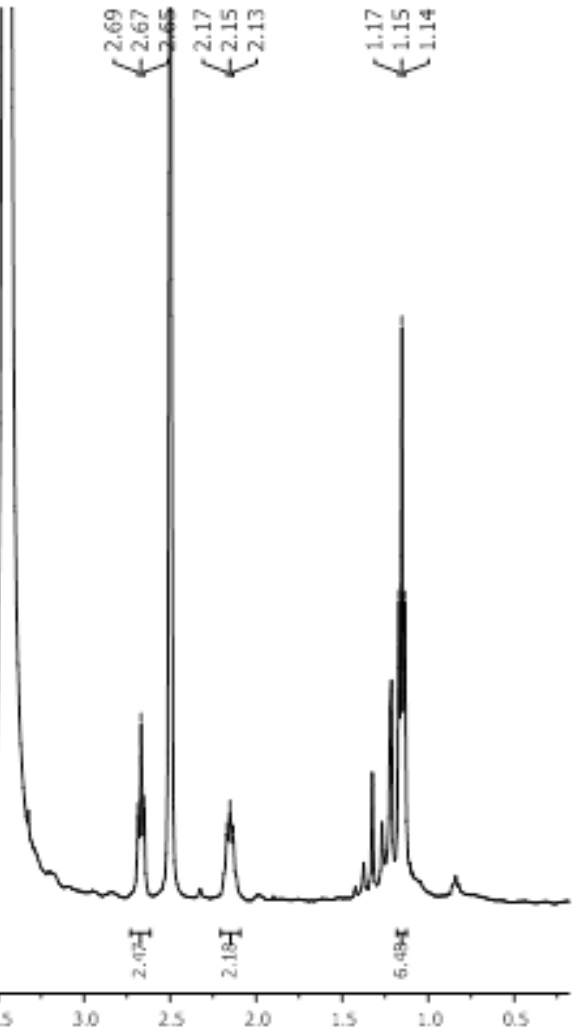

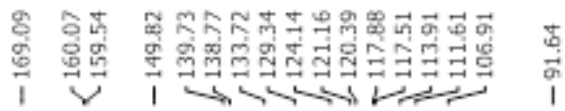

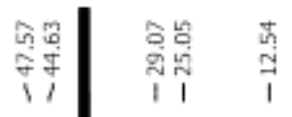

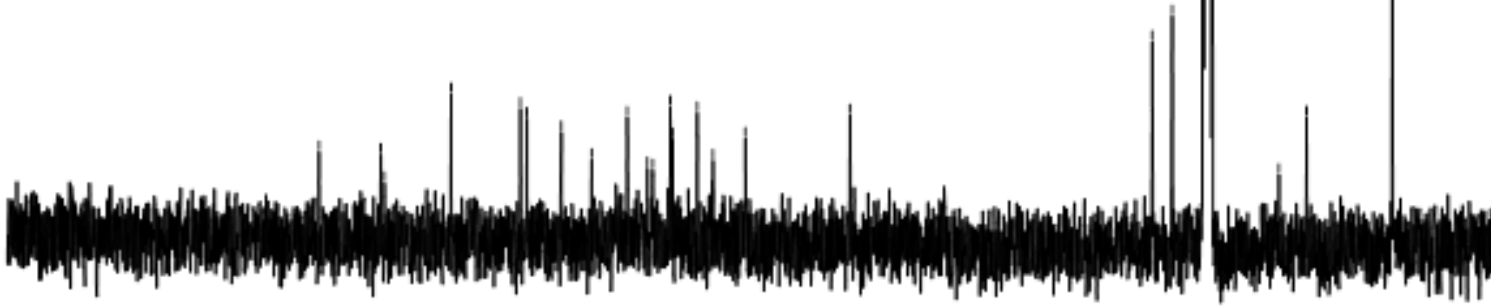



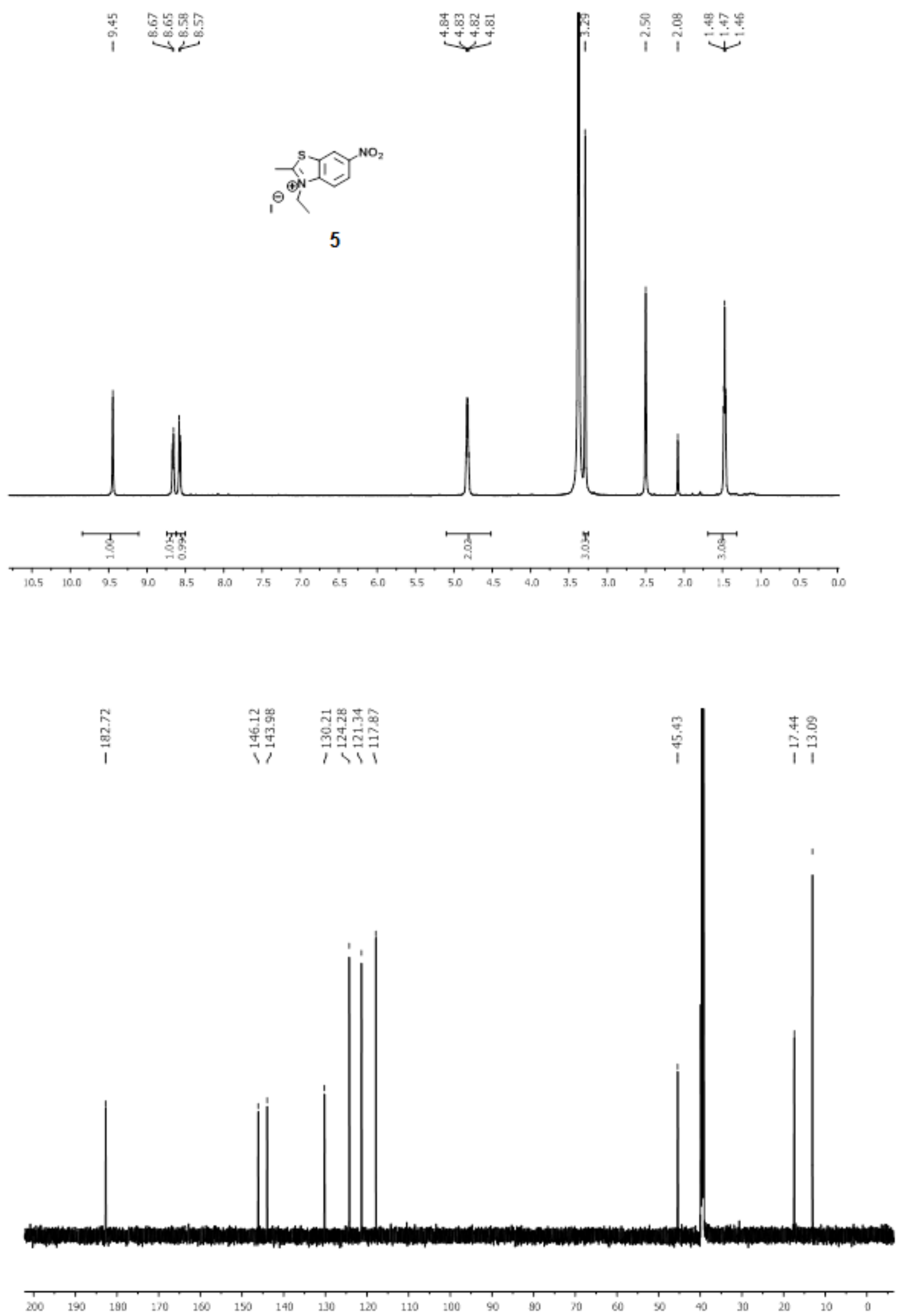

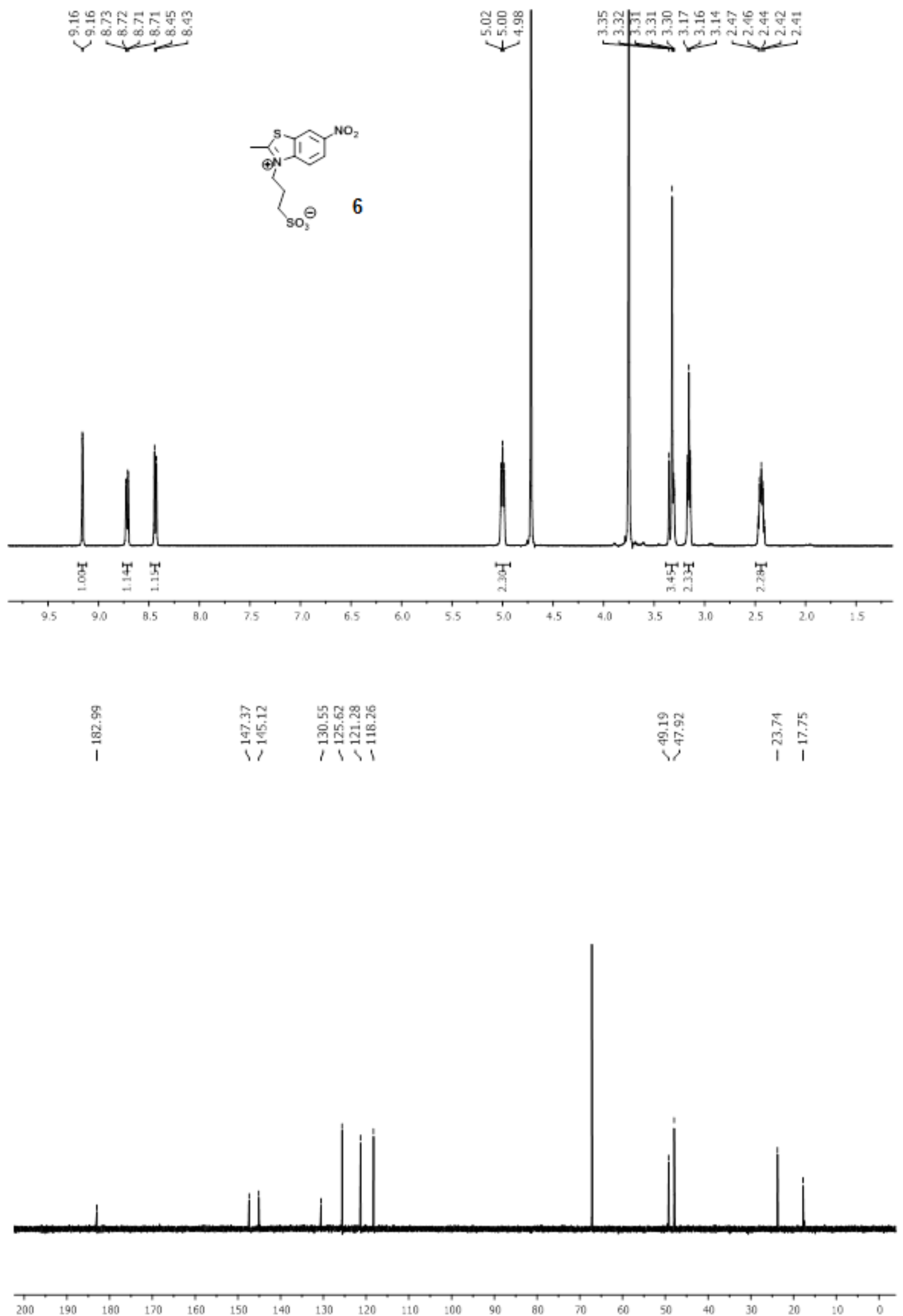
星

PRR

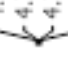

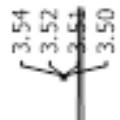

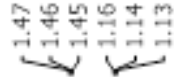

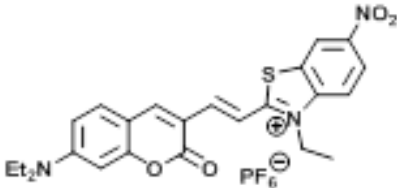

$7 a$

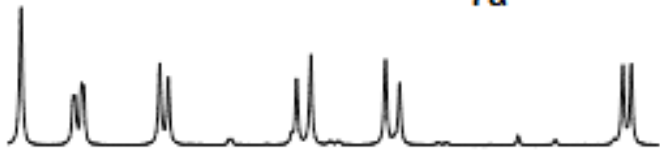

\begin{tabular}{lllllllllllllll}
\hline 1.6 & 8.5 & 8.4 & 8.3 & 8.2 & 8.1 & 8.0 & 7.9 & 7.8 & 7.7 & 7.6 & 7.5
\end{tabular}

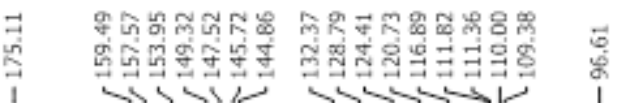

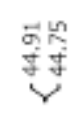

ถึำ

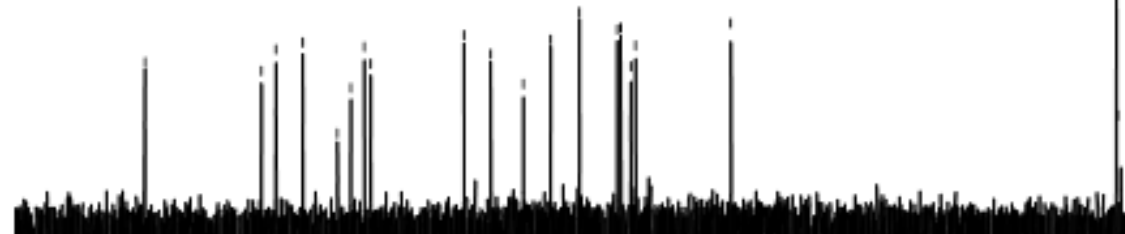

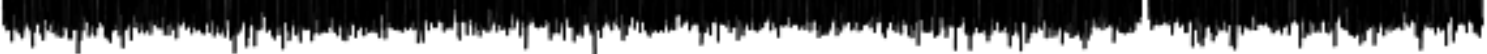

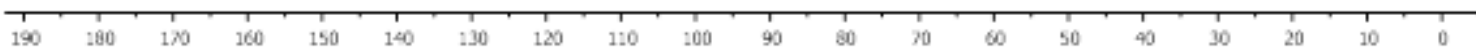


븐

$1 \underbrace{\infty} \infty \underbrace{\infty} \infty \underbrace{\infty}$

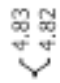

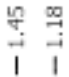

$\mathrm{Ct}_{\mathrm{O}} \mathrm{N}$

7b

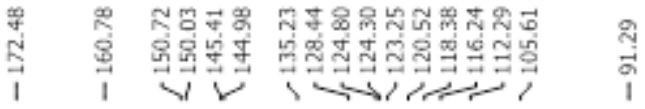

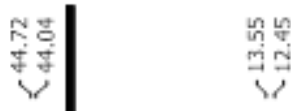

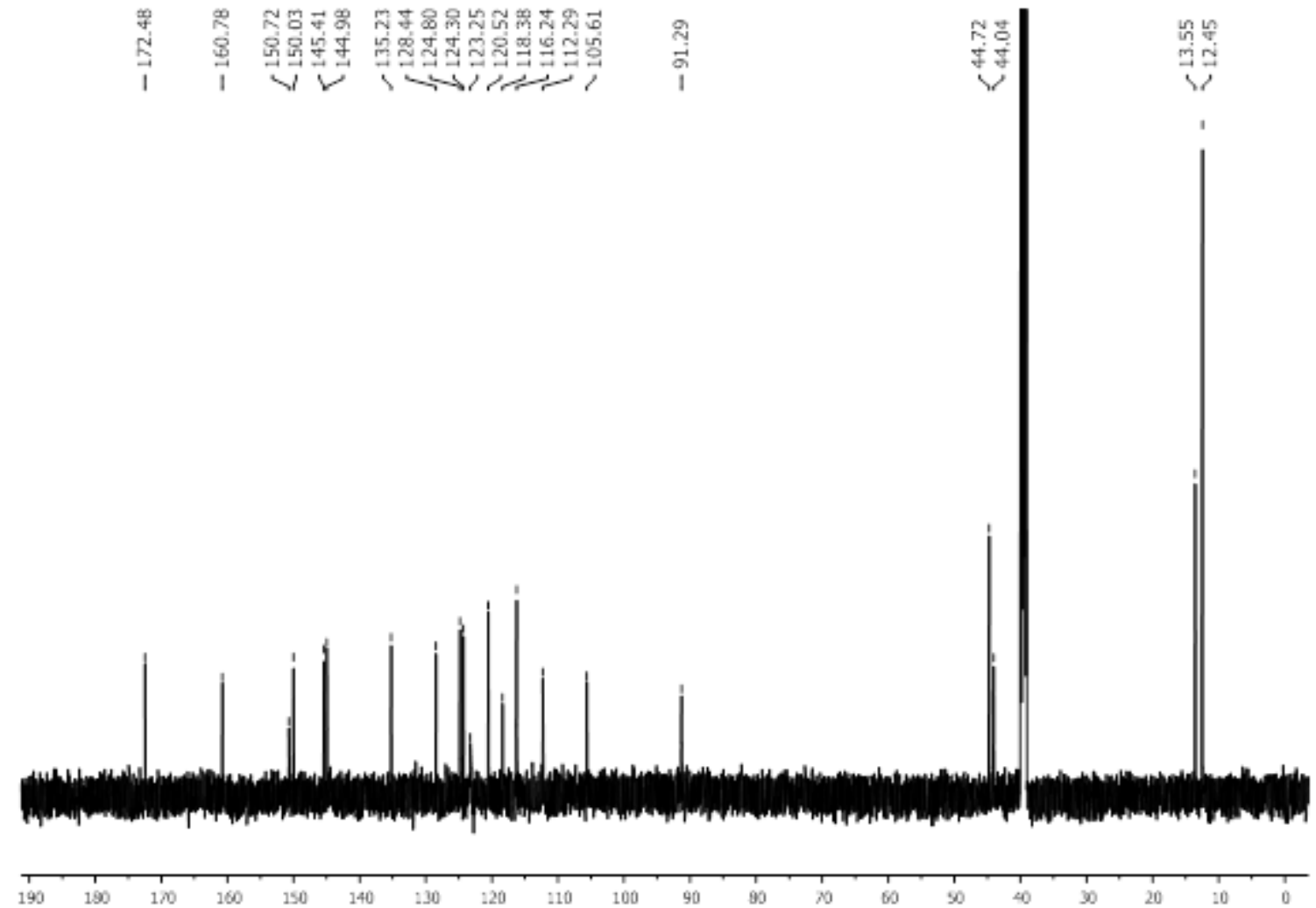

瓷要

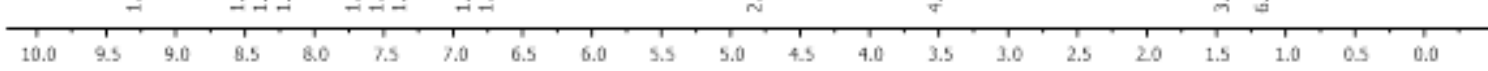


${ }^{1} \mathrm{H}$ (TFA)

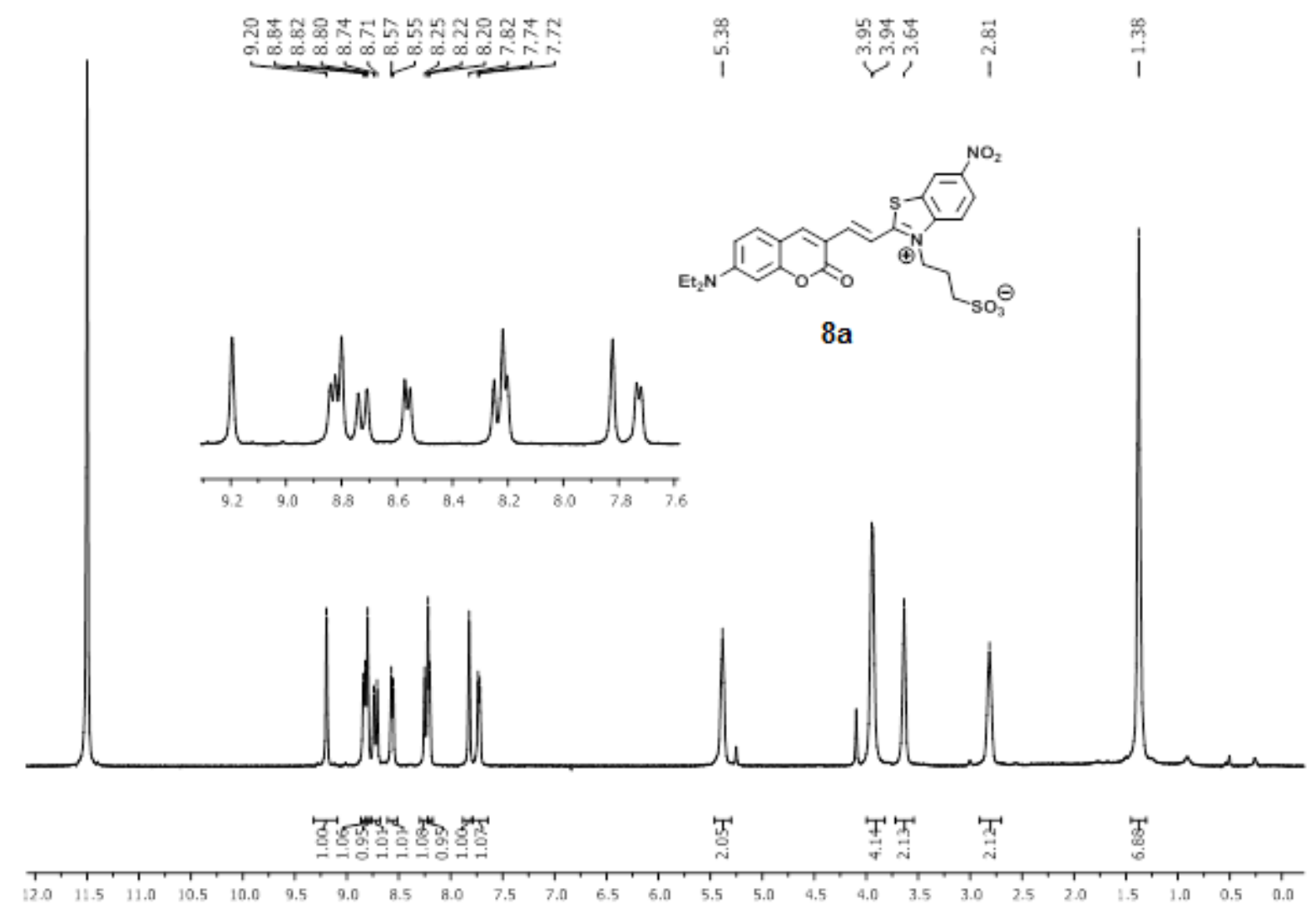

\section{HSQC}

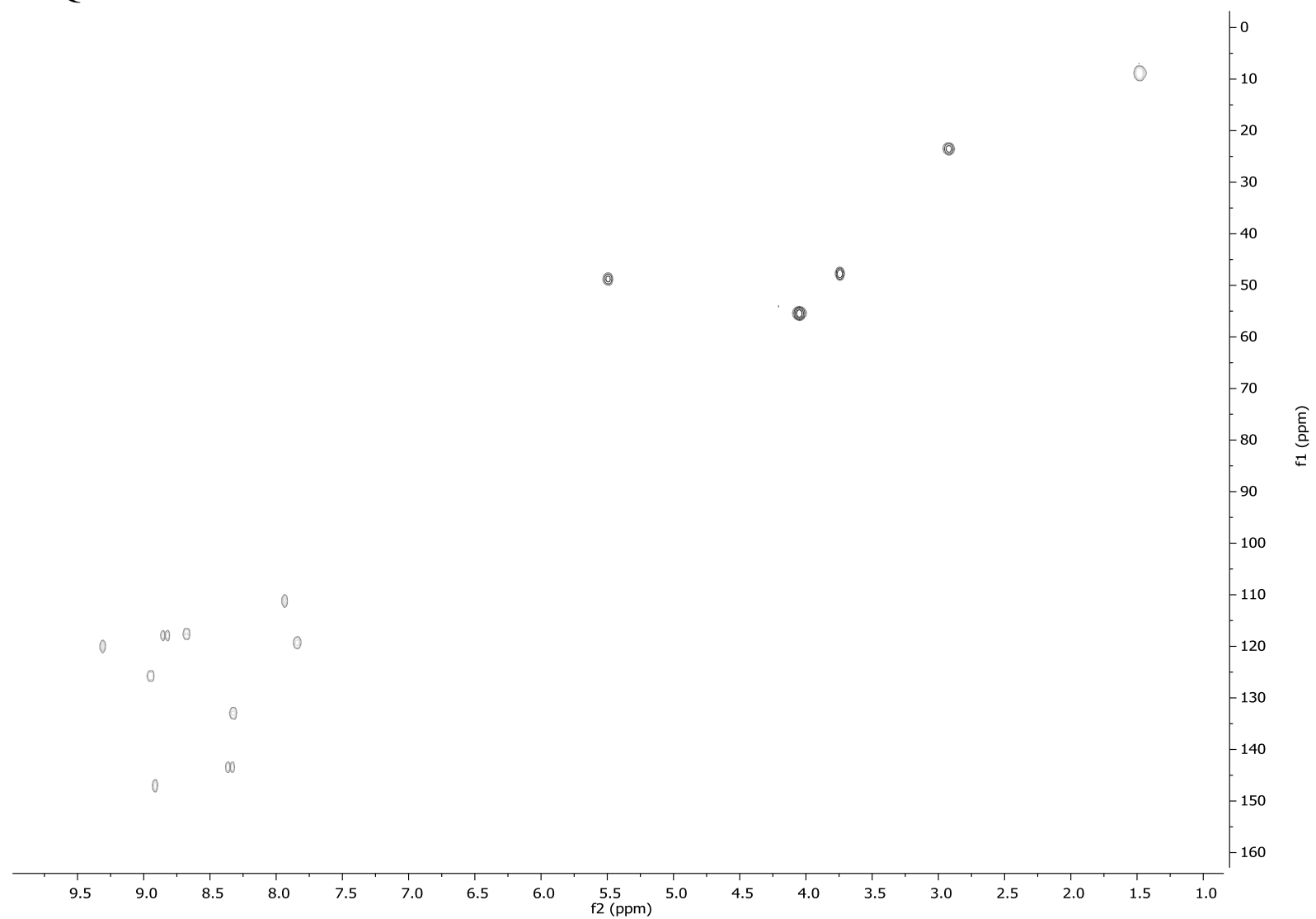




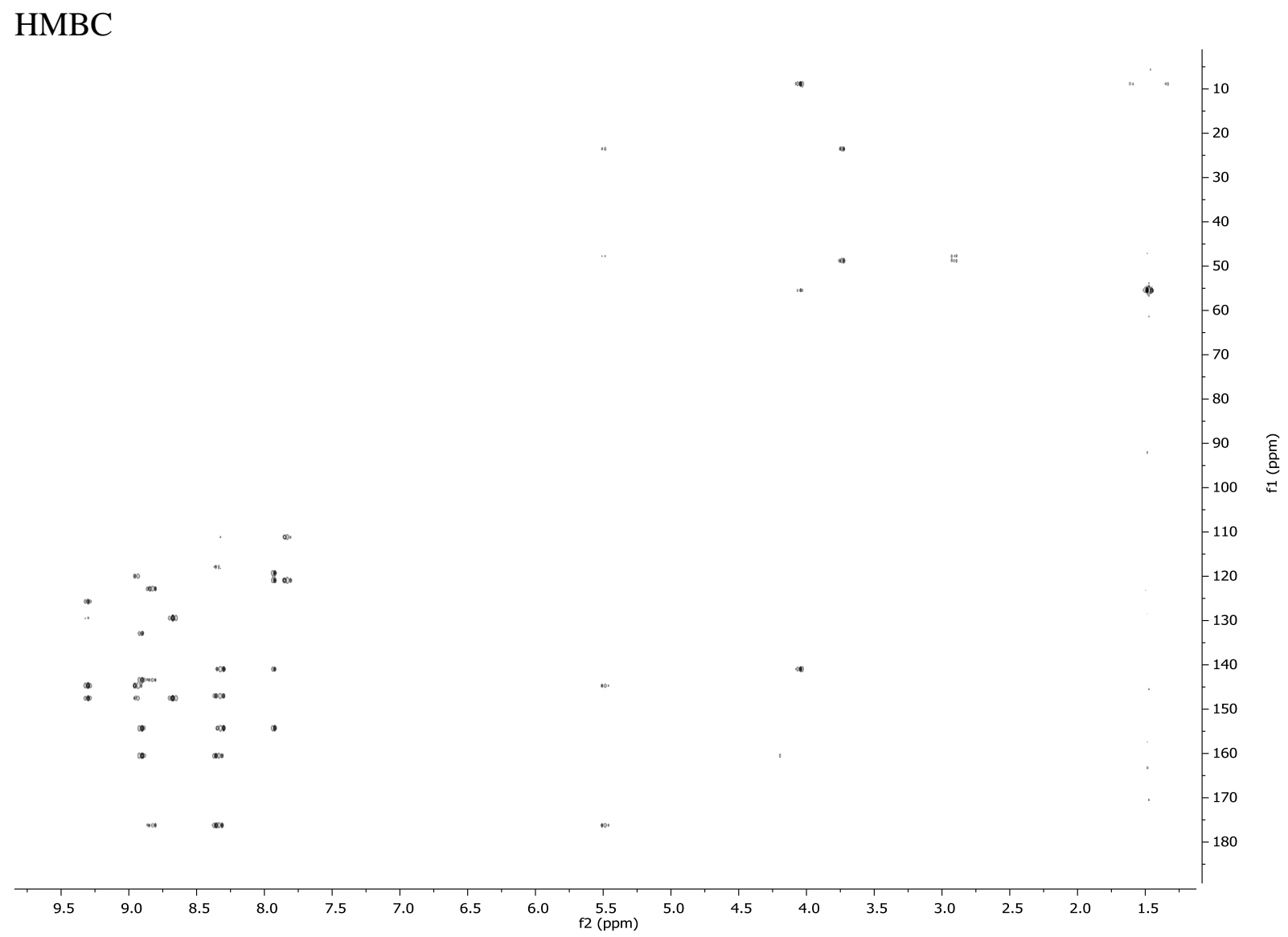




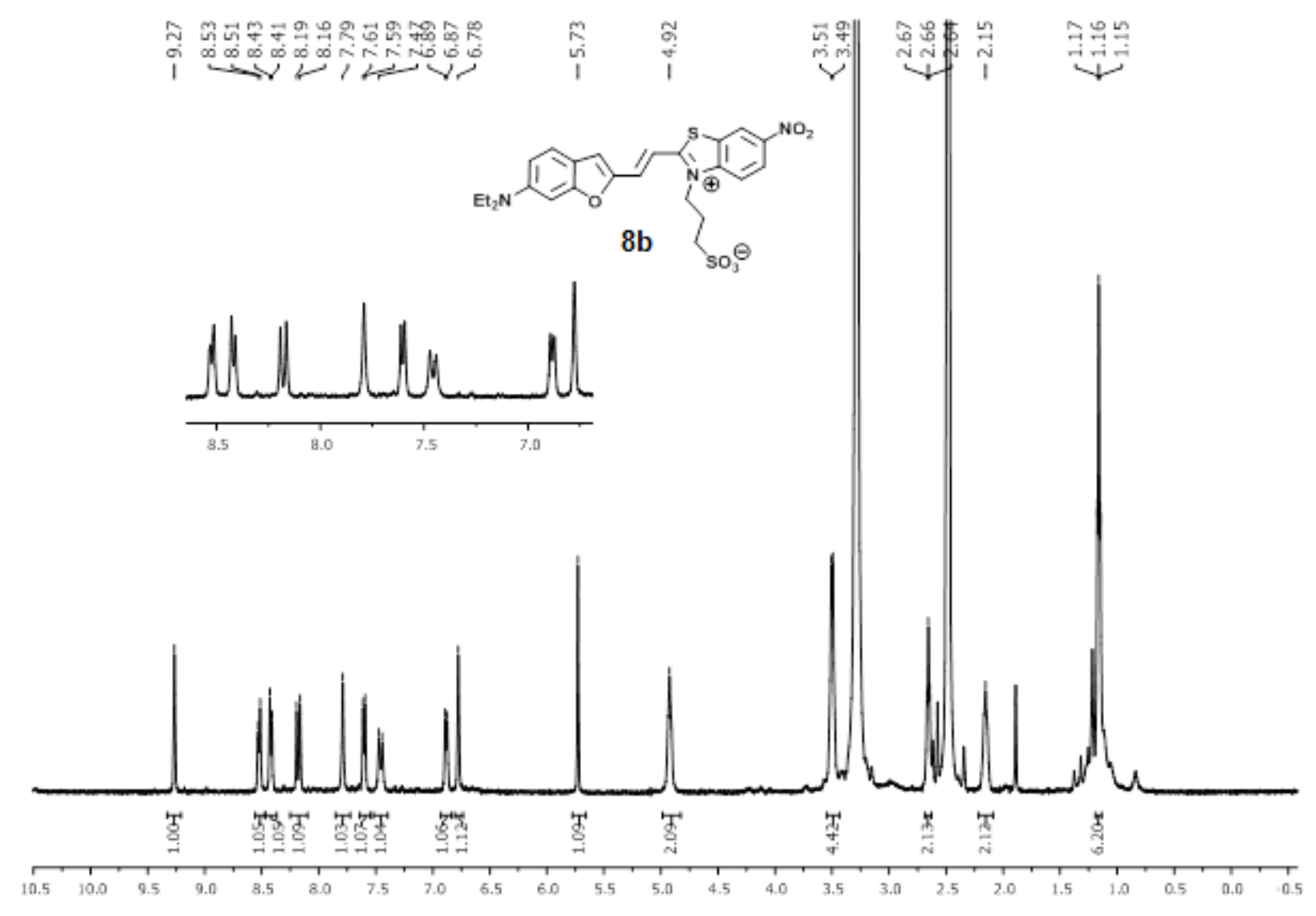

${ }^{1} \mathrm{H}$ (TFA)

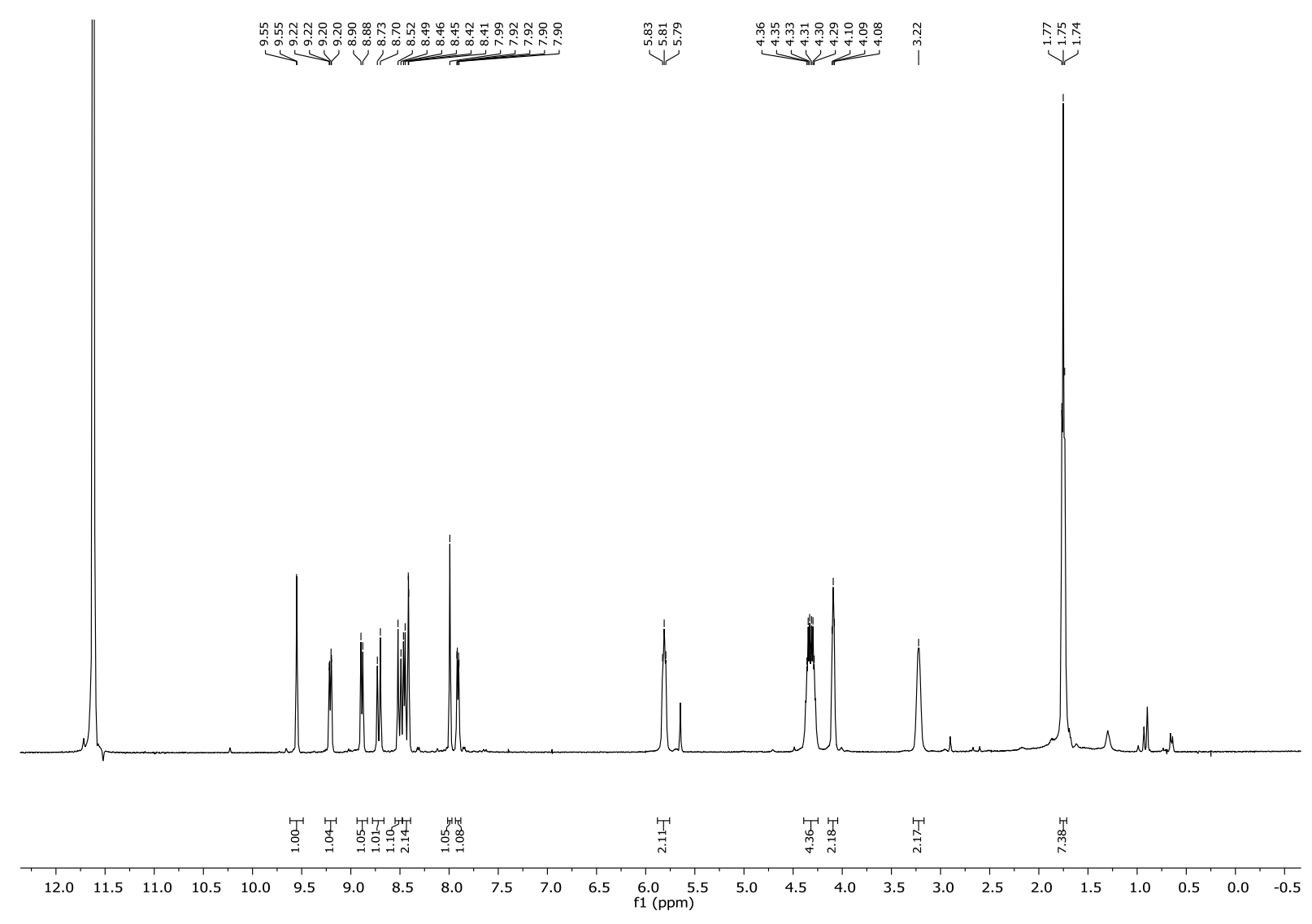


HSQC

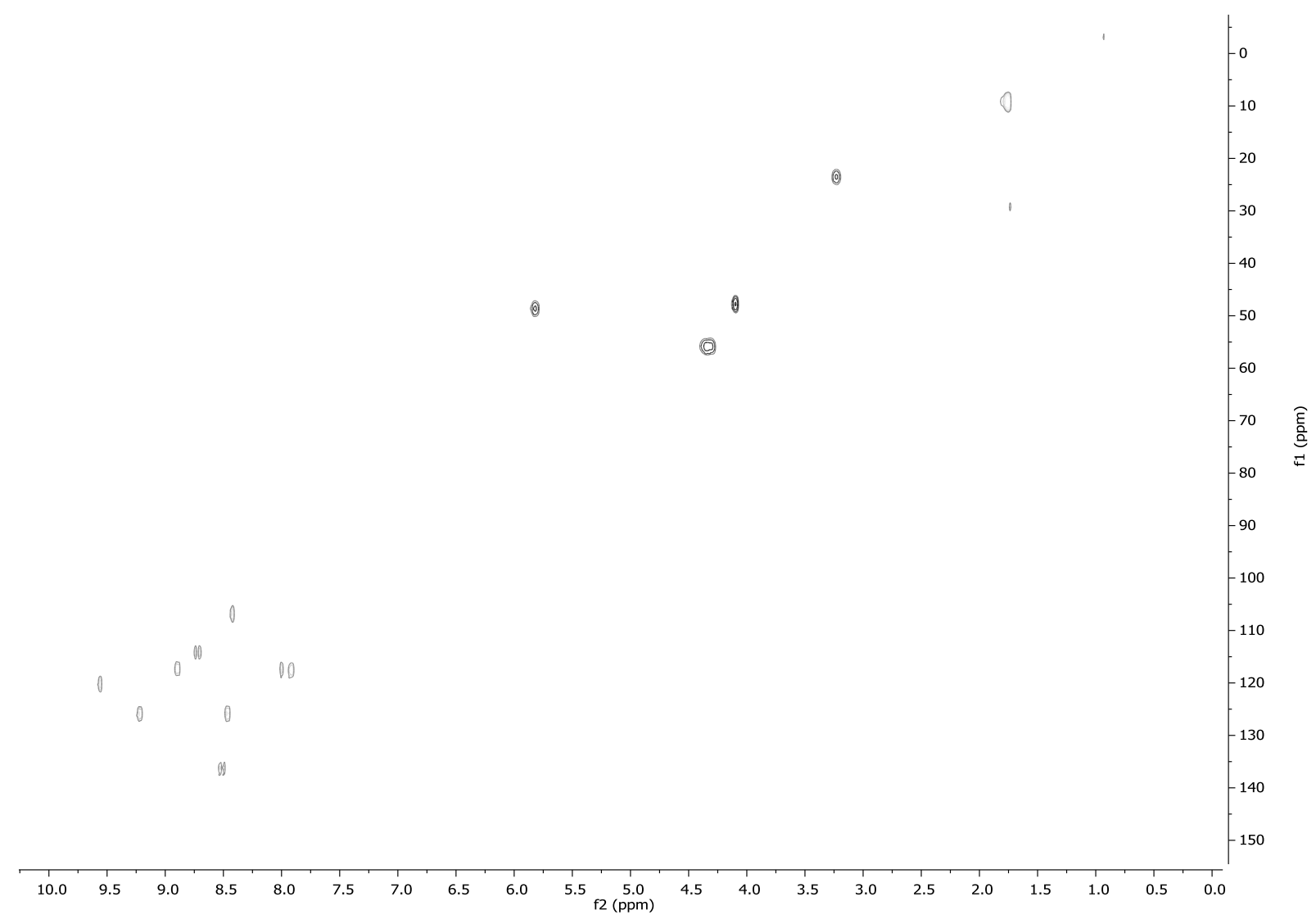

\section{HMBC}

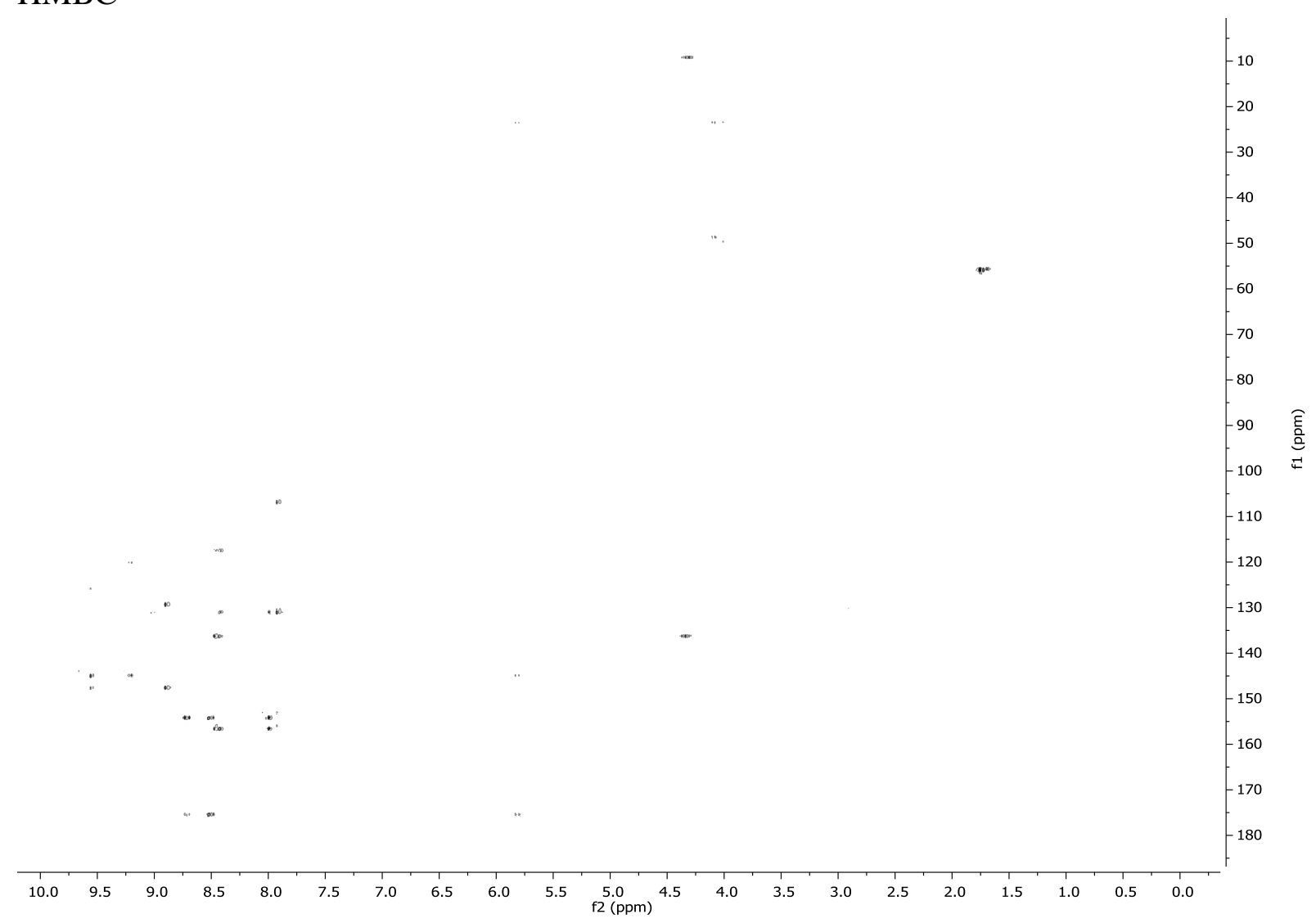



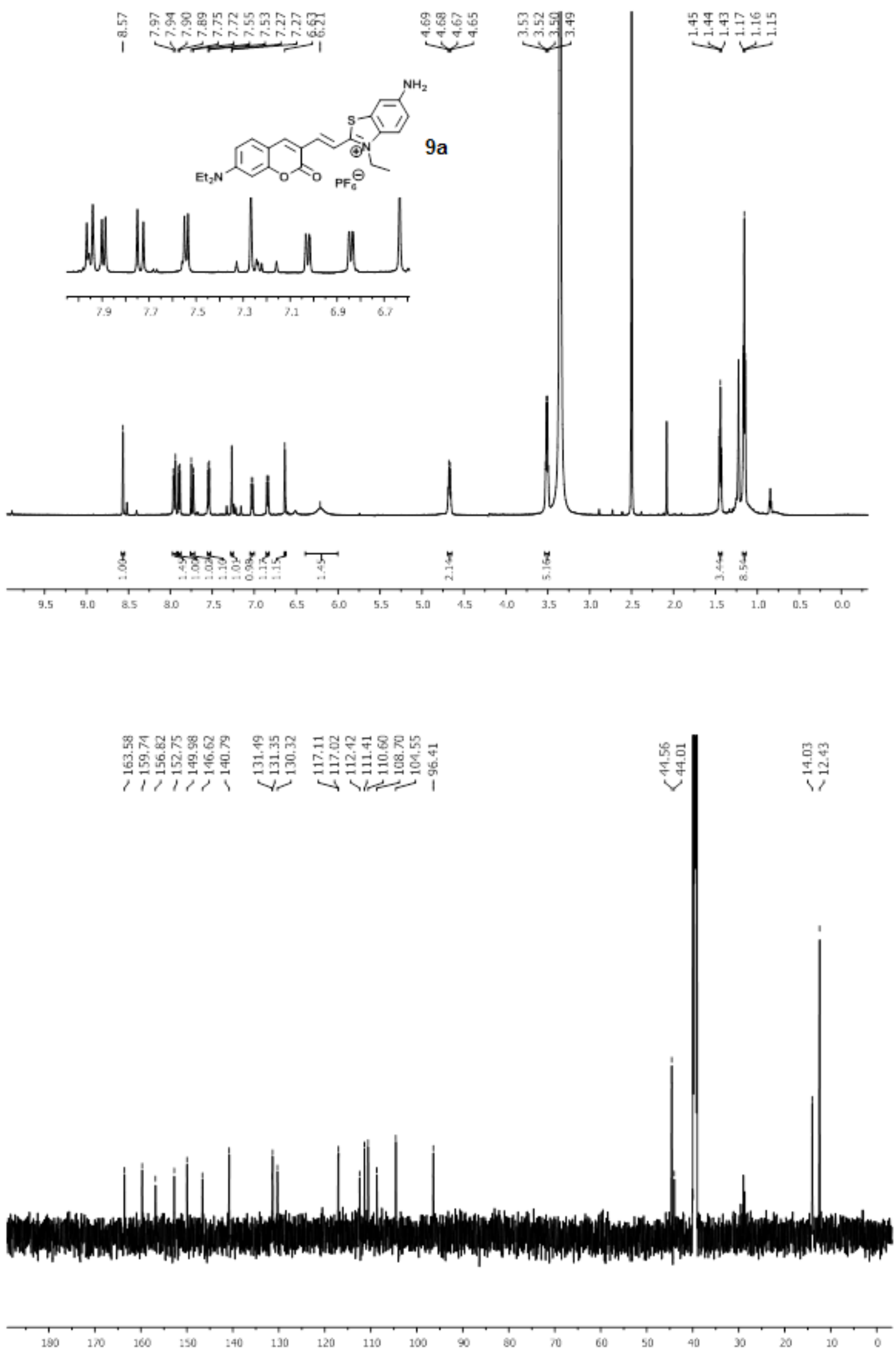

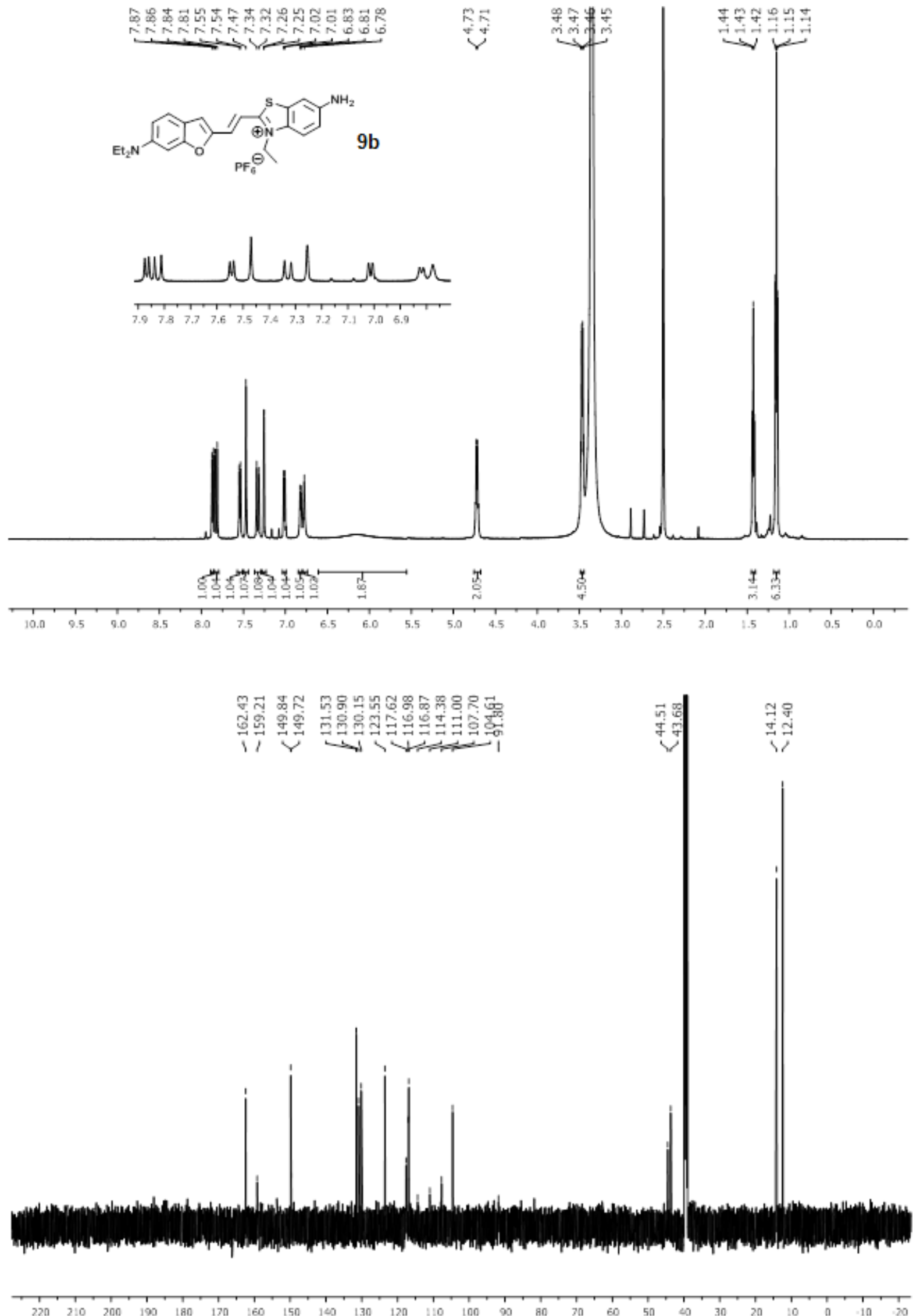


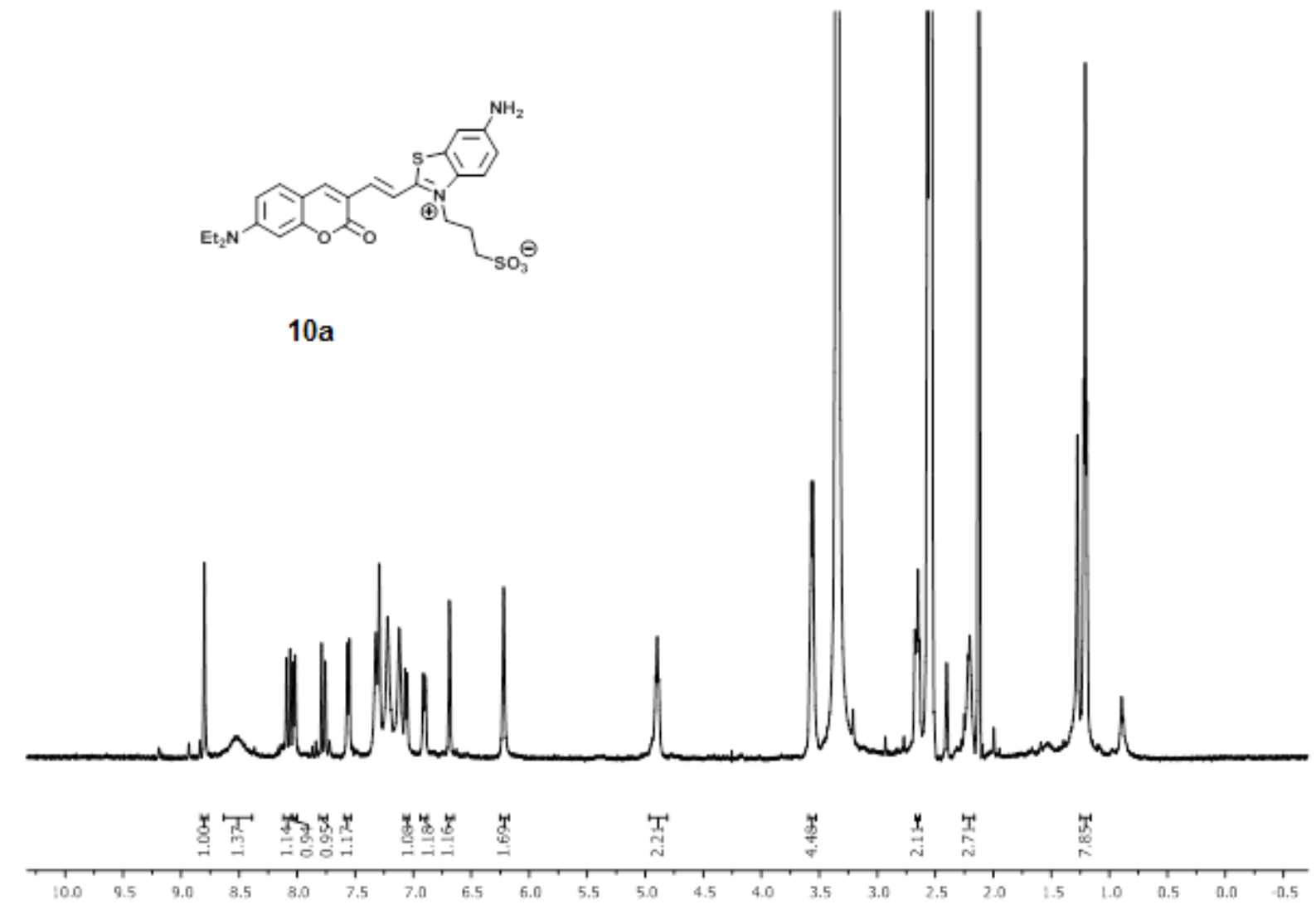

${ }^{1} \mathrm{H}$ (TFA)

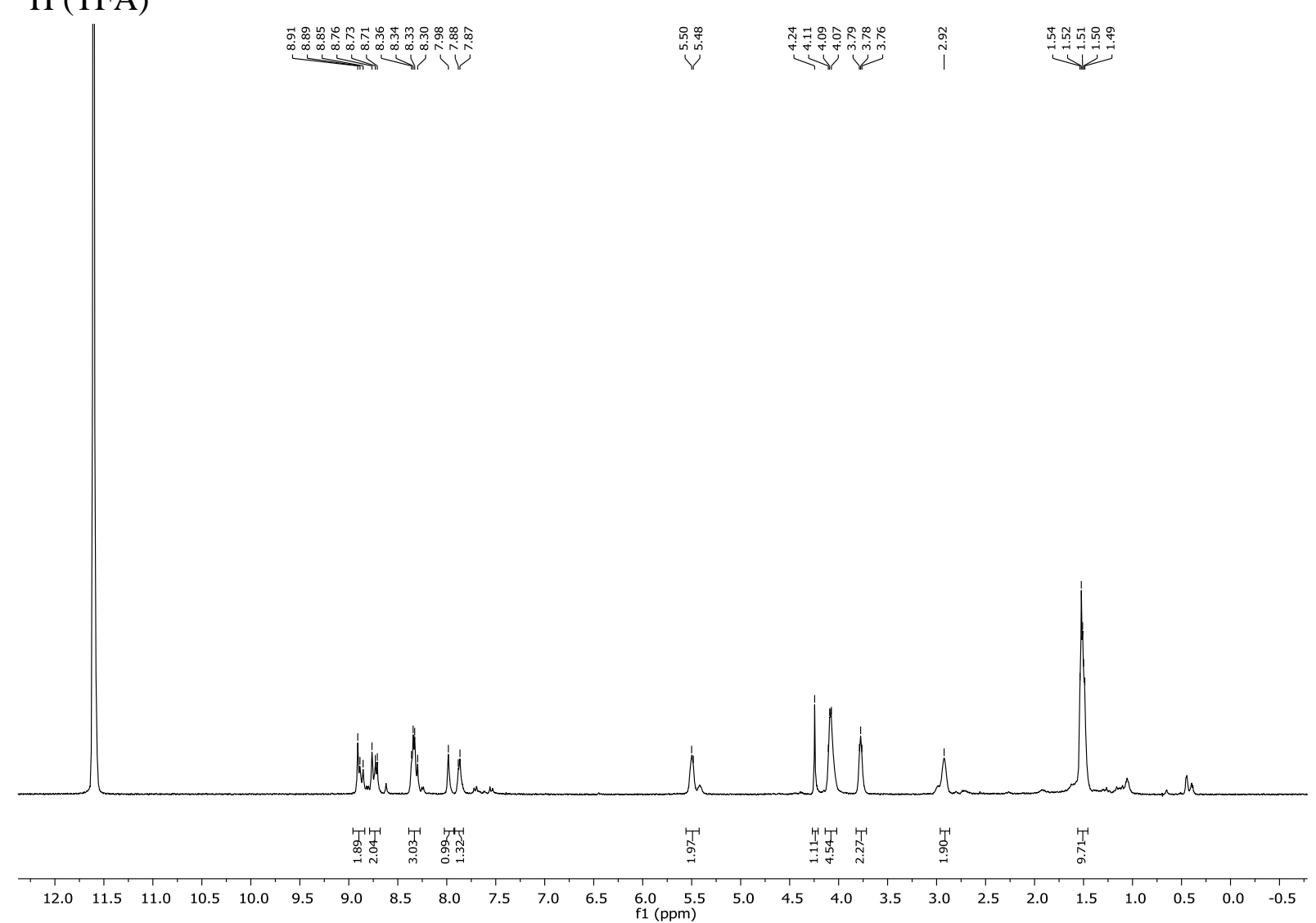




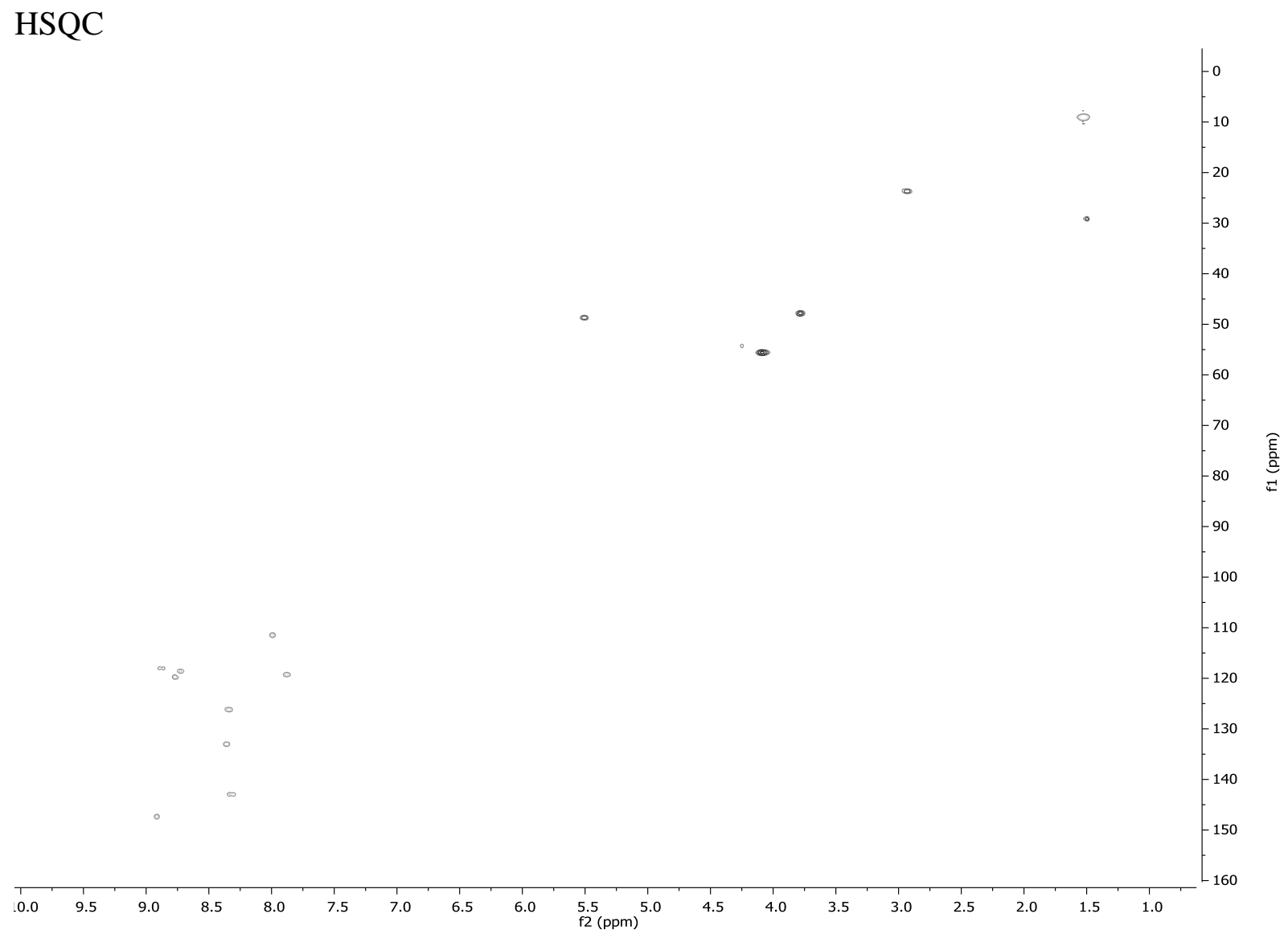

\section{HMBC}

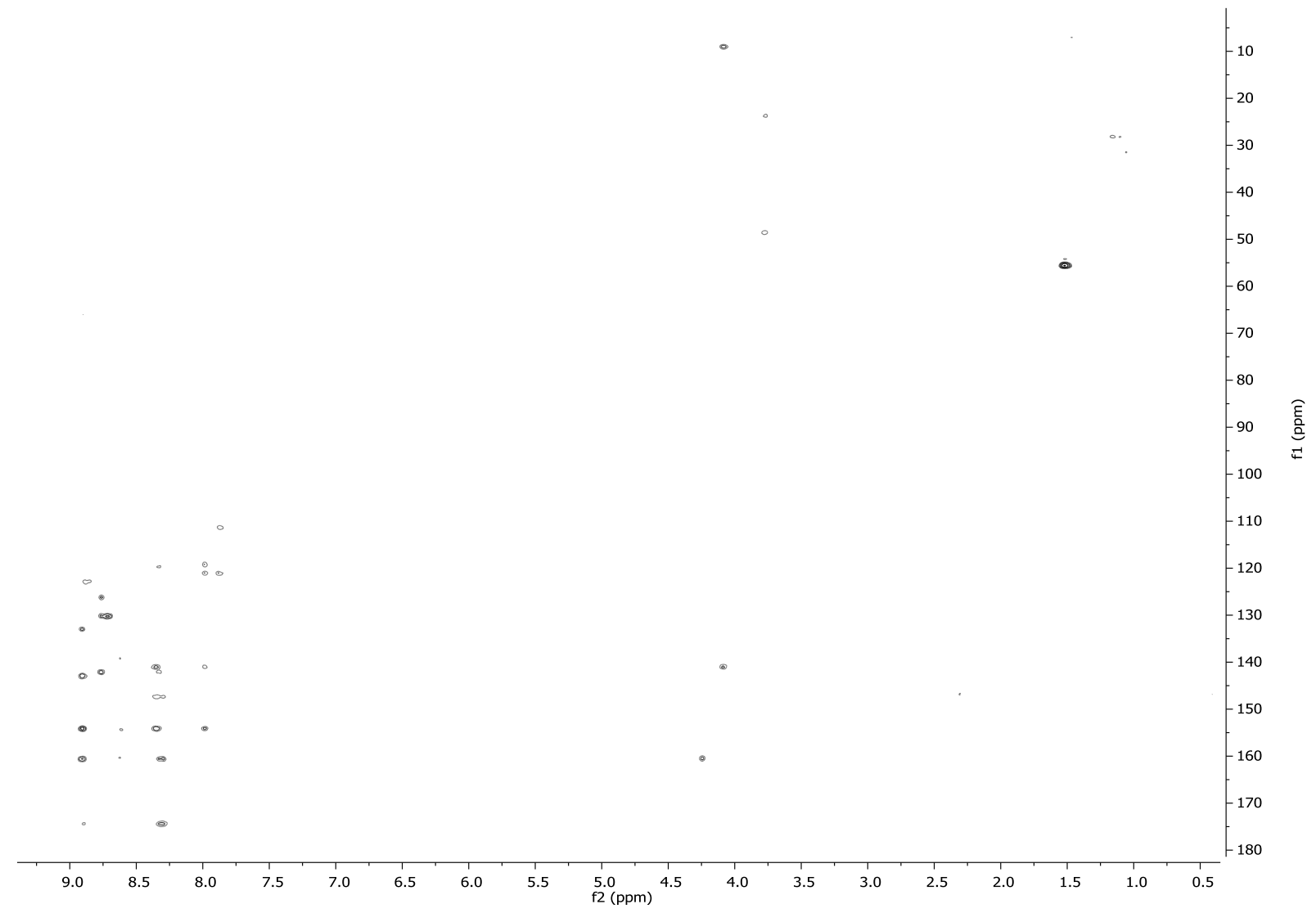



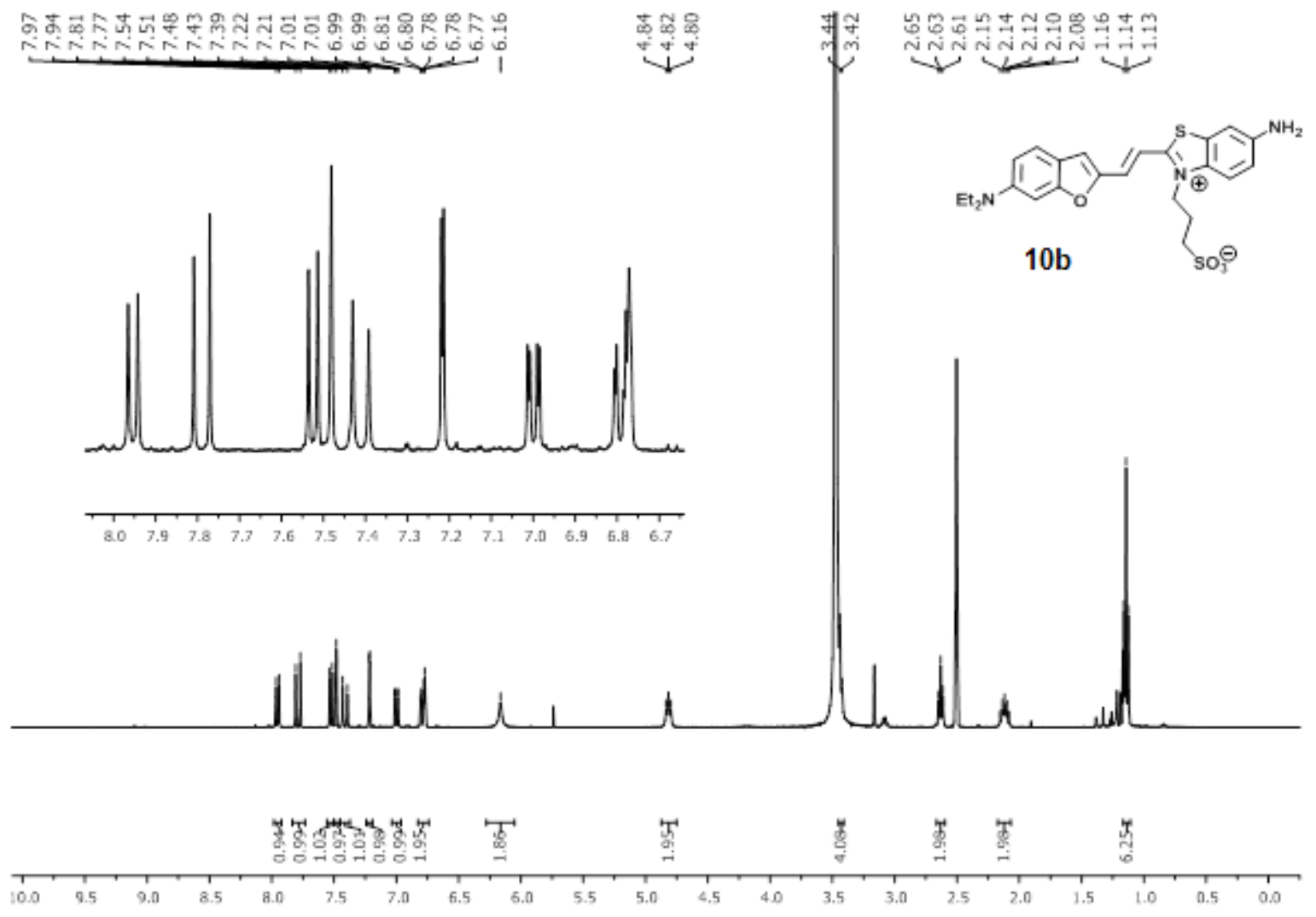

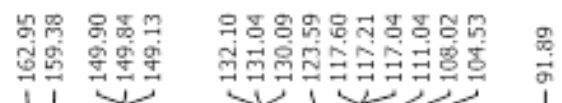

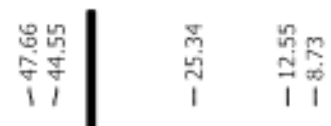

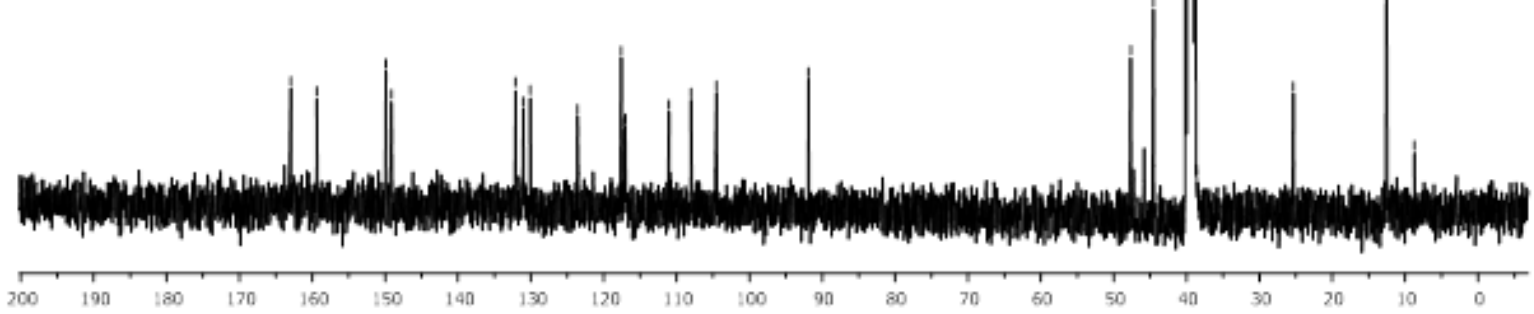




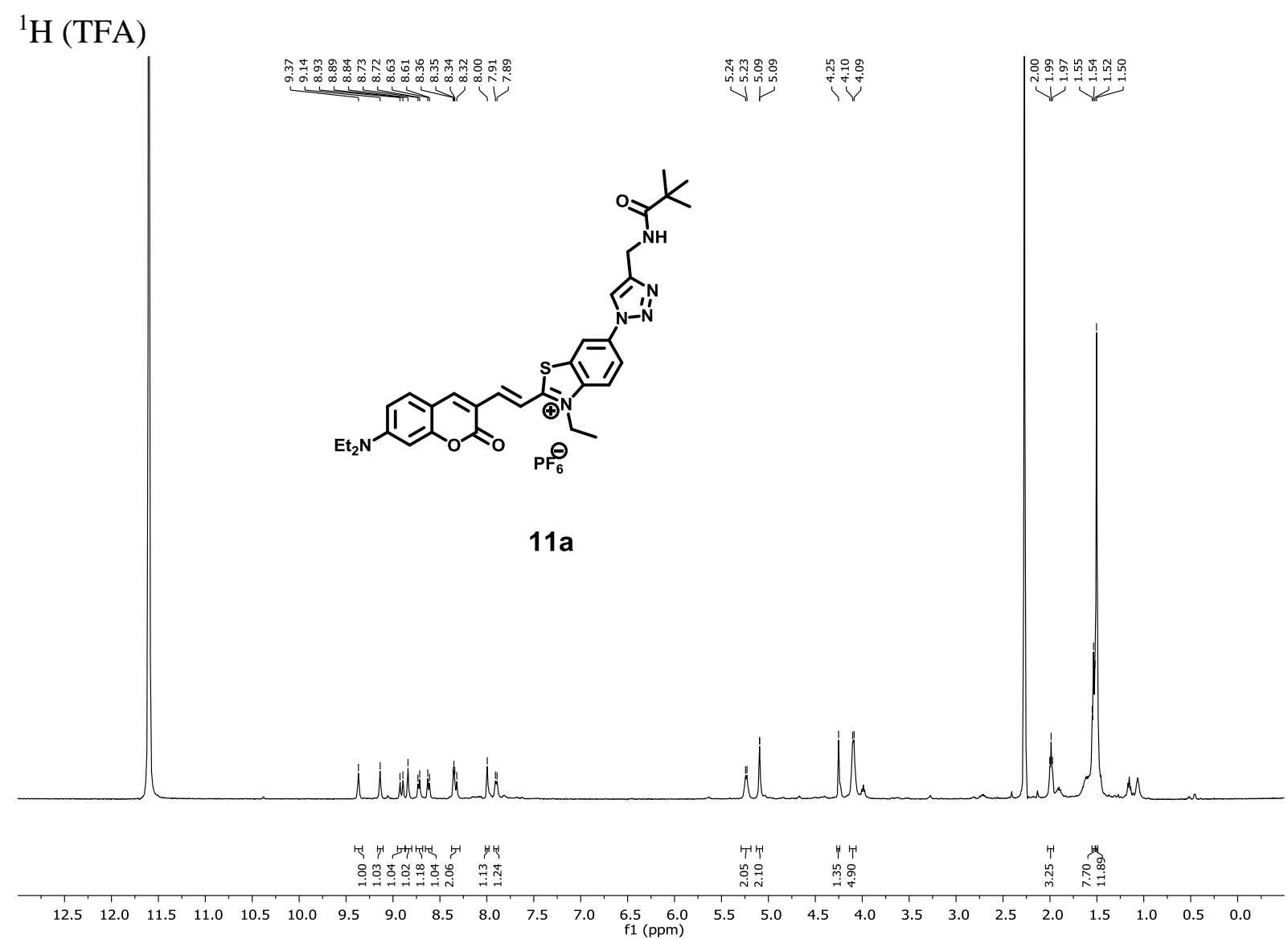

\section{HSQC}

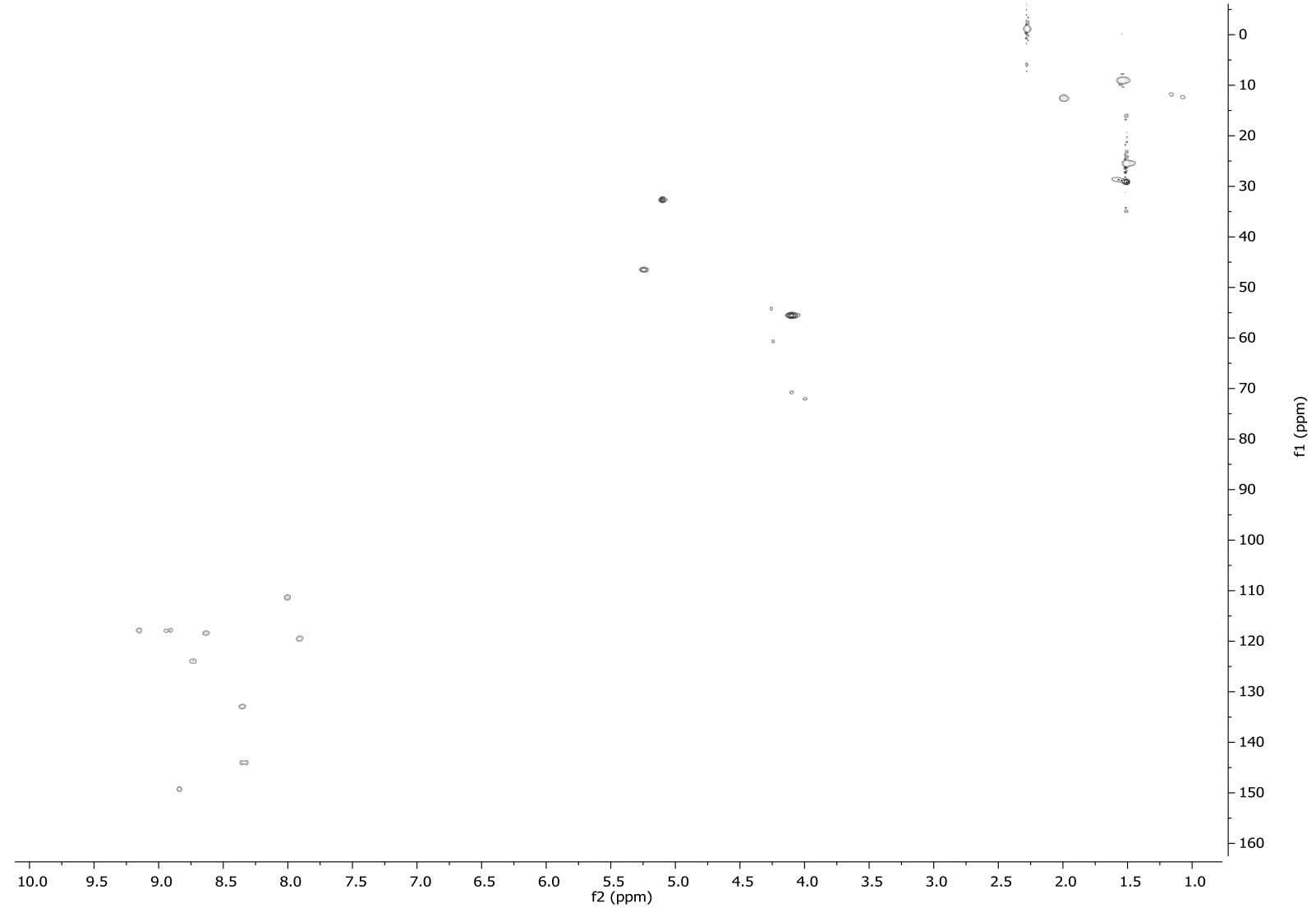


HMBC

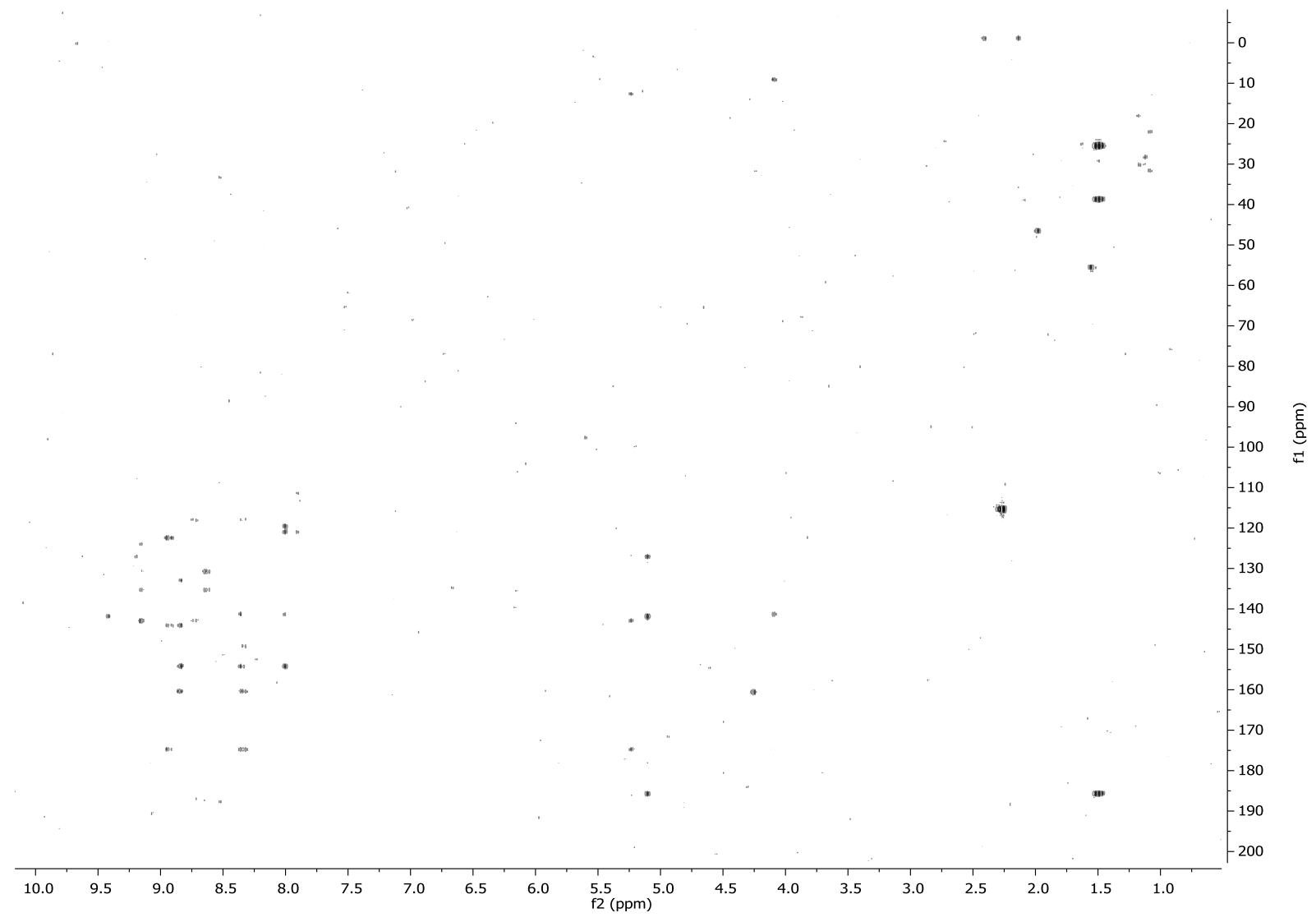




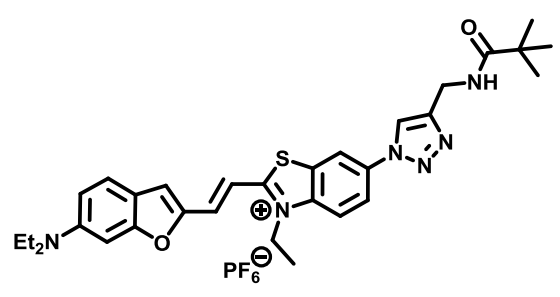

11b

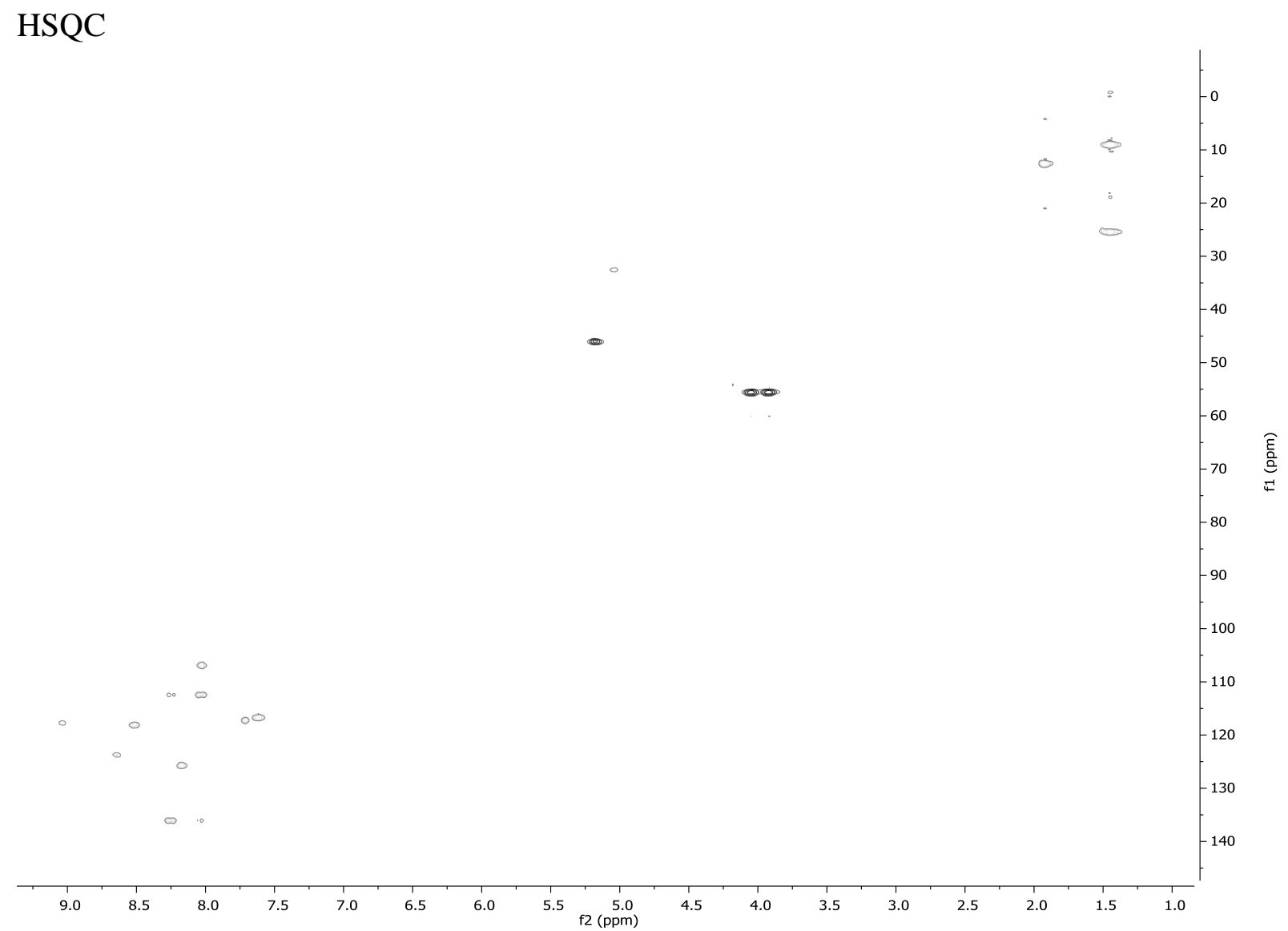


HMBC

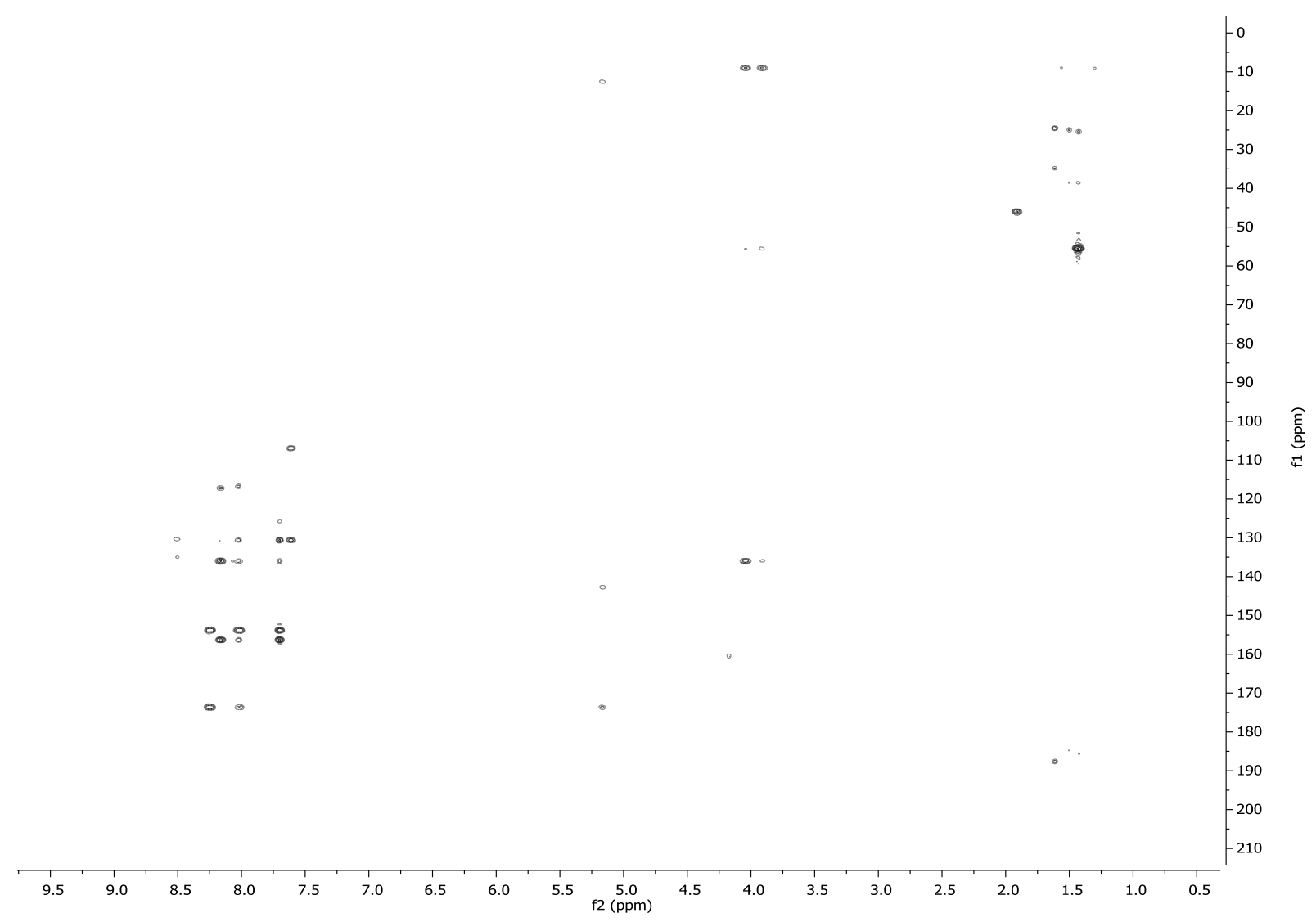




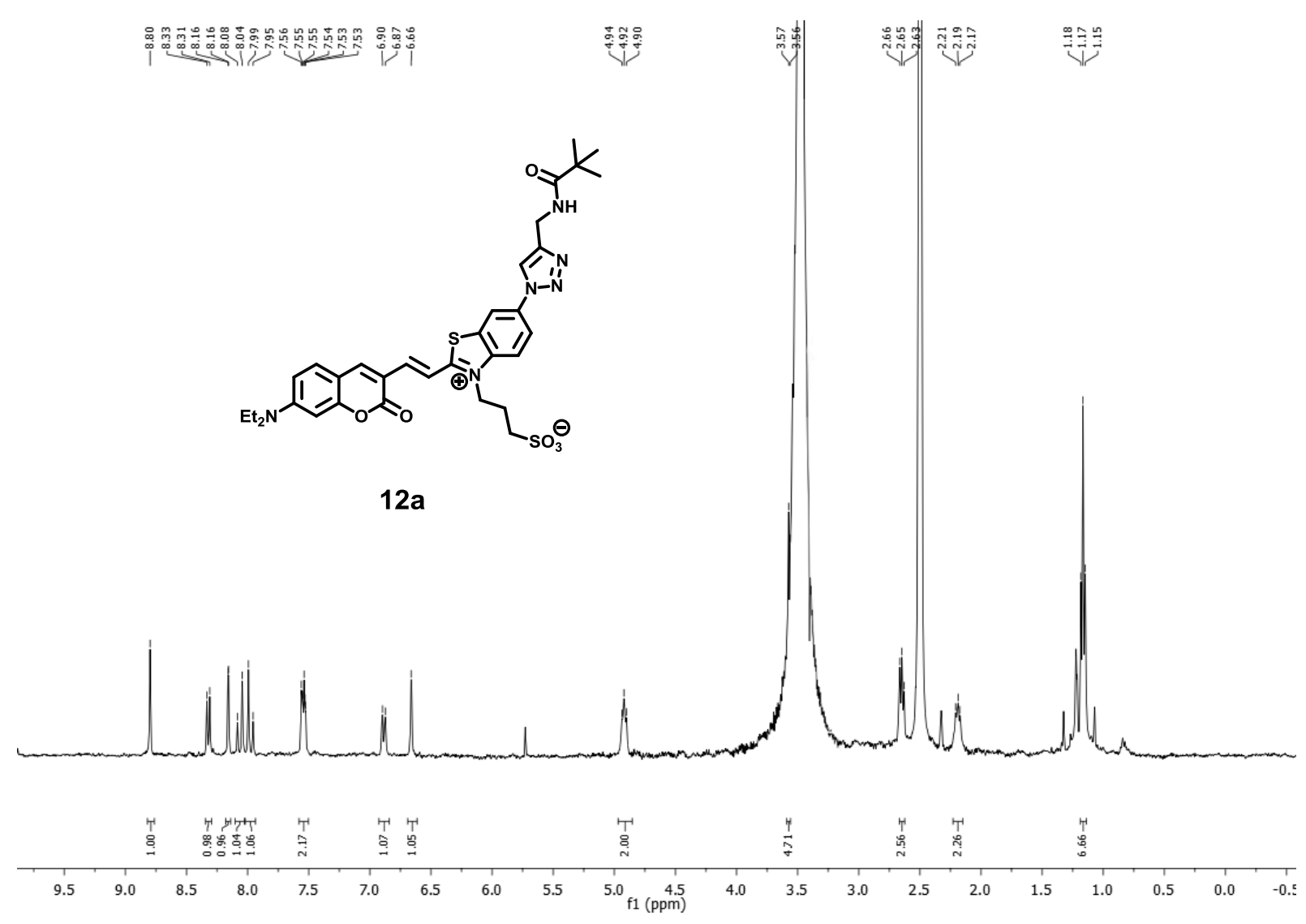




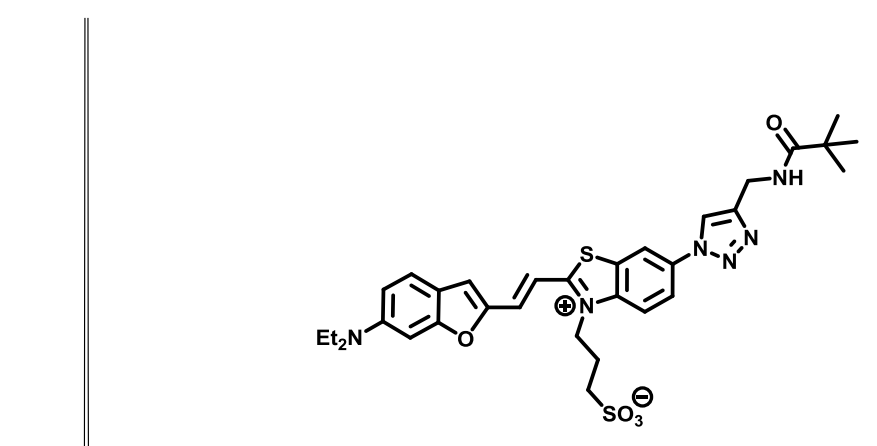

$12 b$

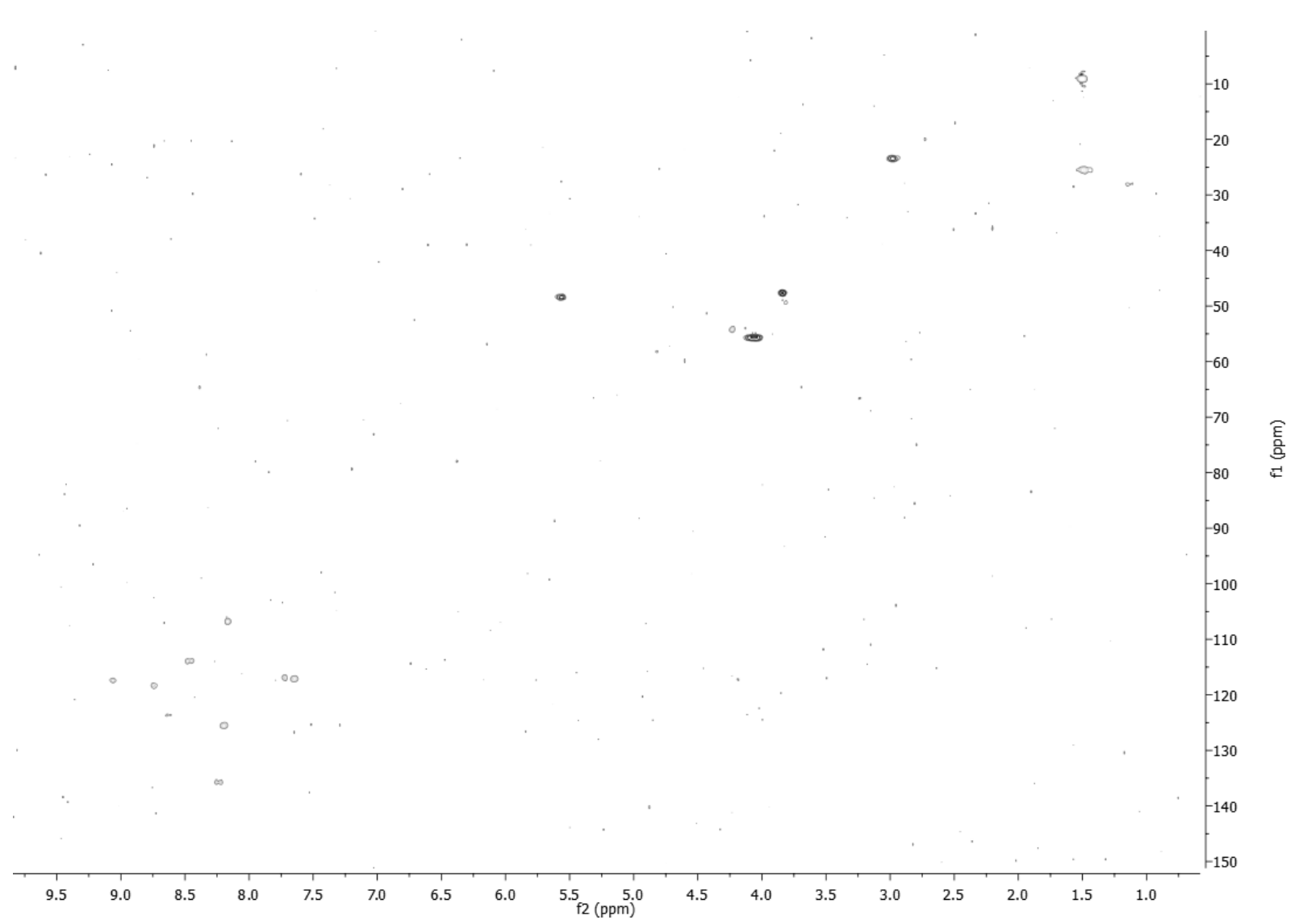




\section{Materials and Methods for DNA Synthesis and Characterization:}

Spectroscopic measurements were recorded in NaPi buffer solution $(10 \mathrm{mM}, \mathrm{pH}=7)$ and $\mathrm{NaCl}$ solution $(250 \mathrm{mM})$ using quartzglass cuvettes $(10 \mathrm{~mm})$ at $20^{\circ} \mathrm{C}$. Absorption spectra were recorded with a Perkin Elmer Lambda $750 \mathrm{UV} / \mathrm{vis}$ spectrometer. Emission spectra were measured with a Horiba Scientific FluoroMax-4 spectrofluorometer with a step width of $1 \mathrm{~nm}$ and an integration time of $0.2 \mathrm{~s}$. Spectra were recorded with an excitation band pass and an emission band pass of $3 \mathrm{~nm}$ for the single modified DNA2a and DNA3a. Spectra of the single modified DNA2b and DNA3b were recorded with an excitation band pass and an emission band pass of $5 \mathrm{~nm}$ and were corrected for Raman emission from the buffer solution.

DNA2a-3b were purified with a Reversed Phase Supelcosil ${ }^{\mathrm{TM}}$ LC-C18 column $(250 \times 10 \mathrm{~mm}$, $5 \mu \mathrm{m}$ ) on a Shimadzu HPLC system (autosampler, SIL-10AD, pump LC-10AT, controller SCL10A, diode array detector SPD-M10A). The purification was approved by MS (MALDI-TOF) either on a Bifelx-IV spectrometer from Bruker Daltonics in the linear negative mode (matrix: either 2:1 mixture of 2,4,6-trihydroxyacetophenone (0.3 $\mathrm{M}$ in EtOH) and diammoniumcitrate $\left(0.1 \mathrm{M}\right.$ in $\left.\mathrm{H}_{2} \mathrm{O}\right)$ or $1: 9$ mixture of diammoniumhydrogencitrate $(100 \mathrm{~g} / \mathrm{L})$ and a saturated 3hydroxypicolinic acid solution (10 g/L in 50\% acetonitrile in water)). DNA concentrations were measured by their absorbance in water at $260 \mathrm{~nm}$ on a ND-1000 spectrometer from NanoDrop in the nucleic acid mode.

\section{Trifluoroacetyl-protected 5-(3''-aminopropyl)-2'-deoxyuridine 15}

Trifluoroacetyl-protected 5-(3' '-aminopropynyl)-2'-deoxyuridine 14 (0.50 mmol, $200 \mathrm{mg}, 1.00$ eq) was dissolved in $10 \mathrm{~mL}$ anhydrous $\mathrm{MeOH}$ then $\mathrm{Pd}(\mathrm{OH})_{2}$ on carbon matrix $(20 \% \mathrm{Wt}, 10$ $\mathrm{mg}$ ) and triethylsilane (5.00 mmol, $800 \mu \mathrm{L}, 10.0$ eq.) were added to the reaction. After stirring for 24 hours at room temperature under argon atmosphere the reaction mixture was filtered through celite and the filtrate was concentrated under reduced pressure. The crude product was purified by column chromatography by flash chromatography on silica gel $\left(1: 1 \mathrm{CH}_{2} \mathrm{Cl}_{2-}\right.$ Acetone) to give a light yellow solid in $70 \%$ yield.

$\mathrm{TLC}\left(\mathrm{CH}_{2} \mathrm{Cl}_{2}:\right.$ Acetone $\left.=1: 1\right): \mathrm{Rf}=0.22$

${ }^{1}$ H-NMR (300 MHz, DMSO) $\delta 11.30(\mathrm{~s}, 1 \mathrm{H}), 9.45-9.34(\mathrm{~m}, 1 \mathrm{H}), 7.68(\mathrm{~s}, 1 \mathrm{H}), 6.16(\mathrm{t}, \mathrm{J}=6.7 \mathrm{~Hz}, 1 \mathrm{H})$, $5.23(\mathrm{dd}, \mathrm{J}=4.0,1.8 \mathrm{~Hz}, 1 \mathrm{H}), 5.01(\mathrm{t}, \mathrm{J}=5.1 \mathrm{~Hz}, 1 \mathrm{H}), 4.23(\mathrm{~s}, 1 \mathrm{H}), 3.76(\mathrm{q}, \mathrm{J}=3.3 \mathrm{~Hz}, 1 \mathrm{H}), 3.56(\mathrm{q}, \mathrm{J}=$ 4.7, $4.3 \mathrm{~Hz}, 2 \mathrm{H}), 3.17(q, J=6.6 \mathrm{~Hz}, 2 \mathrm{H}), 2.19(\mathrm{p}, \mathrm{J}=6.7 \mathrm{~Hz}, 2 \mathrm{H}), 2.13-2.01(\mathrm{~m}, 3 \mathrm{H}), 1.64(\mathrm{p}, \mathrm{J}=7.2 \mathrm{~Hz}$, $2 \mathrm{H})$. 


\section{COMBO modified 5-(3"'-aminopropyl)-2'-deoxyuridine 18}

5-(3' '-aminopropyl)-2'-deoxyuridine (0.09 mmol, $58.0 \mathrm{mg}, 1.00 \mathrm{eq})$, COMBO acid (0.09 mmol, $20.0 \mathrm{mg}, 1.00 \mathrm{eq}), \mathrm{HBtU}$ (0.084 mmol, $32.0 \mathrm{mg}, 0.94 \mathrm{eq})$, HOBt (0.09 mmol, 14.4 $\mathrm{mg}, 1.00 \mathrm{eq}$ ) were added to the reaction flask with dried over vacuum and $4 \mathrm{~mL}$ DMF were added. The reaction mixtures were stirred under an argon atmosphere for 5 minutes then $33 \mu 1$ DIPEA were added to the reaction mixture. The resulting mixture was allowed to stir at room temperature for 2 hours. The crude product was purified by column chromatography (EtOAc: $\mathrm{MeOH}=9.5: 0.5,0.1 \% \mathrm{Et}_{3} \mathrm{~N}$ ) to give a light yellow solid $52 \%$ yield.

TLC (EtOAc: $\mathrm{MeOH}=9.5: 0.5): \mathrm{Rf}=0.50$

${ }^{1} \mathrm{H}-\mathrm{NMR}(400 \mathrm{MHz}, \mathrm{DMSO}) \delta 11.38(\mathrm{~s}, 1 \mathrm{H}), 8.30(\mathrm{q}, \mathrm{J}=5.8 \mathrm{~Hz}, 1 \mathrm{H}), 7.55(\mathrm{q}, \mathrm{J}=3.6 \mathrm{~Hz}, 1 \mathrm{H}), 7.47(\mathrm{~s}, 1 \mathrm{H})$, $7.41-7.33(\mathrm{~m}, 3 \mathrm{H}), 7.34-7.14(\mathrm{~m}, 10 \mathrm{H}), 6.87(\mathrm{~d}, \mathrm{~J}=8.3 \mathrm{~Hz}, 5 \mathrm{H}), 6.21(\mathrm{t}, \mathrm{J}=6.8 \mathrm{~Hz}, 1 \mathrm{H}), 5.33(\mathrm{~d}, \mathrm{~J}=4.6$ $\mathrm{Hz}, 1 \mathrm{H}), 4.31(\mathrm{t}, \mathrm{J}=5.6 \mathrm{~Hz}, 1 \mathrm{H}), 3.87(\mathrm{q}, \mathrm{J}=3.9 \mathrm{~Hz}, 1 \mathrm{H}), 3.70(\mathrm{~s}, 7 \mathrm{H}), 3.28-2.99(\mathrm{~m}, 7 \mathrm{H}), 2.79(\mathrm{q}, \mathrm{J}=5.5$, $5.0 \mathrm{~Hz}, 2 \mathrm{H}), 2.57(\mathrm{dd}, \mathrm{J}=8.2,4.9 \mathrm{~Hz}, 2 \mathrm{H}), 2.37(\mathrm{t}, \mathrm{J}=6.1 \mathrm{~Hz}, 2 \mathrm{H}), 2.28(\mathrm{~d}, \mathrm{~J}=6.9 \mathrm{~Hz}, 1 \mathrm{H}), 2.20-2.09(\mathrm{~m}$, $1 \mathrm{H}), 2.06-1.87(\mathrm{~m}, 2 \mathrm{H}), 1.69(\mathrm{~s}, 2 \mathrm{H}), 1.51(\mathrm{~d}, \mathrm{~J}=7.5 \mathrm{~Hz}, 2 \mathrm{H})$.

${ }^{13} \mathrm{C}-\mathrm{NMR}(100 \mathrm{MHz}$, DMSO) $\delta$ 166.14, 163.57, 158.32, 150.54, 145.00, 142.95, 139.91, 139.69, 136.4, 135.70, 135.50, 133.40, 129.94, 129.38, 129.05, 128.55, 128.08, 127.87, 126.97, 125.67, 113.57, $113.47,85.91,85.65,84.09,70.73,64.41,55.21,49.05,45.97,40.51,38.47,33.15,32.97,28.53,27.74$, $27.43,24.15$.

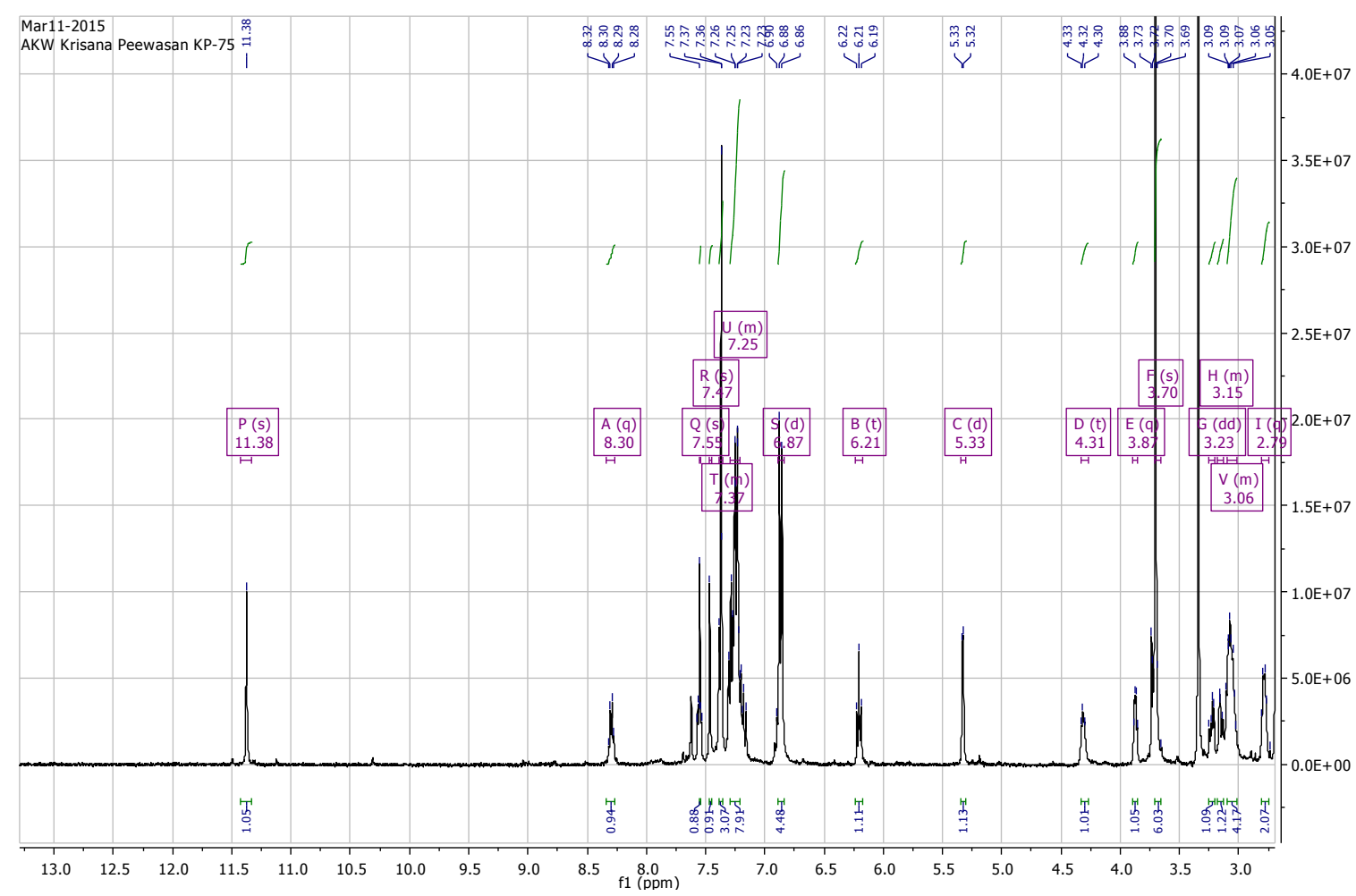




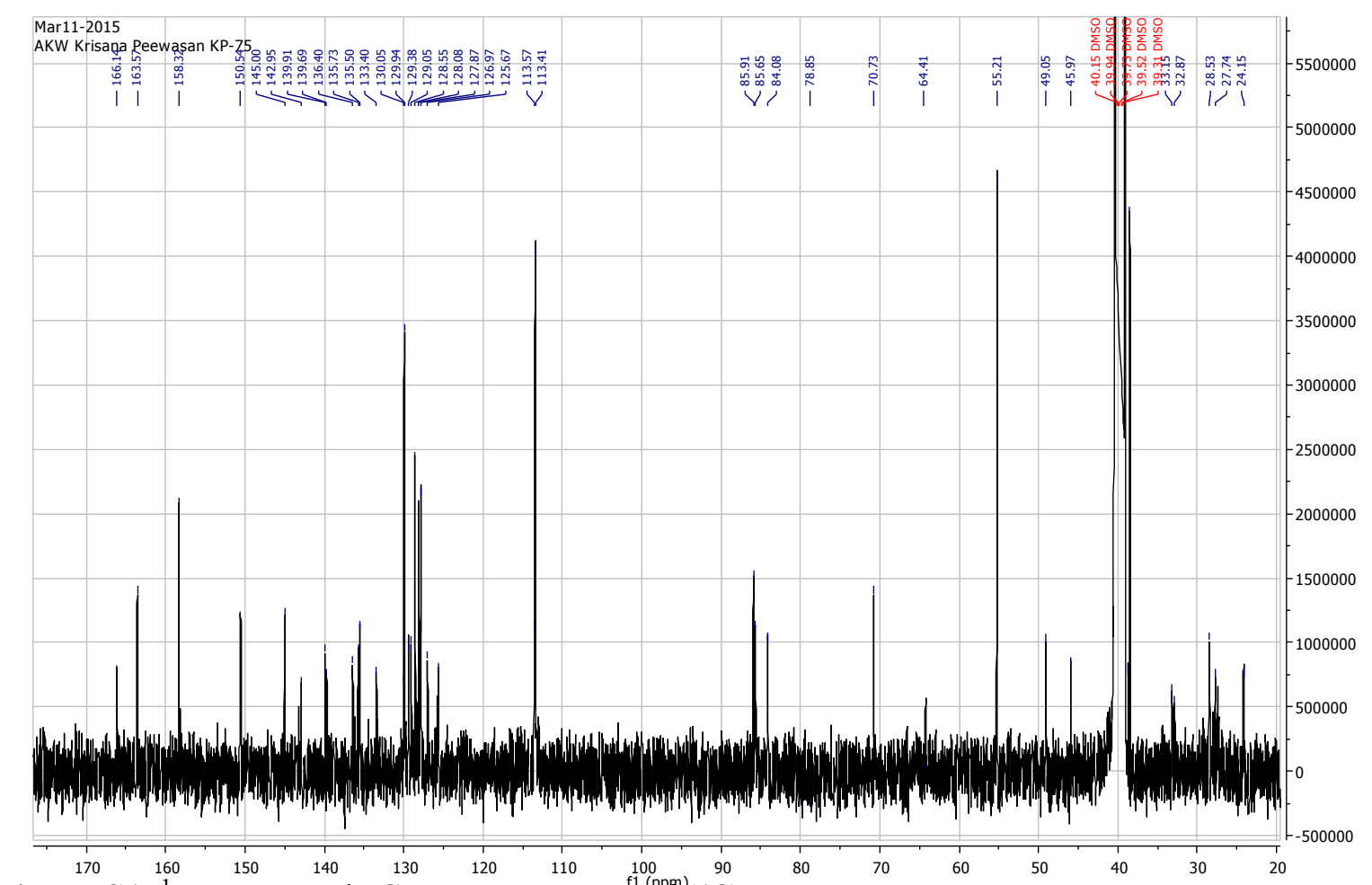

Figure S1. ${ }^{1} \mathrm{H}-\mathrm{NMR}$ and ${ }^{13} \mathrm{C}-\mathrm{NMR}$ spectrum ${ }^{\mathrm{f1}}$ of $\mathrm{fop}^{\mathrm{pm}}(\mathbf{1 8})$

\section{Phosphoramidite 13}

COMBO modified 5-(3'"-aminopropyl)-2'-deoxyuridine 18 (0.15 mmol, $110 \mathrm{mg})$ was dissolved in $3 \mathrm{~mL}$ DCM then DIPEA $(0.68 \mathrm{mmol}, 115 \mu \mathrm{L})$ was added and the reaction mixture wasallowed to stir at room temperature for 15 minutes. Then $\beta$-cyanoethyl-N,Ndiisopropylchlorophorsporamidite $(0.35 \mathrm{mmol}, 78.1 \mu \mathrm{L})$ was added and the reaction was allowed to continue for $1 \mathrm{hr}$. The crude product was direct applied to FC-Chromatography $\left(\mathrm{CH}_{2} \mathrm{Cl}_{2}\right.$ : Acetone $\left.+\mathrm{Et}_{3} \mathrm{~N}=5: 2+0.1 \%\right)$ to give a light yellow solid in $90 \%$ yield.

$\mathrm{TLC}\left(\mathrm{CH}_{2} \mathrm{Cl}_{2}:\right.$ Acetone $\left.+\mathrm{Et}_{3} \mathrm{~N}=5: 2+0.1 \%\right): \mathrm{Rf}=0.73$

FAB $\mathrm{m} / \mathrm{z}(\%): 992.4(50)\left(\mathrm{M}^{+}+\mathrm{Na}\right)$ 


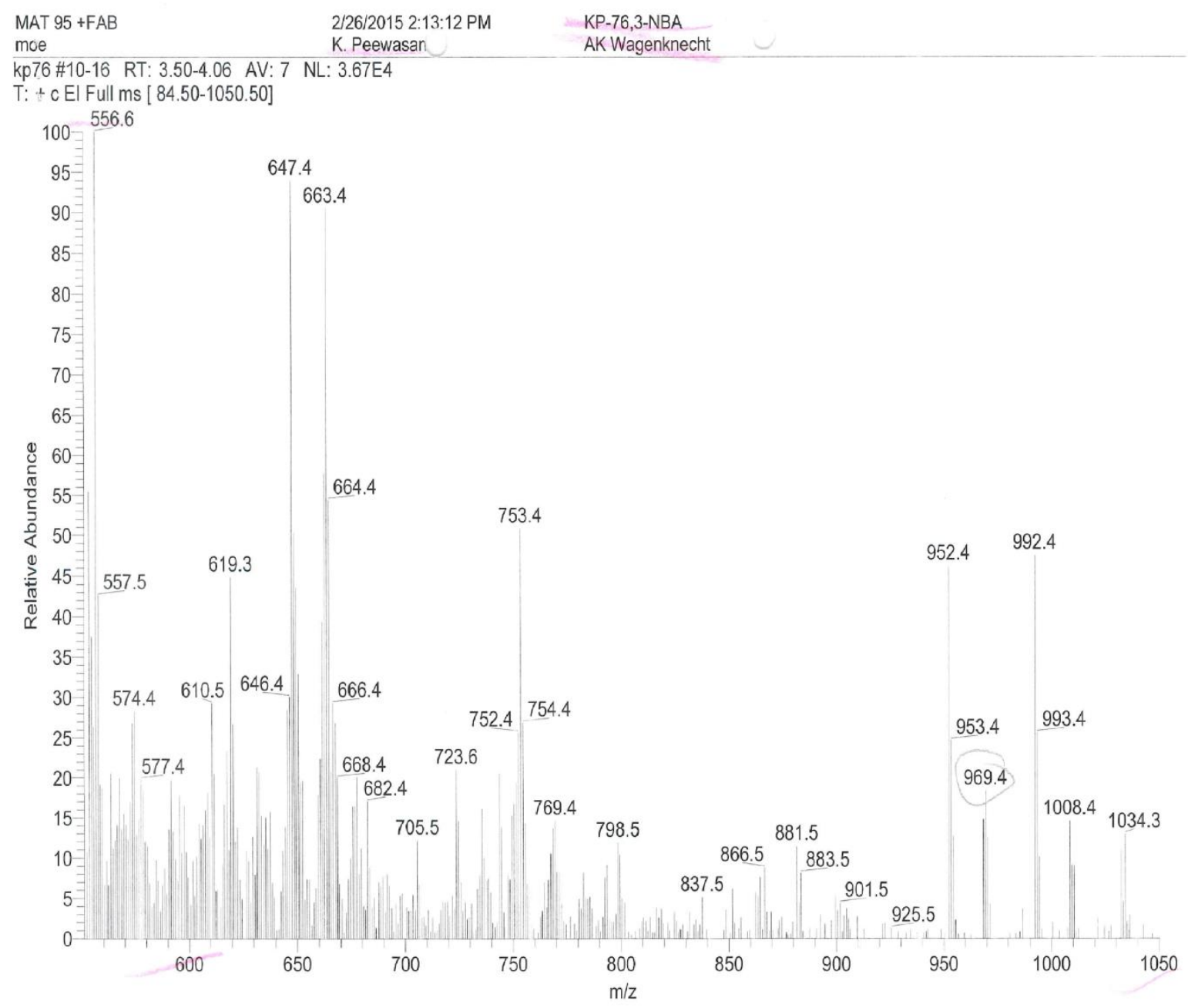

Figure S2: FAB-MS spectrum of (13)

\section{DNA Synthesis}

DNA Synthesis was carried out on an Applied Biosystems Expedite Nucleic Acid Synthesizer System using standard phosphoramidite chemistry. Reagents and controlled pore glass (CPG) $(1 \mu \mathrm{mol})$ were purchased from $A B I$ and Glen Research. COMBO modified DNA has synthesized using a modified protocol. Activator solution ( $0.45 \mathrm{M}$ tetrazole in acetonitrile) was pumped simultaneously with the building block ( $0.1 \mathrm{M}$ in acetonitrile). The coupling time was extended to $20.0 \mathrm{~min}$. The CPG vial was flushed with acetonitrile after the coupling. Thereupon, the oligonucleotides were cleaved from the resin and deprotected by treatment with conc. $\mathrm{NH}_{4} \mathrm{OH}$ at $36^{\circ} \mathrm{C}$ over night.

Click reaction Lyophilized DNA8a/9a (10 nmol, 1.0 equiv.) was dissolved in water $(150 \mu \mathrm{L})$ and $3 \mathrm{~b}$ was added (11 $\mathrm{nmol}, 0.51 \mathrm{mM}$ in DMSO, 1.1 equiv). The colour of the dye immediately turned from dark blue into light green. The mixture was shaken for $3 \mathrm{~h}$. The solvent was removed and the resulting residue absorbed in water $(200 \mu \mathrm{L})$ and purified by reversed-phase HPLC.

\section{HPLC purification}

The DNA strands were purified on a semi preparative RP-C18 column ( $300 \AA$, Supelco) using the following conditions: 
$\mathrm{A}=\mathrm{NH}_{4} \mathrm{OAc}$ buffer $(50 \mathrm{mM}, \mathrm{pH}=6.5) ; \mathrm{B}=$ acetonitrile

Gradient: DNA8a/DNA9a: 0 - 25\% in 55 min

DNA8/9: 0 - 25\% in 55 min

Detection wavelengths: DNA8a/9a: $260 \mathrm{~nm}$ (DNA), $290 \mathrm{~nm}$ (COMBO),

DNA8/9: $260 \mathrm{~nm}$ (DNA), $290 \mathrm{~nm}$ (COMBO), 610nm (3b)

Purification was verified by MS (MALDI) on a Biflex-IV spectrometer from Bruker Daltonics in the linear negative mode. Finally the oligonucleotides were lyophilized and quantified by their absorbance in water at $260 \mathrm{~nm}$.

HPLC and MALDI spectra

DNA8a: 3'-AGTCACTTdU*TTCTGACG-5'
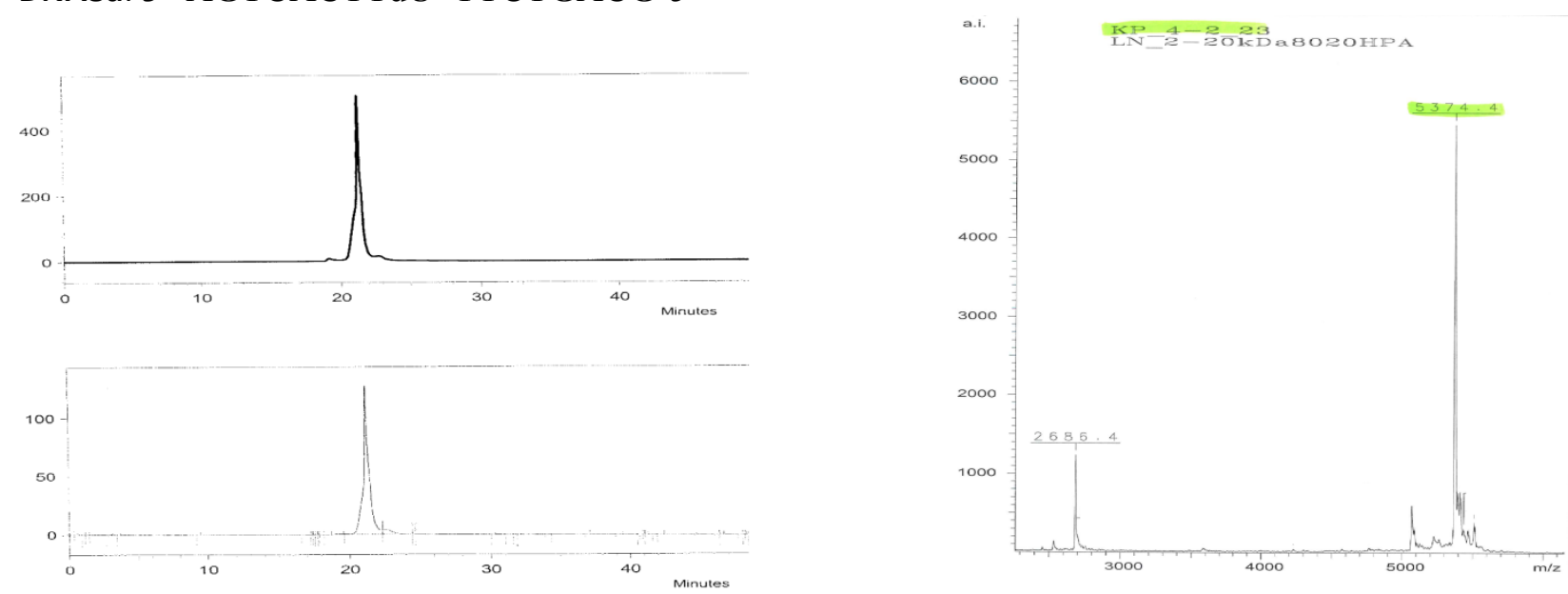

Figure S3: HPLC- and MALDI spectra of DNA8a.

$[\mathrm{M}]($ calculated $)=5369.3 \mathrm{~g} / \mathrm{mol} ;[\mathrm{M}]($ found $)=5374.4 \mathrm{~g} / \mathrm{mol}$

$[\mathrm{M} / 2]($ calculated $)=2684.7 \mathrm{~g} / \mathrm{mol} ;[\mathrm{M} / 2]($ found $)=2686.4 \mathrm{~g} / \mathrm{mol}$

DNA8: $3^{\prime}$-AGTCACTTdU**TTCTGACG-5'
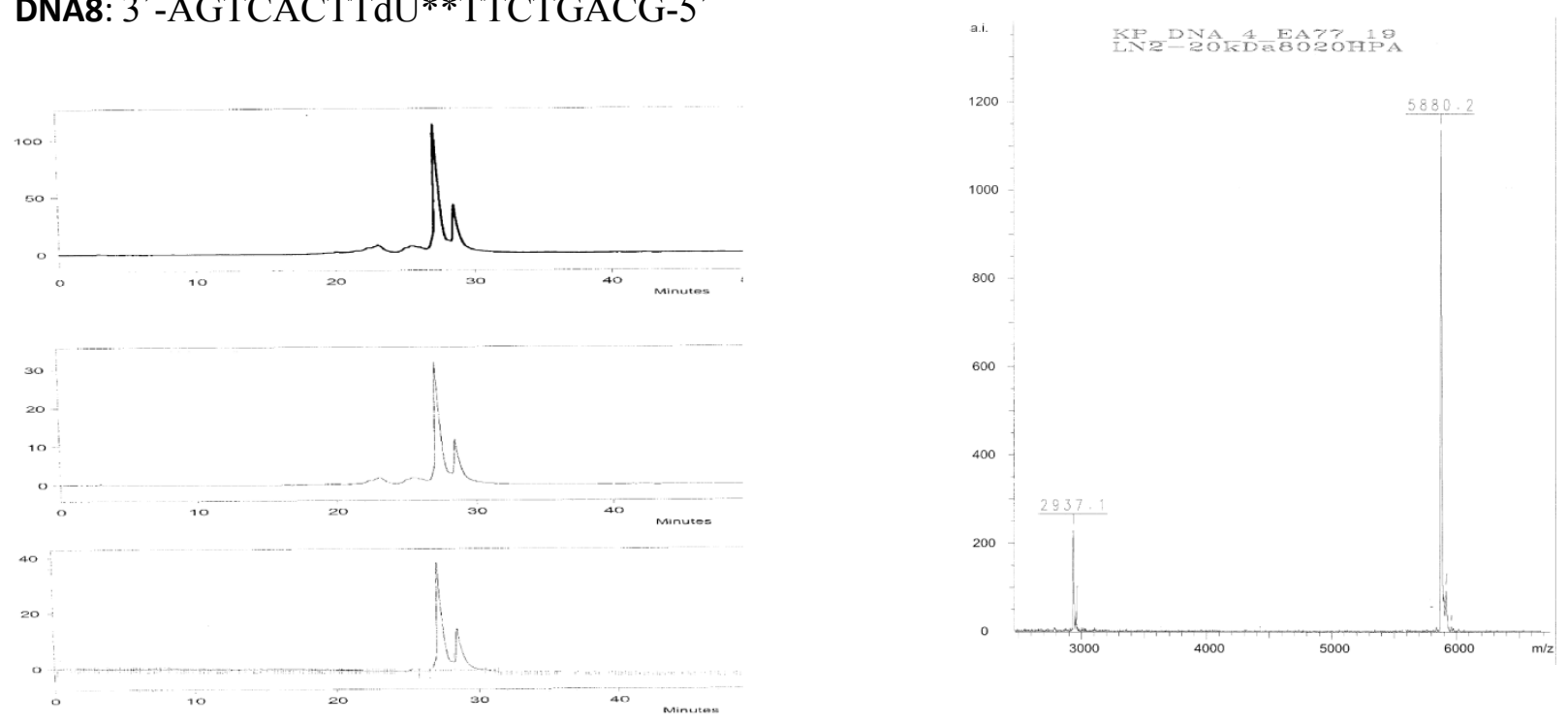

Figure S4: HPLC- and MALDI spectra of DNA8.

$[\mathrm{M}]($ calculated $)=5880.4 \mathrm{~g} / \mathrm{mol} ;[\mathrm{M}]$ (found) $=5880.2 \mathrm{~g} / \mathrm{mol}$ $[\mathrm{M} / 2]($ calculated $)=2940.2 \mathrm{~g} / \mathrm{mol} ;[\mathrm{M} / 2]($ found $)=2937.1 \mathrm{~g} / \mathrm{mol}$ 
DNA9a: 3'-AGTCACTTdU*TTCTGACG-5'

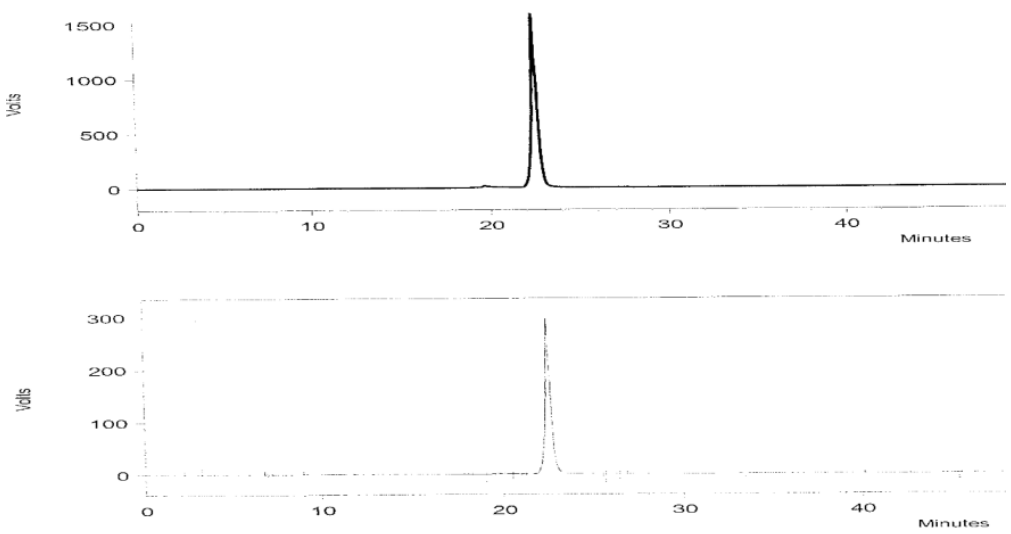

Figure S5: HPLC- and MALDI spectra of DNA8a.

$[\mathrm{M}]($ calculated $)=5373.3 \mathrm{~g} / \mathrm{mol} ;[\mathrm{M}]($ found $)=5373.5 \mathrm{~g} / \mathrm{mol}$

$[\mathrm{M} / 2]($ calculated $)=2686.7 \mathrm{~g} / \mathrm{mol} ;[\mathrm{M} / 2]($ found $)=2687.2 \mathrm{~g} / \mathrm{mol}$

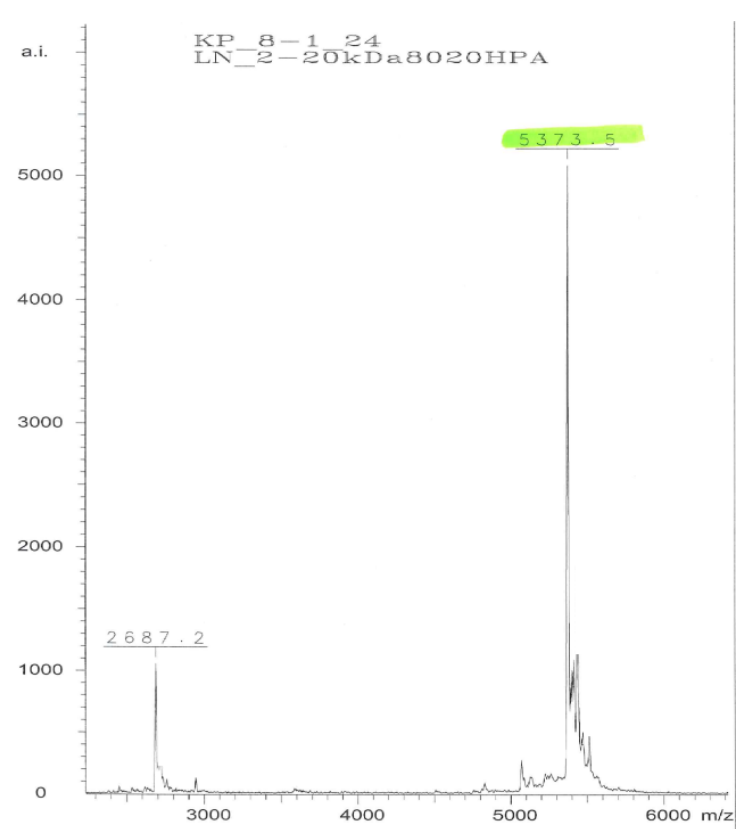

DNA9: 3 '-AGTCACTTdU**TTCTGACG-5'
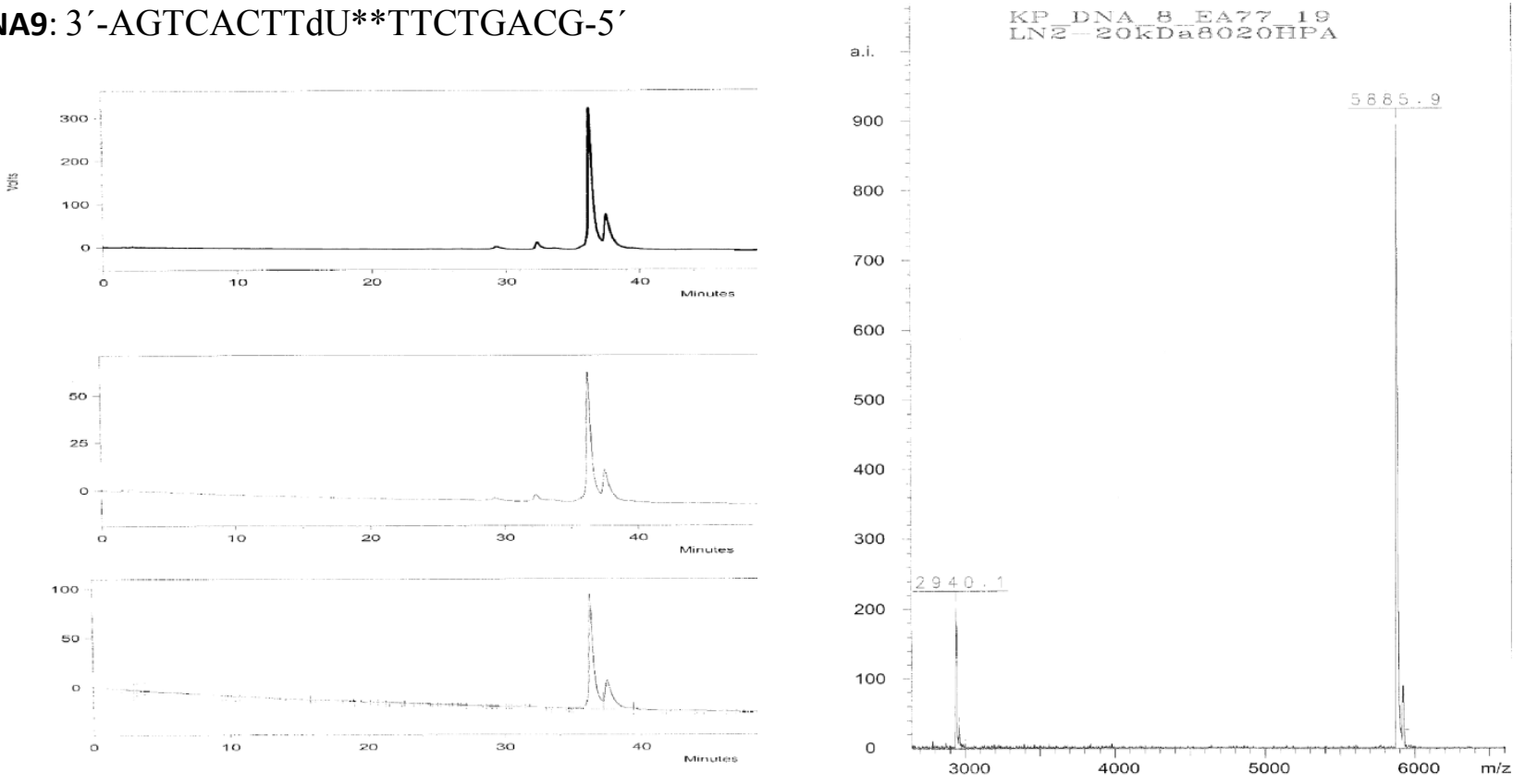

Figure S6: HPLC- and MALDI spectra of DNA9.

$[\mathrm{M}]($ calculated $)=5884.5 \mathrm{~g} / \mathrm{mol} ;[\mathrm{M}]($ found $)=5885.9 \mathrm{~g} / \mathrm{mol}$ $[\mathrm{M} / 2]($ calculated $)=2942.9 \mathrm{~g} / \mathrm{mol} ;[\mathrm{M} / 2]($ found $)=2940.1 \mathrm{~g} / \mathrm{mol}$ 


\section{Spectroscopic measurements}

\section{General remarks}

Spectroscopic measurements for the DNA experiments were performed in Na-Pi buffer solution (10 $\mathrm{mM}, \mathrm{pH}=7$ ) with $250 \mathrm{mM} \mathrm{NaCl}$ using quartz glass cuvettes $(10 \mathrm{~mm})$. Absorption spectra were recorded with a Carry 100 Scan spectrometer. Fluorescence was measured with a Fluoromax-4-NIR fluorimeter. All spectra were recorded with an excitation band pass of $5 \mathrm{~nm}$, an emission band pass of $5 \mathrm{~nm}$, an excitation wavelength of $615 \mathrm{~nm}$ and are corrected for Raman emission from the buffer solution.
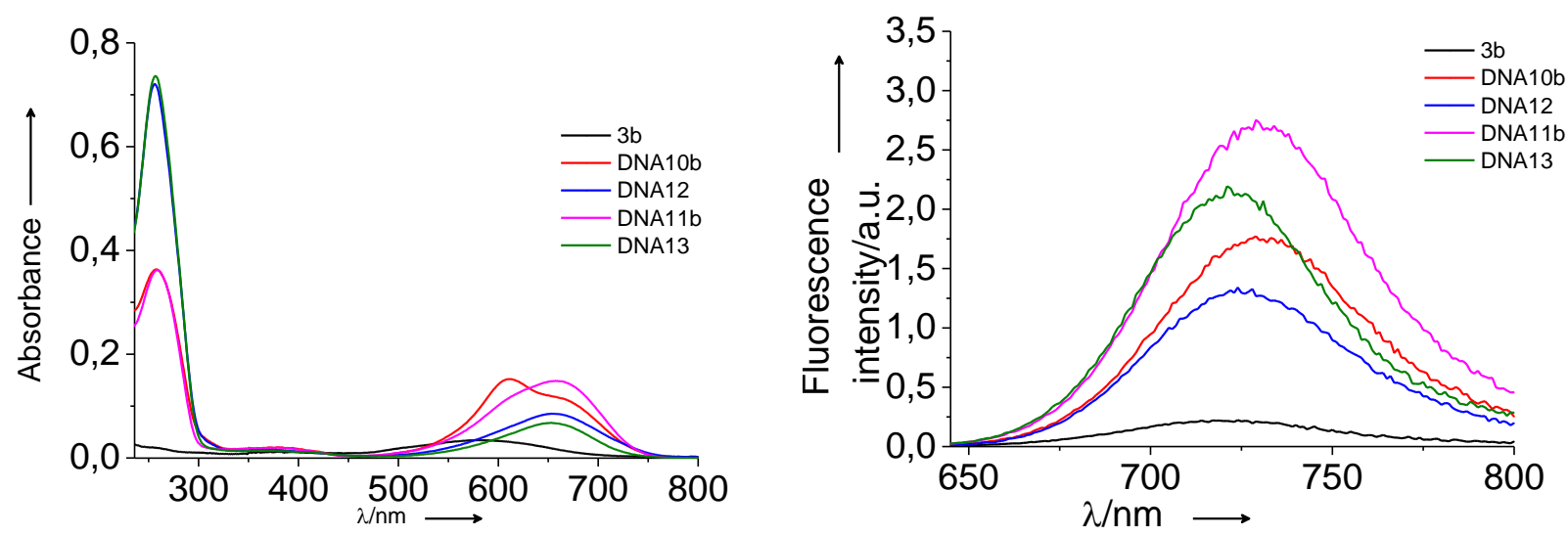

Figure S7. Comparison of the absorption (left) and fluorescence (right) of DNA10b, DNA11b, DNA12 and DNA13. 


\section{Preparation of DNA-sequences:}

\section{Preparation and purification of DNA1a-3b:}

The oligonucleotides were synthesized on an Expedite 8909 Synthesizer from Applied Biosystems (ABI) using standard phosphoramidite chemistry. The reagents and the controlled pore glass $(\mathrm{CPG})(1 \mu \mathrm{mol})$ were purchased from Proligo and the 2 ' propargyl-uridine (cU) from ChemGenes. DNA synthesis was performed using standard coupling conditions in which the concentration of $\mathrm{cU}$ was $0.1 \mathrm{~mol} / \mathrm{L}$ (in acetonitrile). After preparation the DMT-off nucleotides were cleaved from resin and deprotected with conc. $\mathrm{NH}_{4} \mathrm{OH}$ at $55{ }^{\circ} \mathrm{C}$ for $16 \mathrm{~h}$.

\section{Click reaction of dye $1 \mathrm{a}, 1 \mathrm{~b}, 2 \mathrm{a}, 2 \mathrm{~b}, 3 \mathrm{a}$ and $3 \mathrm{~b}$ with $\mathrm{cU}$-modified oligonucleotides:}

The lyophilized oligonucleotides were solved in $50 \mu 1$ water, treated with $25 \mu \mathrm{L}$ of a sodium ascorbate solution (0.4 M in water), $34 \mu \mathrm{L}$ tris-[(1-benzyl-1H-1,2,3-triazol-4-yl)methyl]amine (0.1 $\mathrm{M}$ in DMSO/t-BuOH 3:1), $114 \mu \mathrm{L}$ of the azide (0.01 $\mathrm{M}$ in DMSO/t-BuOH 3:1) and finally $17 \mu \mathrm{L}$ of a tetrakis(acetonitrile) copper(I)hexafluorophosphate solution $(0.1 \mathrm{M}$ in DMSO/t$\mathrm{BuOH} 3: 1)$. The reaction mixture was stirred for $16 \mathrm{~h}$ at room temperature. Afterwards the oligonucleotides were precipitated by adding $150 \mu \mathrm{L} \mathrm{Na} 2$ EDTA (0.05 M in water), $450 \mu \mathrm{L}$ sodium acetate $\left(0.3 \mathrm{M}\right.$ in water) and $8 \mathrm{~mL}$ isopropyl alcohol $(100 \%)$ and stored at $-32{ }^{\circ} \mathrm{C}$ for $14 \mathrm{~h}$. After centrifugation the precipitation was washed two times with $3 \mathrm{~mL}$ isopropyl alcohol (90\%). The dried DNA-pellet was solved in $250 \mu 1$ water and purified via HPLC.

\section{HPLC-purification of DNA1a-3b:}

The oligonucleotides were purified by HPLC Reversed Phase Supelcosil ${ }^{\mathrm{TM}}$ LC-C18 column (250 x $10 \mathrm{~mm}, 5 \mu \mathrm{m}$ ) on a Shimadzu HPLC system (autosampler SIL-10AD, pump LC-10AT, controller SCL-10A, diode array detector SPD-M10A) using the following conditions: Eluent A: $\mathrm{NH}_{4} \mathrm{OAc}$ buffer $(50 \mathrm{mM}), \mathrm{pH}=6.5$; Eluent $\mathrm{B}$ : acetonitrile. For the used gradient see table 1 . The flow rate was $2.5 \mathrm{~mL} / \mathrm{min}$ and the UV/vis detection at $260 \mathrm{~nm}, 585 \mathrm{~nm}$ for DNA1a, $645 \mathrm{~nm}$ for DNA1b, $591 \mathrm{~nm}$ for DNA2a and DNA3a, $669 \mathrm{~nm}$ for DNA2b and DNA3b. 
Table 1: HPLC-gradients for semi-preparative determination of the oligonucleotides modified with dye 1a-3b.

$$
\text { time }[\mathrm{min}] \quad \text { Eluent B [\%] }
$$

\section{HPLC-analytic of purified DNA1a-3b:}

Analytical HPLC of the purified oligonucleotides were performed by HPLC Reversed Phase Supercosil ${ }^{\mathrm{TM}}$ LC-C18 column $(250 \times 4.5 \mathrm{~mm}, 5 \mu \mathrm{m})$ on a Shimadzu HPLC system (autosampler SIL-10AD, pump LC-10AT, controller SCL-10A, diode array detector SPD-M10A) using the following conditions: Eluent A: $\mathrm{NH}_{4} \mathrm{OAc}$ buffer $(50 \mathrm{mM}), \mathrm{pH}=6.5$; Eluent B: acetonitrile. For the used gradient see table 2 . The flow rate was $1.0 \mathrm{~mL} / \mathrm{min}$ and the UV/vis detection at 260 $\mathrm{nm}, 585 \mathrm{~nm}$ for DNA1a, $645 \mathrm{~nm}$ for DNA1b, $591 \mathrm{~nm}$ for DNA2a and DNA3a, $669 \mathrm{~nm}$ for DNA2b and DNA3b. 
Table 2: HPLC-gradients for analytical determination of purified oligonucleotides modified with dye 2a-3b.

time $[\mathrm{min}] \quad$ Eluent B [\%]

0

0

45

20

55

20

56

90

65

90

66

0

75

0 


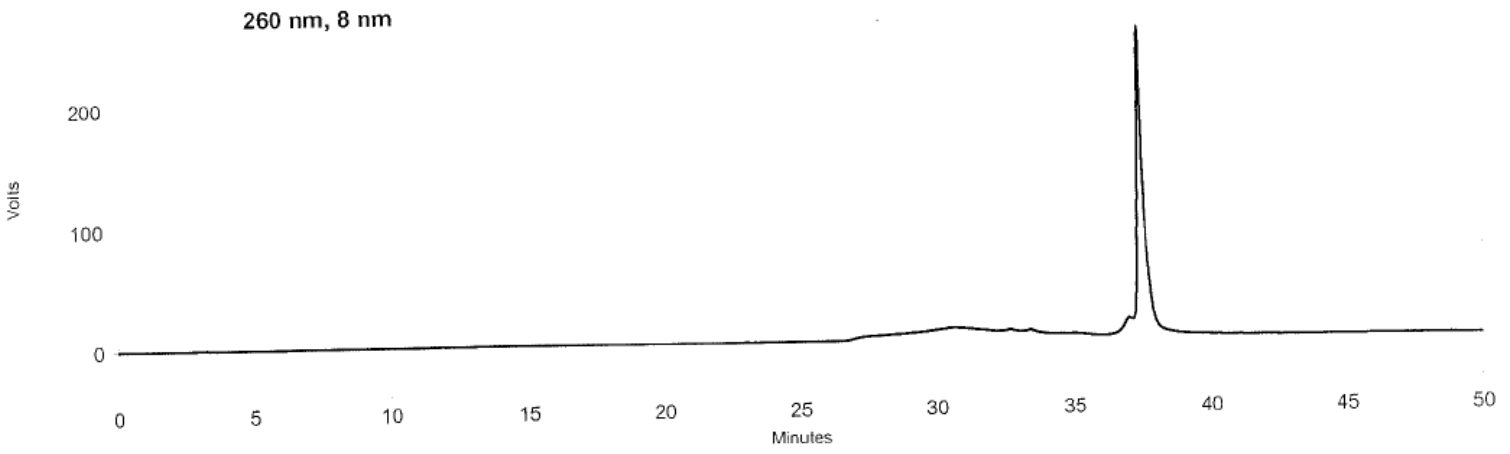

$585 \mathrm{~nm}, 8 \mathrm{~nm}$

50

25

$0 \quad 5$

10

15

$20 \quad 25$

30

35

$40 \quad 45$

50

Figure 1: HPLC-chromatogram of purified DNA1a.
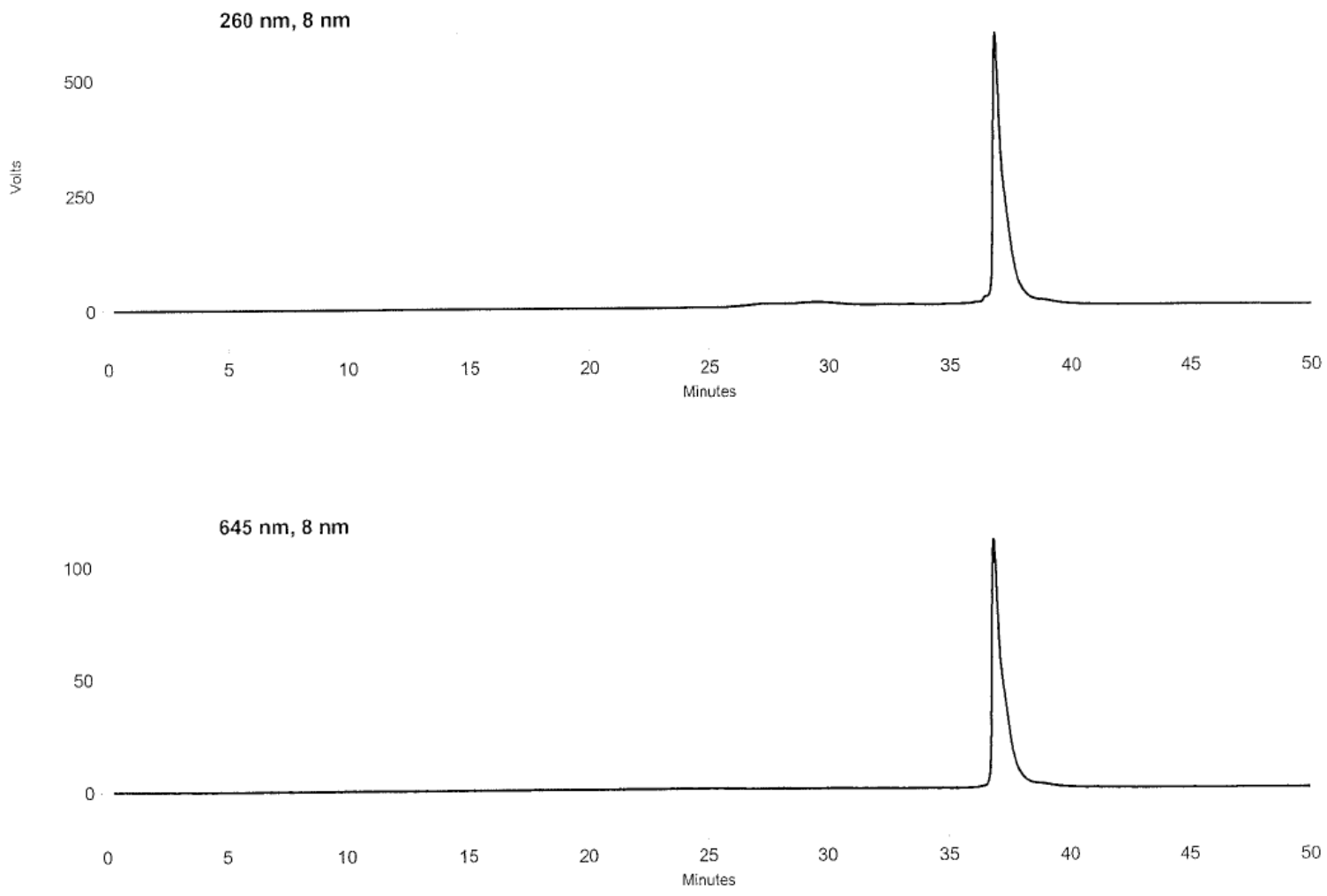

Figure 2: HPLC-chromatogram of purified DNA1b. 


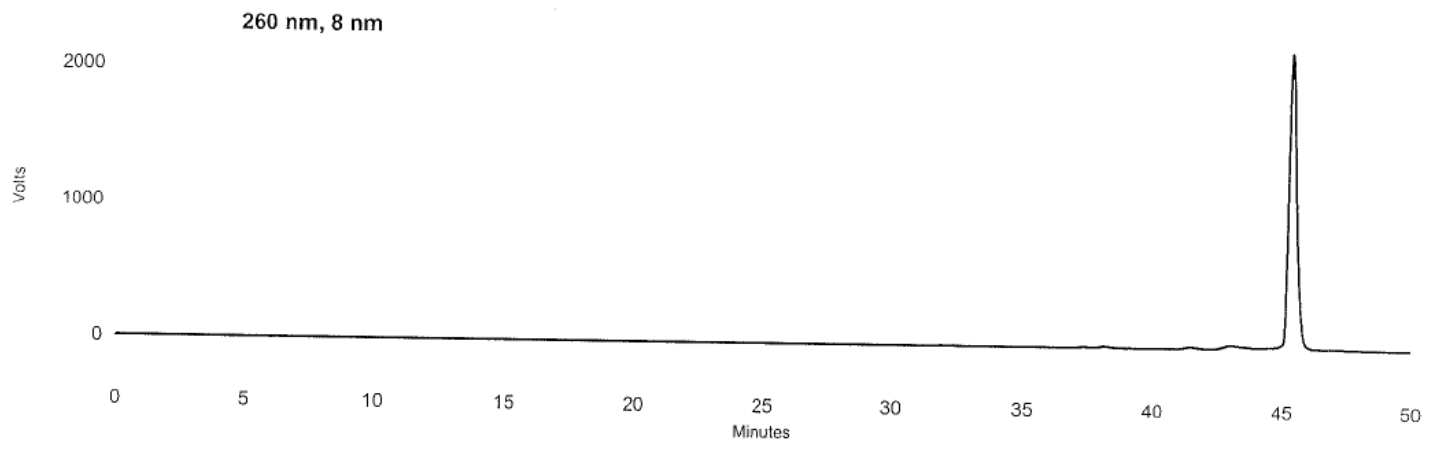

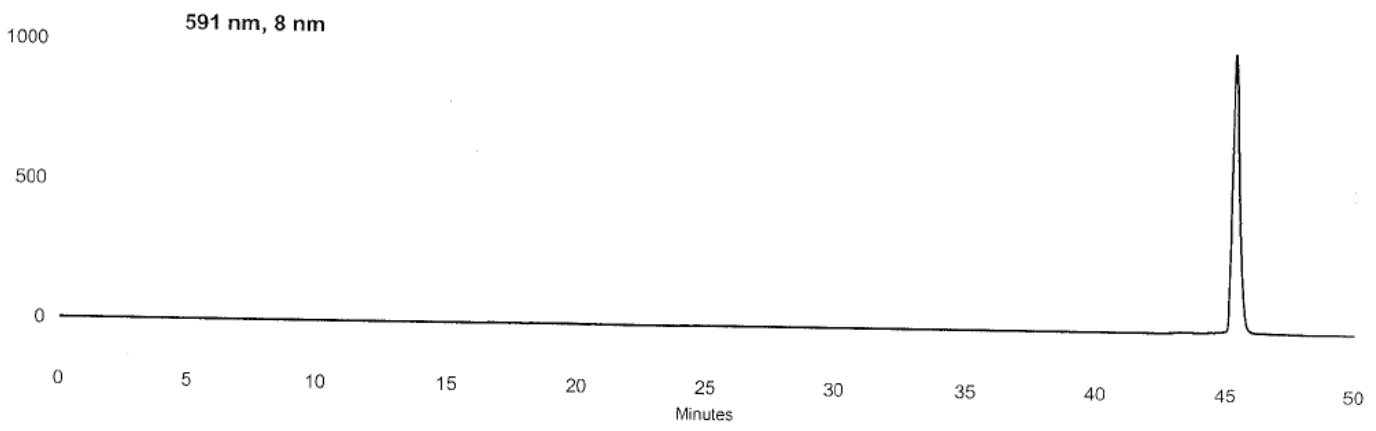

Figure 3: HPLC-chromatogram of purified DNA2a. 


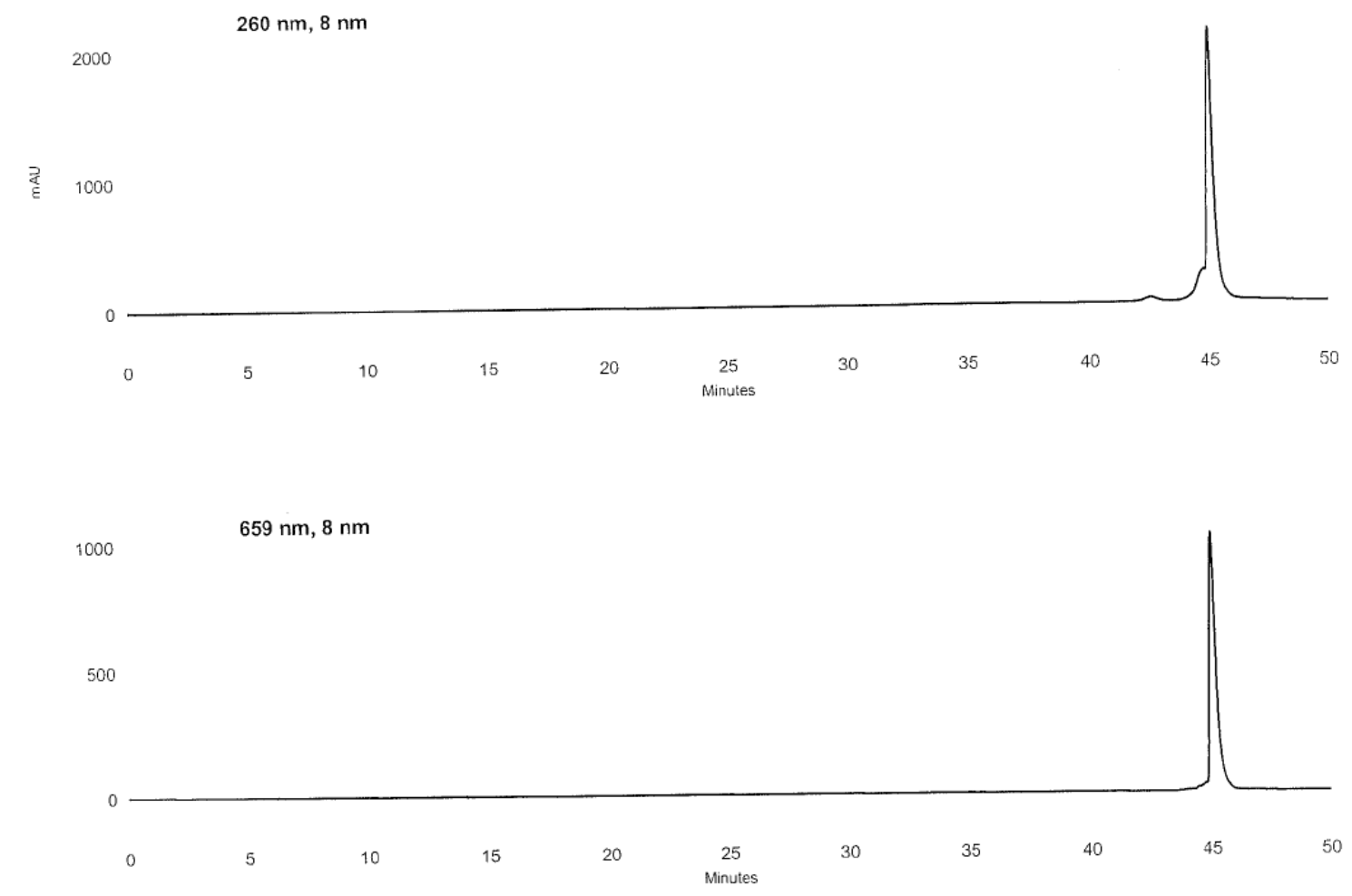

Figure 4: HPLC-chromatogram of purified DNA2b.

$260 \mathrm{~nm}, 8 \mathrm{~nm}$

500
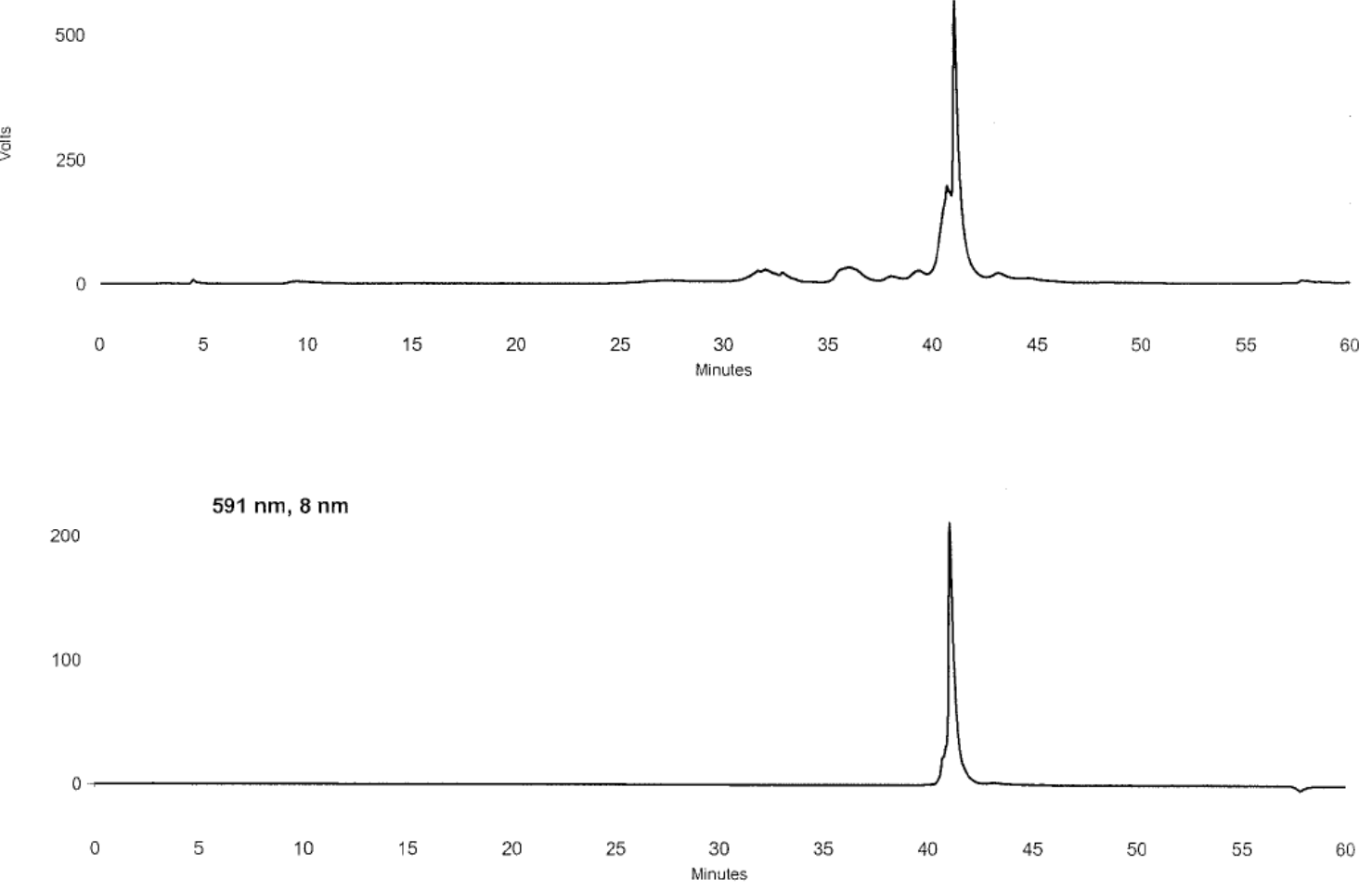

Figure 5: HPLC-chromatogram of purified DNA3a. 

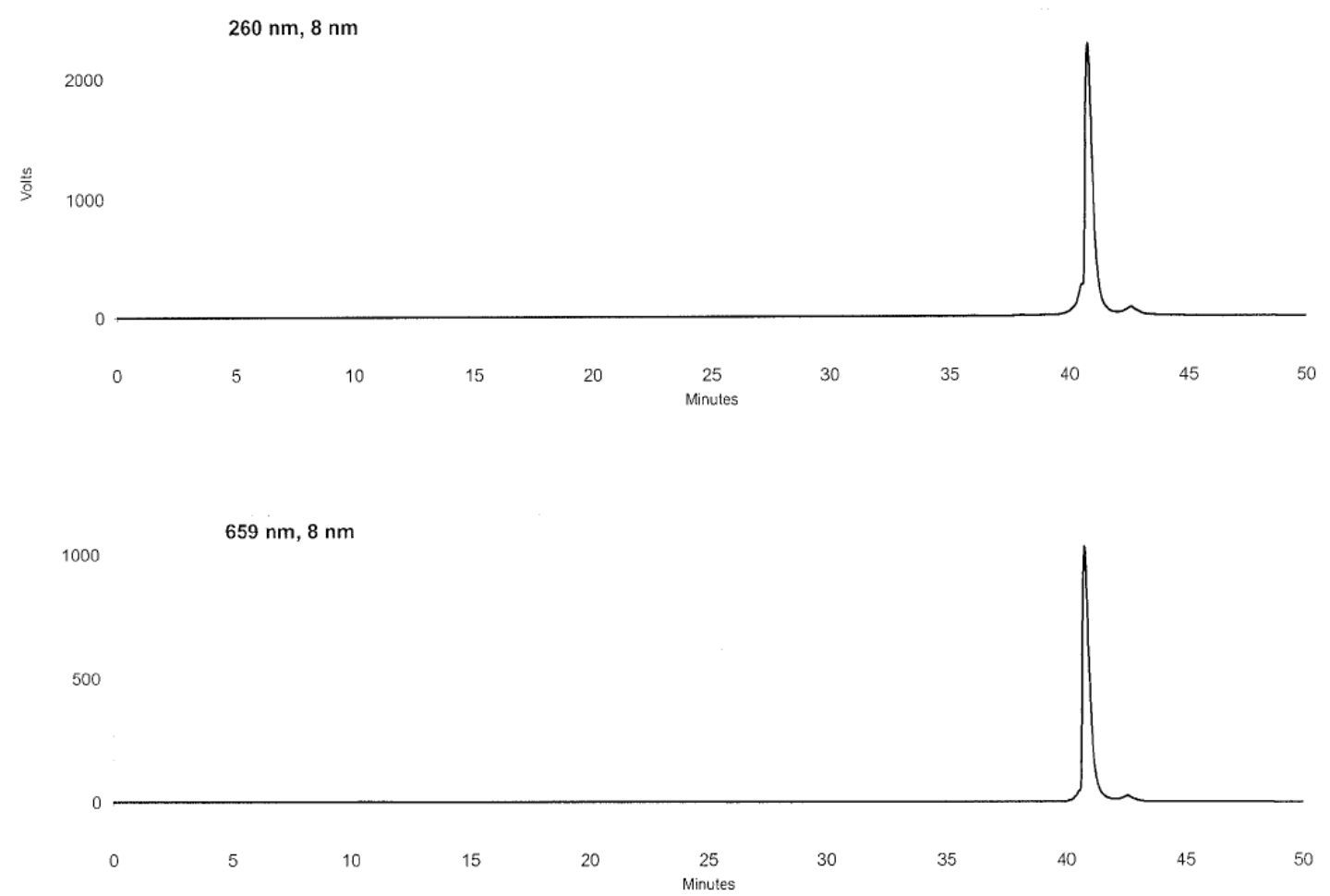

Figure 6: HPLC-chromatogram of purified DNA3b.

\section{MALDI spectra of DNA1a-DNA3b:}

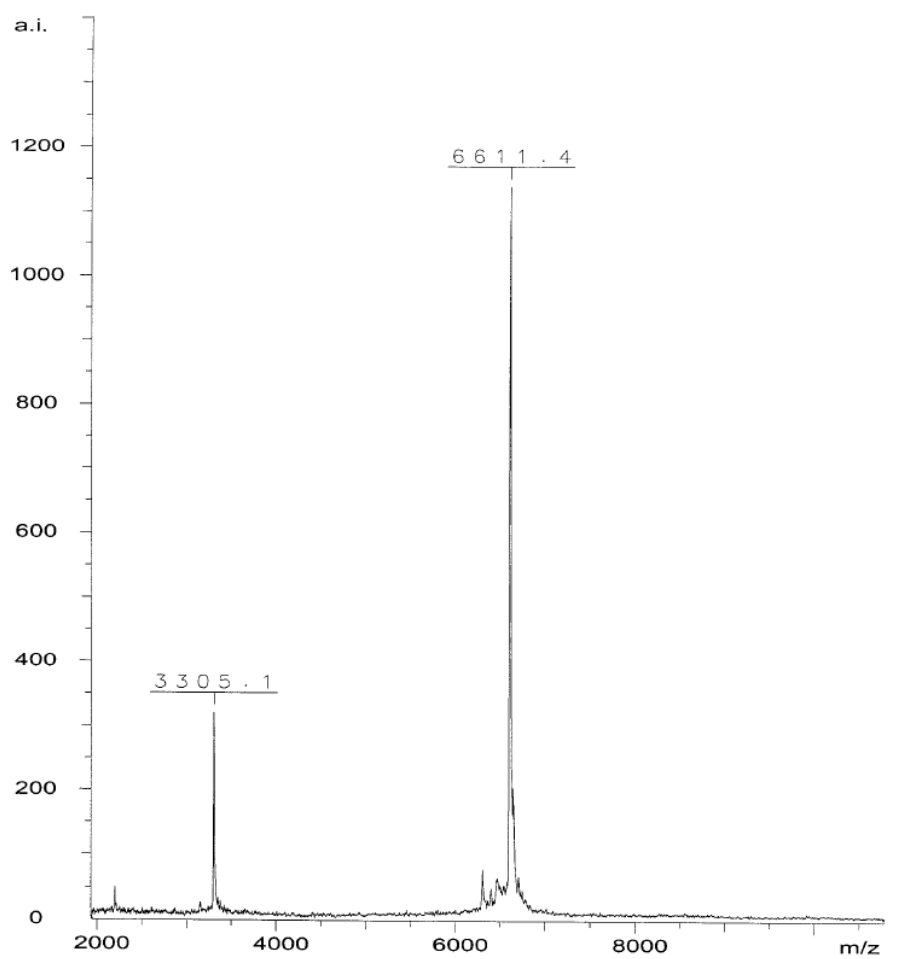

Figure 7: MALDI-spectra of purified DNA1a, calculated: $6607.3 \mathrm{Da}$, found: $6611.4 \mathrm{Da}$. 


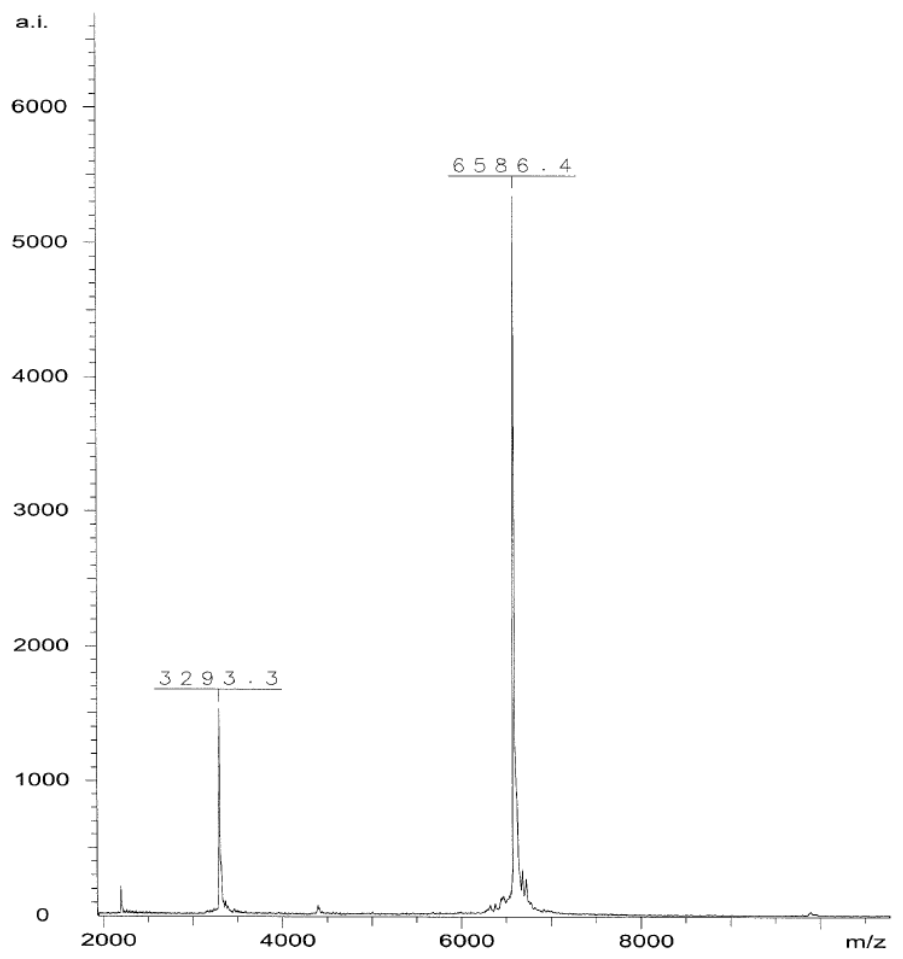

Figure 8: MALDI-spectra of purified DNA1b, calculated: 6579.3 Da, found: 6586.4 Da. 


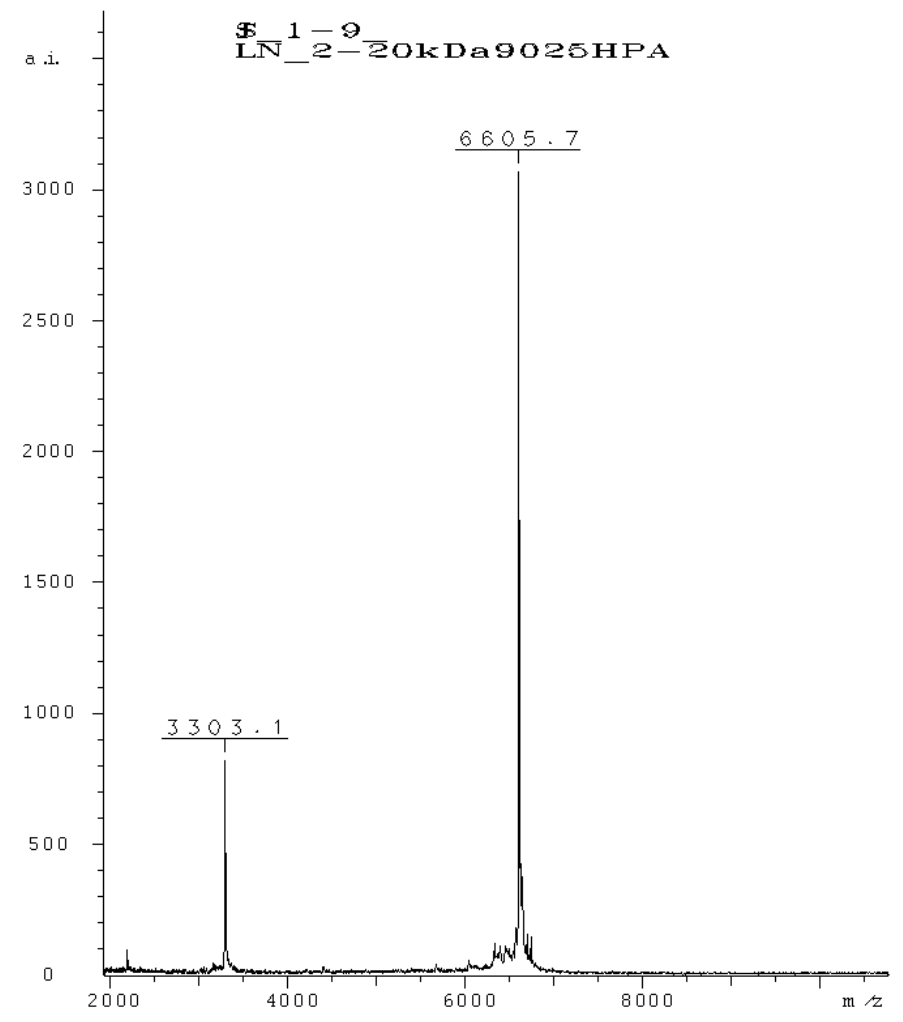

Figure 9: MALDI-spectra of purified DNA2a, calculated: 6599.2 Da, found: 6605.7 Da.

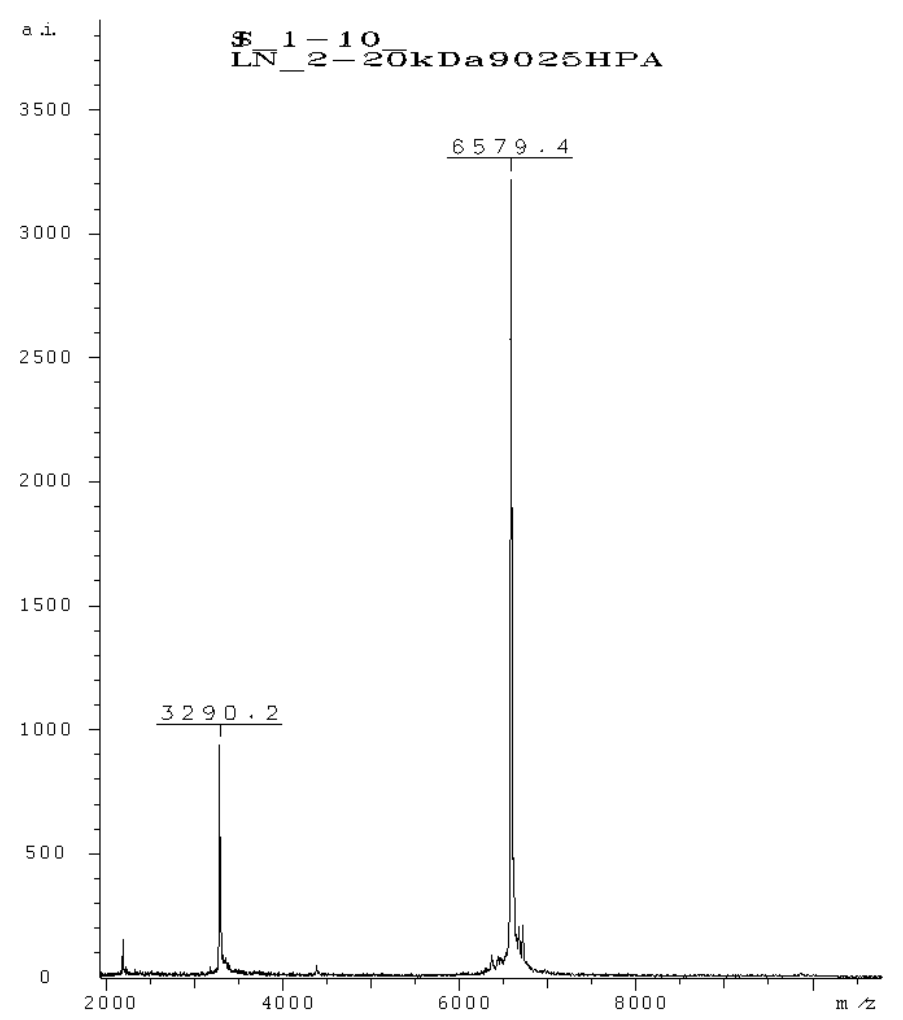

Figure10: MALDI-spectra of purified DNA2b, calculated: 6571.2 Da, found: 6579.4 Da. 


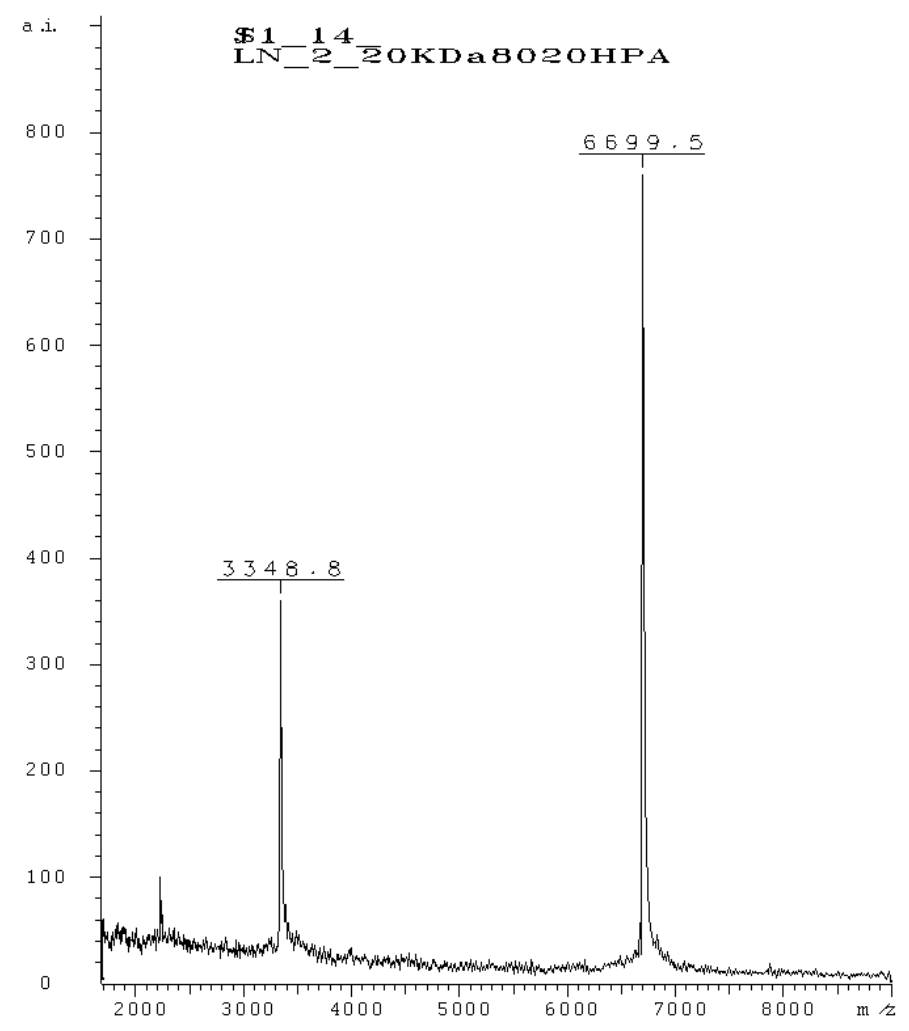

Figure 11: MALDI-spectra of purified DNA3a, calculated: 6692.2 Da, found: 6699.5 Da.

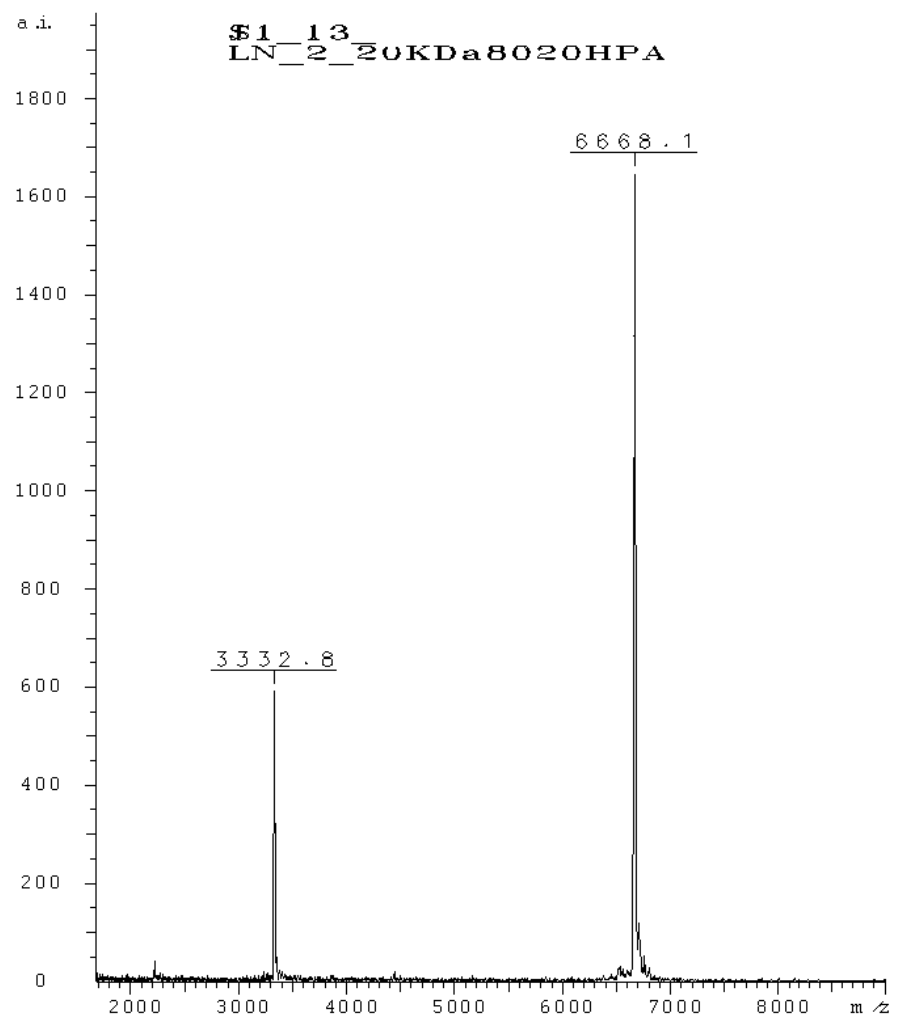

Figure 12: MALDI-spectra of purified DNA3b, calculated: 6664.2 Da, found: 6668.1 Da. 


\section{Additional spectroscopic data:}
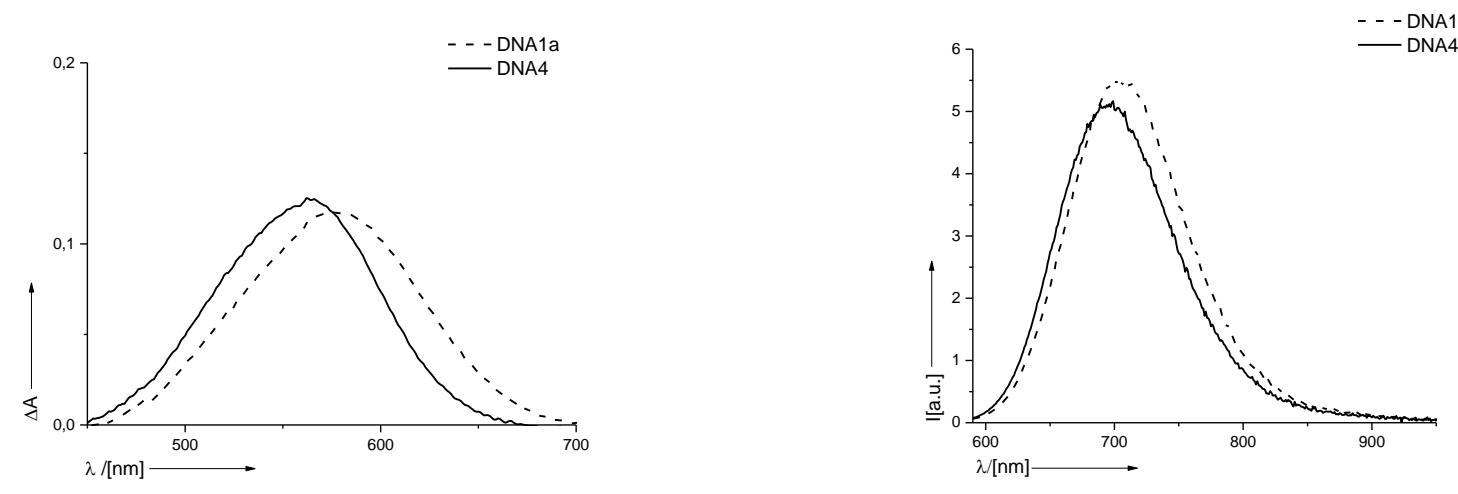

Figure 13: left: absorption spectra, right: emission spectra of DNA1a and DNA4.
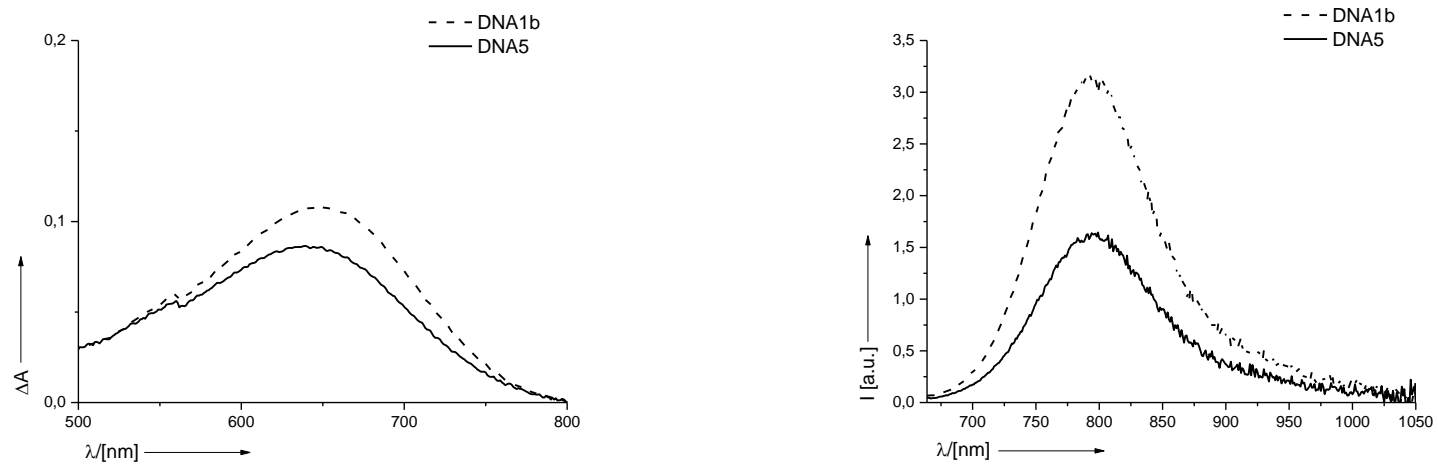

Figure 14: left: absorption spectra, right: emission spectra of DNA1b and DNA5.
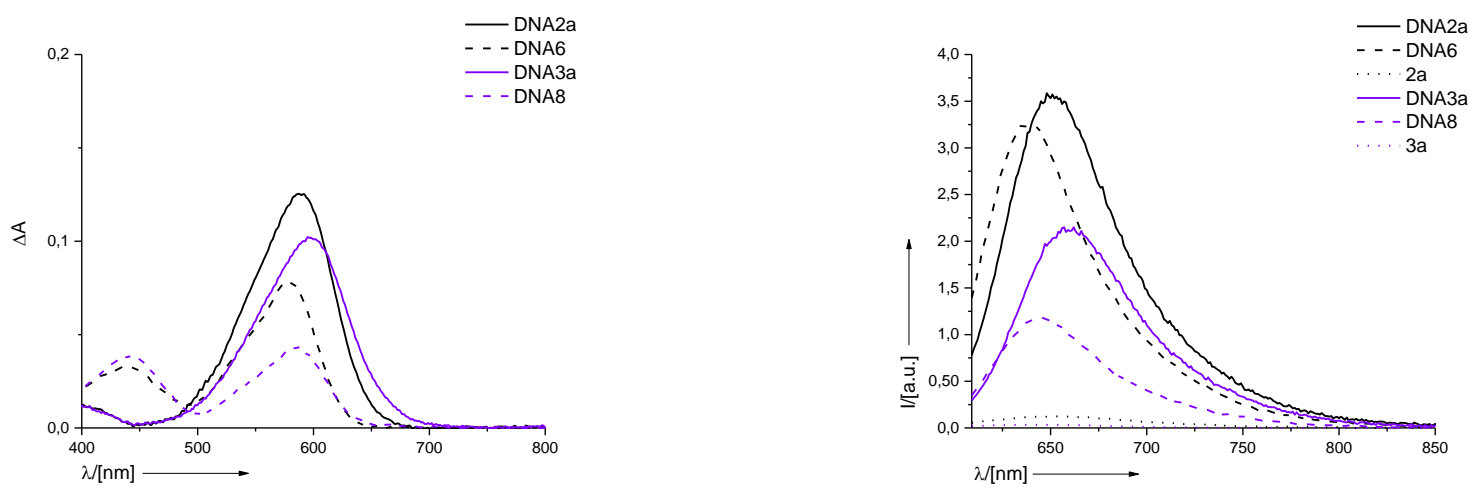

Figure 15: left: absorption spectra, right: emission spectra of DNA2a, DNA3a, DNA6 and DNA8. 

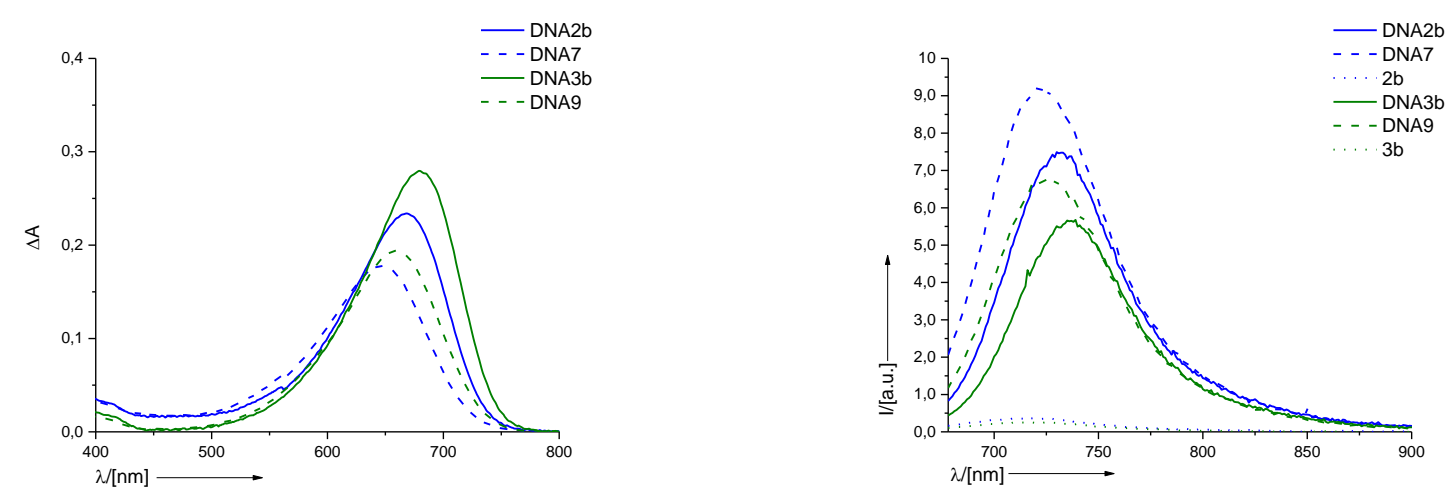

Figure 16: left: absorption spectra, right: emission spectra of DNA2b, DNA3b, DNA7 and DNA9.

\section{Cell Experiments}

\section{Cell culture}

Human cervix carcinoma cells (HeLa cells) were cultured in Dulbecco's modified Eagle medium (DMEM) supplemented with $10 \%$ fetal calf serum and $1 \%$ penicillin Streptomycin $(100 \mu \mathrm{g} / \mathrm{mL})$ at $37^{\circ} \mathrm{C}$ and $5 \% \mathrm{CO} 2$. Prior to transfection $5 \times 10^{4} \mathrm{HeLa}$ cells per well were seeded in an 8 -well chamber slide ( $\mu$ Slide 8 well ibiTreat, IBIDI, Martinsried, Germany) in $200 \mu \mathrm{L}$ of media.

\section{Transfection of DNA oligonucleotides}

15 pmol of the respective DNA oligonucleotides were diluted in Dilution Buffer of ScreenFect ${ }^{\circledR} A$ (Incella, Eggenstein-Leopoldshafen, Germany) to a final volume of $9 \mu 1.1 .5 \mu 1$ of ScreenFect $\AA A$ was diluted and thoroughly mixed in Dilution Buffer to a final volume of 15 $\mu 1$. Both, the diluted DNA and the ScreenFect ${ }^{\circledR A}$ solution were rapidly mixed and incubated for $20 \mathrm{~min}$ at room temperature to allow for the formation of the DNA-liposome complex. Finally, the transfection mixture was transfered to the cells in each well of an 8-well chamber slide ( $\mu$ Slide 8 well ibiTreat, IBIDI, Martinsried, Germany). The cells were incubated with the respective transfection mixture at $37{ }^{\circ} \mathrm{C}, 5 \% \mathrm{CO}_{2}$ for $24 \mathrm{~h}$. Eventually, the cells were washed 3 times with media.

\section{In vivo Click reaction}

For the sequential labelling of the single stranded DNA11a with the respective azidofluorophores the transfection of the DNA was performed as described above. After $24 \mathrm{~h}$, the cells were washed and the medium was replaced. Eventually, $30 \mathrm{pmol}$ of the different azidofluorophores (diluted in $10 \%$ DMSO as a $15 \mu \mathrm{M}$ stock solution) were added and the cells were incubated for further $24 \mathrm{~h}$ at $37{ }^{\circ} \mathrm{C}, 5 \% \mathrm{CO}_{2}$. Afterwards, they were washed 3 times and then subjected to confocal fluorescence microscopy.

\section{Live confocal fluorescence microscopy}

Simultaneous visualization was performed using a Leica TCS-SP5 II (DMI6000) inverted microscope with an HCX PL APO CS 63.0x1.2 oil objective. Fluorophores were excited using an argon ion laser $(532 \mathrm{~nm})$ and a HeNe laser $(633 \mathrm{~nm})$. The emission detection bandwidths 
were at $600-800 \mathrm{~nm}$ for fluorophores $\mathbf{1 a}, \mathbf{2 a}+\mathbf{b}$ and $\mathbf{3 a}+\mathbf{b}$ and $700-800 \mathrm{~nm}$ for the fluorophore 1b. Using the acquisition software LAS-AF 2.0.2.4647, the picture ratio was adjusted to 1024 $\times 1024$ pixels 8 bit depth.

\section{Cytotoxicity in HeLa cells}

To determine the toxic effect of the respective DNA constructs in HeLa cells the viability was tested using the CellTiter 96® Non-Radioactive Cell Proliferation Assay (Promega) according to the manufacturer's instructions. This assay is based on the intracellular reduction of a tetrazolium salt (yellow) into a formazan product (blue), which only takes place in metabolic active cells. The generated formazan is detectable at wavelengths between $630-750 \mathrm{~nm}$ and is a direct measure for the viability of the cells.

$1 \times 10^{4} \mathrm{HeLa}$ cells were seeded in each well of a 96 well plate (Costar 3596, 96 Well Cell Culture Cluster, sterile) and cultured in $100 \mu \mathrm{L}$ Dulbecco's modified Eagle's medium (DMEM, high glucose, Gibco) supplemented with $10 \%$ fetal calf serum (FCS, Sigma-Aldrich), and 60 $\mu \mathrm{g} / \mathrm{ml}$ penicillin, $100 \mu \mathrm{g} / \mathrm{ml}$ streptomycin at $37{ }^{\circ} \mathrm{C}, 5 \% \mathrm{CO}_{2}$. After 24 hours the cells were treated with different concentrations of dyes 1a-3b $(7.5 \mathrm{pmol}(0.0375 \mu \mathrm{M})-60 \mathrm{pmol}(0.30 \mu \mathrm{M}))$. For each amount 8 wells were prepared and incubated for 72 hours. A negative control for $100 \%$ dead cells (cells treated with $5 \mu 1$ of $20 \%$ triton) and positive control (cells treated with DMSO) were added. After $72 \mathrm{~h}$ all cells were treated with $15 \mu \mathrm{l}$ of the tetrazolium salt solution (Dye Solution according to the instruction of the Cell titer 96 assay of Promega) per well and incubated for $1.5 \mathrm{~h}$. Subsequently, $100 \mu \mathrm{L}$ Solubilization Solution/Stop Mix was added to each well to solubilize cells and liberate the formazan, according to the manufacturer's instructions. After $1 \mathrm{~h}$ incubation at $37^{\circ} \mathrm{C}$ the absorbance was measured at $595 \mathrm{~nm}$ using a 96-well plate reader (Ultra Microplate Reader ELx808, BioTEK Instruments, INC). Mean values and standard deviation were calculated from $n=8$ experiments using Student's T-Test 
Cell viability tests:

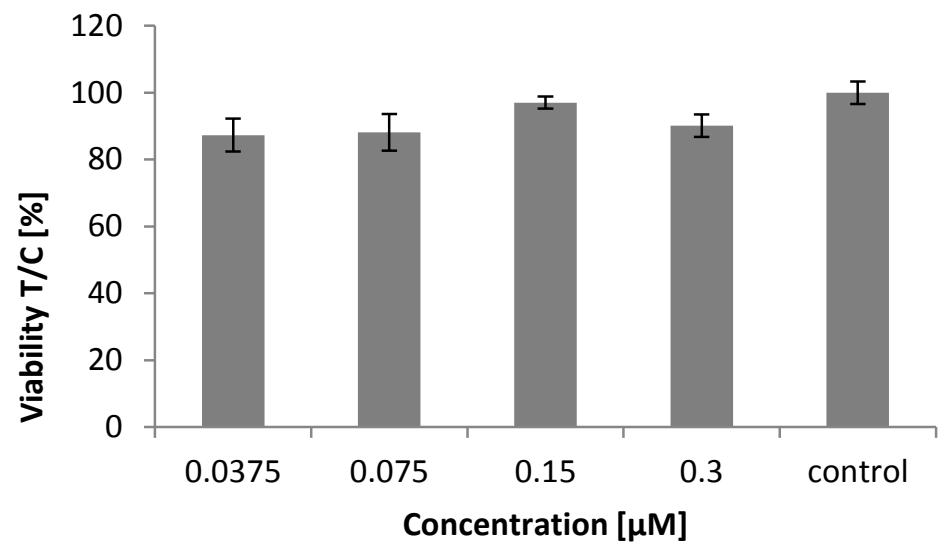

Figure 17: Cell viability of HeLa-cells after treatment with dye 1a for $72 \mathrm{~h}$.

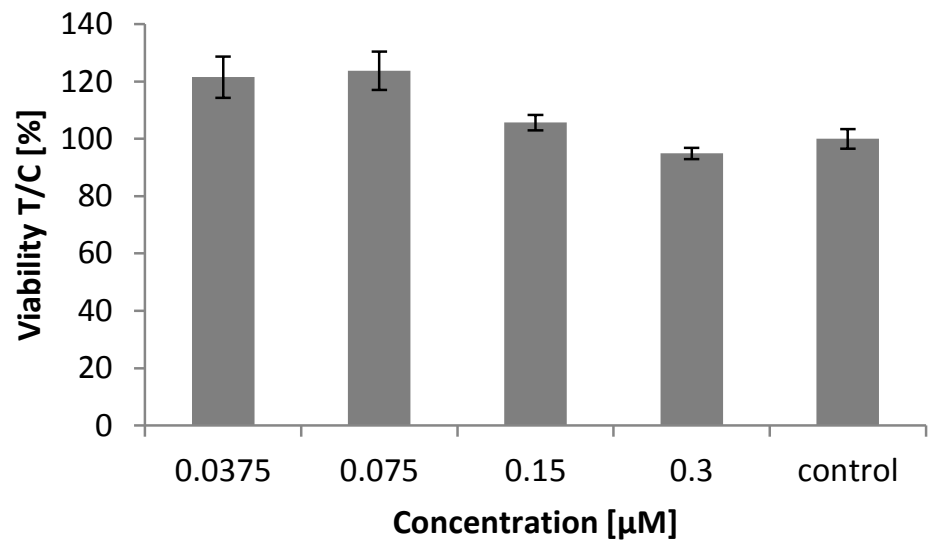

Figure 18: Cell viability of HeLa-cells after treatment with dye $1 \mathrm{~b}$ for $72 \mathrm{~h}$.

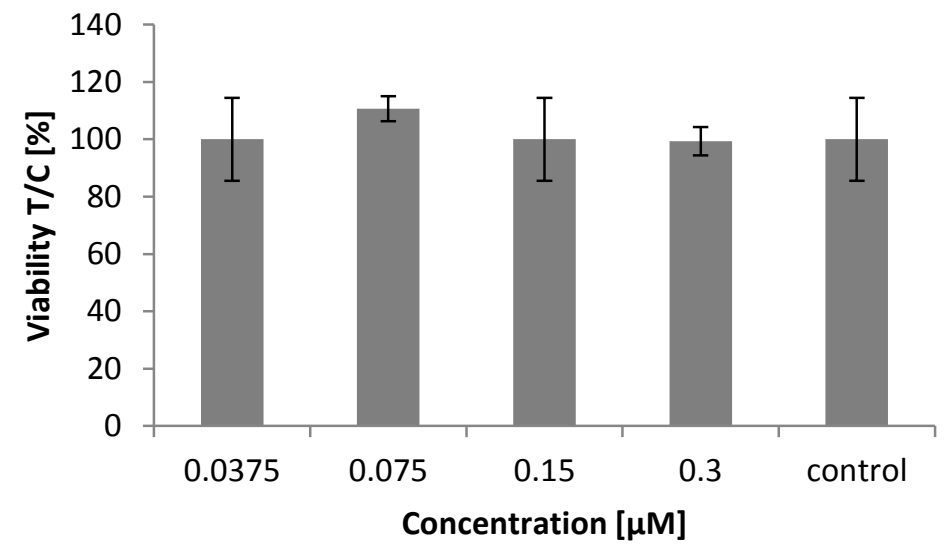

Figure 19: Cell viability of HeLa-cells after treatment with dye 2a for $72 \mathrm{~h}$. 


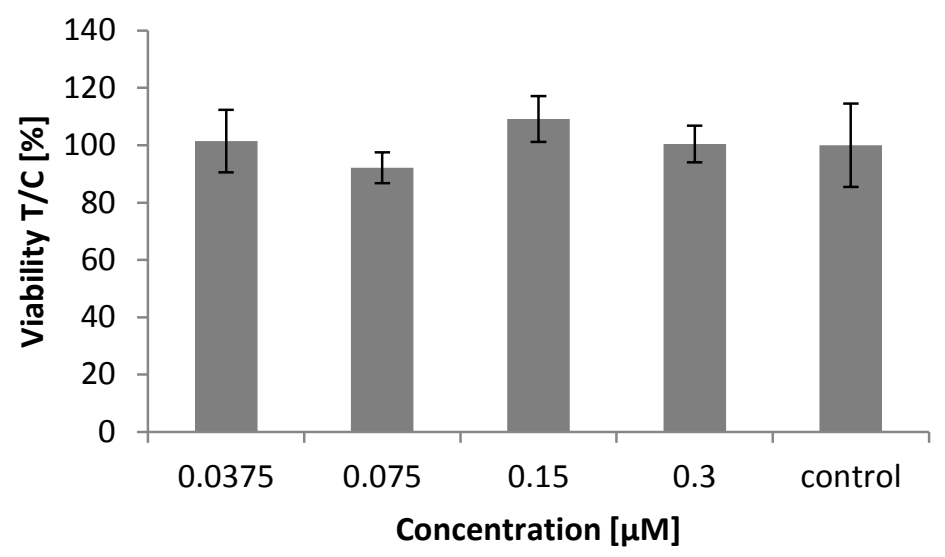

Figure 20: Cell viability of HeLa-cells after treatment with dye $2 b$ for $72 \mathrm{~h}$.

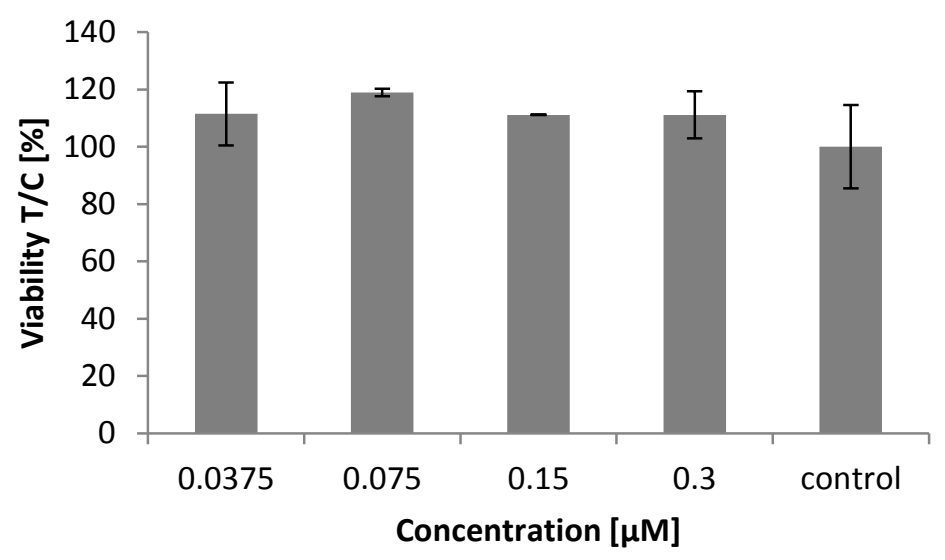

Figure 21: Cell viability of HeLa-cells after treatment with dye 3a for $72 \mathrm{~h}$.

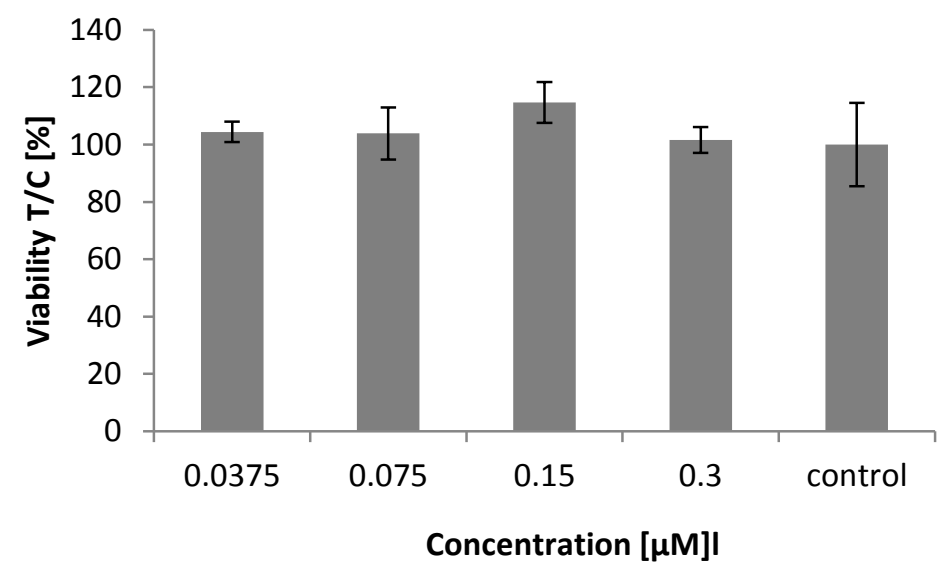

Figure 22: Cell viability of HeLa-cells after treatment with dye $3 b$ for $72 \mathrm{~h}$. 